\author{
UNIVERSIDADE DE SÃO PAULO \\ ESCOLA DE ENGENHARIA DE SÃO CARLOS
}

\title{
ESTUDO DA ESTABILIDADE DIMENSIONAL DE MADEIRAS TROPICAIS BRASILEIRAS
}





\title{
TIAGO HENDRIGO DE ALMEIDA
}

\section{ESTUDO DA ESTABILIDADE DIMENSIONAL DE MADEIRAS TROPICAIS BRASILEIRAS}

\author{
Versão Corrigida
}

Dissertação apresentada ao Programa de Ciência e Engenharia de Materiais, da Universidade de São Paulo para a obtenção do título de Mestre em Ciências.

Área de concentração: Desenvolvimento, Caracterização e Aplicação de Materiais

Orientador: Francisco Antonio Rocco Lahr

São Carlos 
AUTORIZO A REPRODUÇÃO TOTAL OU PARCIAL DESTE TRABALHO, POR QUALQUER MEIO CONVENCIONAL OU ELETRÔNICO, PARA FINS DE ESTUDO E PESQUISA, DESDE QUE CITADA A FONTE.

ALMEIDA, Tiago Hendrigo de
A447e ESTUDO DA ESTABILIDADE DIMENSIONAI DE MADEIRAS TROPICAIS BRASILEIRAS / Tiago Hendrigo de ALMEIDA; orientador Francisco Antonio Rocco Lahr. São Carlos, 2015 .

Dissertação (Mestrado) - Programa de Pós-Graduação em Ciências e Engenharia de Materiais e Área de Concentração em Desenvolvimento Caracterização e Aplicação de Materiais -- Escola de Engenharia de São Carlos da Universidade de São Paulo, 2015.

1. Estabilidade dimensional. 2. Propriedades físicas. 3. Madeira. I. Título. 


\section{FOLHA DE JULGAMENTO}

Candidato: Engenheiro TIAGO HENDRIGO DE ALMEIDA.

Título da dissertação: "Estudo da estabilidade dimensional de madeiras tropicais brasileiras".

Data da defesa: 21/07/2015

\section{Comissão Julgadora:}

Resultado:

Prof. Titular Francisco Antonio Rocco Lahr (Orientador)

APRONADO

(Escola de Engenharia de São Carlos/EESC)

Prof. Dr. André Luis Christoforo

APROVAPO

(Universidade Federal de São Carlos/UFSCar)

Prof. Dr. Eduardo Chahud

(Universidade Federal de Minas Gerais/UFMG)

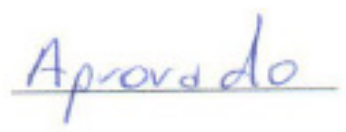

Coordenador do Programa de Pós-Graduação em Ciências e Engenharia de Materiais:

Prof. Associado Antonio José Felix de Carvalho

Presidente da Comissão de Pós-Graduação:

Prof. Associado Paulo César Lima Segantine 



\section{DEDICATÓRIA}

Dedico este trabalho à minha família: meu pai Salomão de Almeida, minha mãe Teresinha do Carmo Ferreira de Almeida, meu irmão Diego Henrique de Almeida e minha irmã Ingrid Gabriela de Almeida. 



\section{AGRADECIMENTOS}

Em primeiro lugar, agradeço a Deus por todas as coisas, e por me fazer capaz de atingir objetivos.

À minha família, que estão sempre comigo, mesmo que em lugares diferentes.

Agradeço ao meu amigo Professor Rocco, que também é meu orientador, e não mede esforços para ajudar a mim e à minha família. De coração, Obrigado Chico!

Aos meus familiares.

Ao professor André Luís Christoforo por toda ajuda.

Aos amigos que trabalham comigo no laboratório, que mesmo com seus afazeres, estão sempre dispostos a ajudar, sendo eles: Caio, Amós, Luciano, Fabiane, Marcos, Raquel, Fátima, Felipe, Marcio, Lorenzo, Sabrina, Andreia e Leonardo.

Agradeço ao Laboratório de Madeiras Estruturas de Madeiras (LaMEM), do Departamento de Engenharia de Estruturas (SET), da Escola de Engenharia de São Carlos (EESC), Universidade de São Paulo (USP), e aos professores Carlito Calil Junior e Antonio Alves Dias.

Aos funcionários do Laboratório, sendo eles: Aparecido Galindo, Jaime Galindo, Roberto Galindo, Arnaldo, Tânia, Silvio, Bragatto e Samuel. Nossos companheiros diários.

Ao Departamento de Engenharia de Materiais e aos secretários Victor e Bruno.

Aos professores que compuseram a banca de qualificação, sendo eles: José Ricardo Tarpani, Antonio Aprígio da Silva Curvelo e Débora Terezia Balogh.

Aos amigos, sempre comigo nessa caminhada, e que mesmo distantes mantemos o vínculo inicial, sendo eles: Rafael, Jaime, Renann, Vinicius, Rodrigo e Renato.

Ao Conselho Nacional de Desenvolvimento Científico e Tecnológico (CNPq).

A todos que contribuíram para a realização deste trabalho. 



\section{RESUMO}

ALMEIDA, T. H. Estudo da Estabilidade Dimensional de Madeiras Tropicais Brasileiras. 2015. 99 p. Dissertação (Mestrado em Ciências Engenharia de Materiais) Escola de Engenharia de São Carlos, Universidade de São Paulo, São Carlos, 2015.

A madeira é um material de origem biológica, renovável, com papel importante no ciclo do carbono, que contribui para o desenvolvimento sustentável. As madeiras tropicais brasileiras são apreciadas na indústria da construção civil em peças estruturais, componentes de edificação e mobiliário. A melhor utilização da matéria-prima nos diversos processos depende do conhecimento das suas propriedades, e nesse aspecto, os estudos sobre estabilidade dimensional são escassos, em sua maioria, desenvolvidos para coníferas do hemisfério Norte. Este trabalho tem como objetivo geral aprofundar o estudo da estabilidade dimensional, trabalhando com propriedades físicas de madeiras tropicais brasileiras, com ênfase nas densidades, ponto de saturação das fibras, retratibilidade e inchamento. Utilizando madeira de quinze espécies tropicais brasileiras, foram realizados ensaios, de acordo com a NBR 7190/97 para determinar: densidade aparente $0 \%$ e $12 \%$ de umidade, densidade básica, ponto de saturação das fibras, retração, inchamento, coeficiente de anisotropia, coeficiente de retratibilidade volumétrica e coeficiente de inchamento volumétrico. Investigaram-se as relações entre as propriedades determinadas de modo a poder inferir sobre: a estabilidade dimensional baseando-se nas densidades; as precisões de relações desenvolvidas em pesquisas correlatas. Além disso, foi desenvolvida (e investigada sua precisão, ao nível de significância $5 \%$ ) uma relação entre densidade básica e densidade aparente via retratibilidade/inchamento. De acordo com os resultados, o melhor coeficiente de determinação ajustado atingido na tentativa de relacionar densidades com os parâmetros da estabilidade dimensional foi 19,58\% indicando que a densidade não é um bom estimador da estabilidade dimensional da madeira. Algumas das relações desenvolvidas em pesquisas correlatas não foram consideradas válidas, de acordo com a análise estatística. Para a relação desenvolvida no presente trabalho, embora a mesma apresente média e coeficiente de variação próximos aos dos resultados experimentais, a análise de representatividade não confirmou sua significância.

Palavras chaves: Estabilidade dimensional; Propriedades físicas; Madeira. 



\begin{abstract}
ALMEIDA, T. H. Study of Dimensional Stability of Tropical Timber. 2015. 99 p. Master’s Dissertation (Master in Science and Engineering of Materials) - School of Engineering of São Carlos, University of São Paulo.

Wood is an organic and renewable material, with important role in carbon cycle, which contributes to sustainable development. Brazilian tropical woods are considered in building industry in structural ant other components and in furniture. The better use of raw materials in different processes depends on knowledge of their properties and, in this respect, studies of dimensional stability are scarce, mostly developed for Northern Hemisphere conifers. This work aims to extend the study of dimensional stability, now working with physical properties of Brazilian tropical woods, emphasizing densities, fiber saturation point; shrinkage and swelling. Using wood of fifteen Brazilian tropical species, tests were carried out, according to NBR 7190/97 to determine: density (0\% and 12\% moisture content); basic density; fiber saturation point; shrinkage; swelling; anisotropy coefficient; volumetric shrinkage coefficient; and volumetric swelling coefficient. Correlations between certain properties were investigated in order to be able to infer: dimensional stability based on densities; precision of relationships developed in related research. Furthermore, it was developed (and investigated their accuracy, $5 \%$ significance level) a relationship between specific gravity and bulk density via shrinkage/ swelling. According to results, the best determination coefficient, obtained in attempt to correlate density with parameters of dimensional stability, was $19.58 \%$. This indicates that density is not a good estimator of dimensional stability for tropical wood. Based on statistical analysis, some of the relationships developed in related researches were not considered valid. For the relationship developed in this research, although it presents average and coefficient of variation close to experimental results, analysis of accuracy did not confirm its significance.
\end{abstract}

Keywords: Dimensional stability; Physical properties; Wood 



\section{LISTA DE FIGURAS}

Figura 1: Lenhos de (A) Conífera e (B) Dicotiledônea. Fonte: TAYLOR (1978)....................31

Figura 2: Representação das direções de orientação da madeira..............................................32

Figura 3: Representação de uma célula contendo água livre no lume......................................34

Figura 4: Representação da água de impregnação na estrutura do material.............................34

Figura 5: Retratibilidade da madeira nas três direções convencionadas e volumétrica. ...........37

Figura 6: Inchamento da madeira nas três direções convencionadas e volumétrico.................37

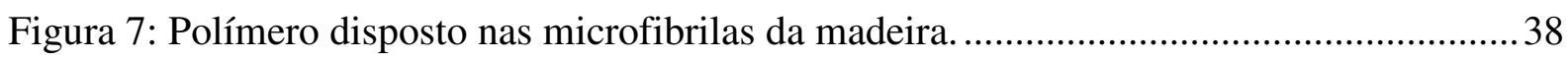

Figura 8: Determinação das dimensões dos corpos de prova................................................. 46

Figura 9: Boxplot das densidades e pontos de saturação referentes às cinco classes de

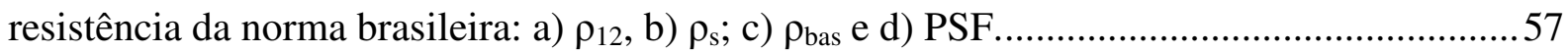
Figura 10: Boxplot das retrações referentes às cinco classes de resistência da norma brasileira: a) $\beta_{\mathrm{r}}$, b) $\beta_{\mathrm{t}}$; c) $\beta_{\mathrm{v}}$ e d) $\beta_{\mathrm{l}}$ 58

Figura 11: Boxplot dos valores de inchamento referentes às cinco classes de resistência da norma brasileira: a) $\alpha_{1}$, b) $\alpha_{r}$; c) $\alpha_{t}$ e d) $\alpha_{v}$.

Figura 12: Boxplot dos coeficientes referentes às cinco classes de resistência da norma brasileira: a) CA, b) $\alpha_{v} / \mathrm{PSF}$ e c) $\beta_{v} / \mathrm{PSF}$.

Figura 13: Ajuste do modelo logarítmico entre a retração radial $\left(\beta_{\mathrm{r}}\right)$ e a densidade aparente $\left(\rho_{12}\right)$.

Figura 14: Ajuste do modelo geométrico entre a retração tangencial $\left(\beta_{t}\right)$ e a densidade aparente $\left(\rho_{12}\right)$.

Figura 15: Ajuste do modelo geométrico entre a retração longitudinal $\left(\beta_{1}\right)$ e a densidade aparente $\left(\rho_{12}\right)$.

Figura 16: Ajuste do modelo geométrico entre a retração volumétrica $\left(\beta_{\mathrm{v}}\right)$ e a densidade aparente $\left(\rho_{12}\right)$.

Figura 17: Ajuste do modelo geométrico entre o coeficiente de anisotropia (CA) e a densidade aparente $\left(\rho_{12}\right)$.

Figura 18: Ajuste do modelo geométrico entre o coeficiente de retratibilidade volumétrica e a densidade aparente $\left(\rho_{12}\right)$. .68

Figura 19: Ajuste do modelo geométrico entre o coeficiente de inchamento volumétrico e a densidade aparente $\left(\rho_{12}\right)$. 
Figura 20: Modelo de regressão geométrico ajustado na estimativa da densidade básica ( $\left.\rho_{\text {bas}}\right)$ em função da densidade aparente $\left(\rho_{12}\right)$.

Figura 21: Resultados dos testes de normalidade (a) e de homogeneidade de variâncias ....... 70

Figura 22: Resultados dos testes de normalidade (a) e de homogeneidade de variâncias ........ 71

Figura 23: Ajuste do coeficiente ótimo $(\gamma)$ da relação entre as retrações $\beta_{l}=\gamma^{*} \beta_{t} \ldots \ldots \ldots \ldots \ldots \ldots . . . . . .72$

Figura 24: Resultados dos testes de normalidade (a) e de homogeneidade de variâncias (b) dos resíduos da ANOVA para a relação $\beta_{v}=\beta_{t}+\beta_{r}$.

Figura 25: Resultados dos testes de normalidade (a) e de homogeneidade de variâncias (b) dos resíduos da ANOVA para a relação $\alpha_{v}=\alpha_{t}+\alpha_{r}$.

Figura 26: Resultados dos testes de normalidade (a) e de homogeneidade de variâncias (b) dos resíduos da ANOVA para a relação $\alpha_{v} / P S F=0,84 * \rho_{s}$. 75

Figura 27: Resultados dos testes de normalidade (a) e de homogeneidade de variâncias (b) dos

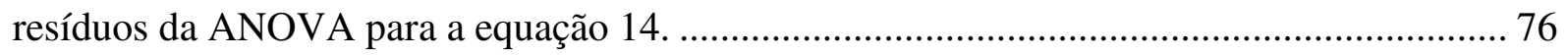

Figura 28: Gráfico genérico do Inchamento em função do Teor de Umidade. ........................ 85

Figura 29: Gráfico genérico da retração em função do Teor de Umidade................................. 86

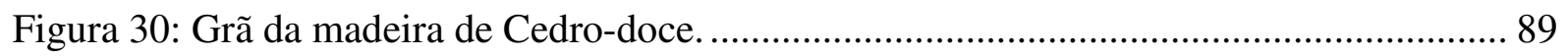

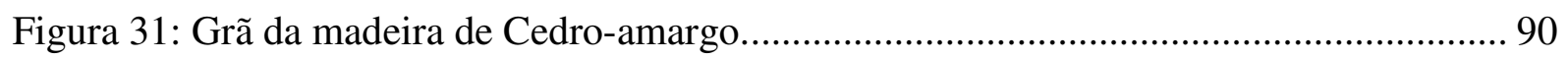

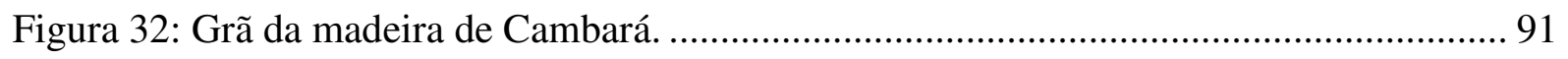

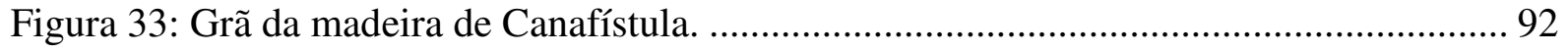

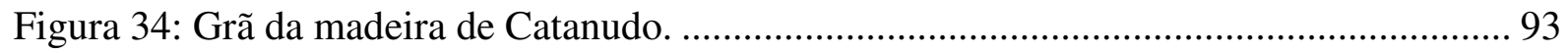

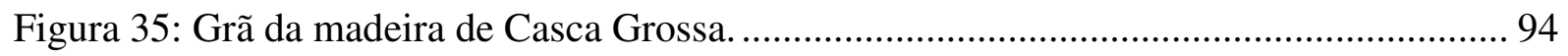

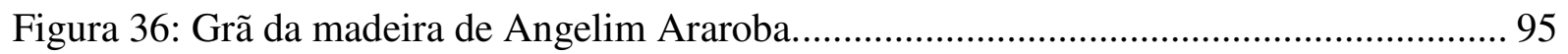

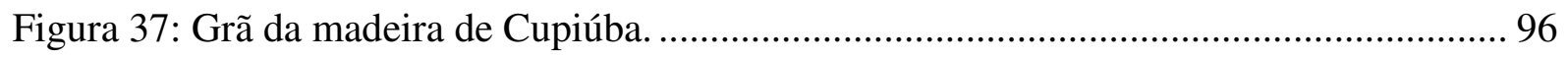

Figura 38: Grã da madeira de Angelim Amargoso........................................................... 97

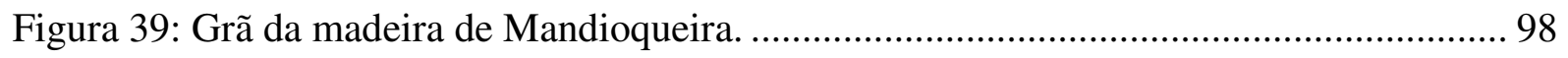

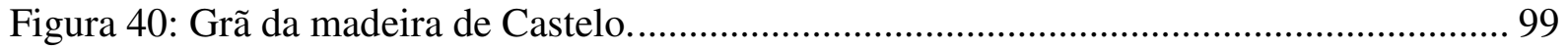

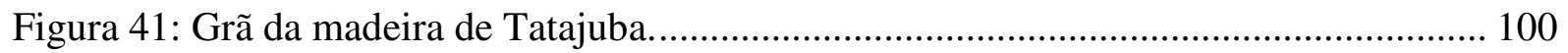

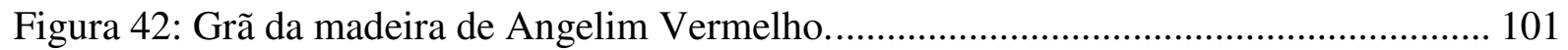

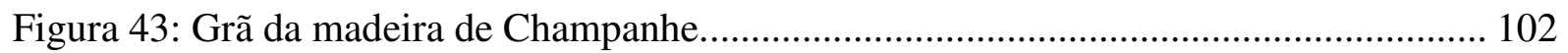

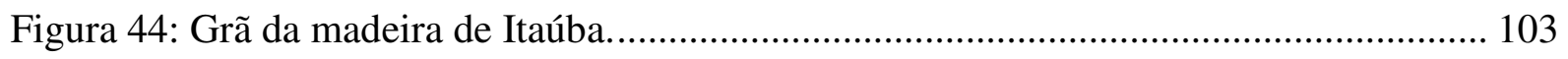




\section{LISTA DE TABELAS}

Tabela 1: Classes de resistência da madeira previstas pela norma brasileira. .43

Tabela 2: Relação de espécies de madeira utilizadas no estudo.

Tabela 3: Modelos de regressão utilizados na estimativa de propriedades físicas. 49

Tabela 4: Resultados para Cedro-doce (C20).

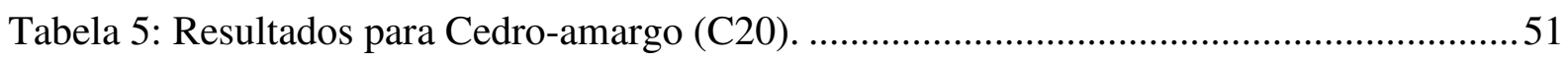

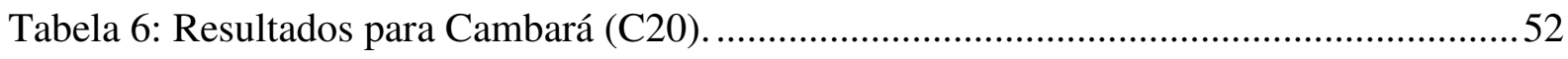

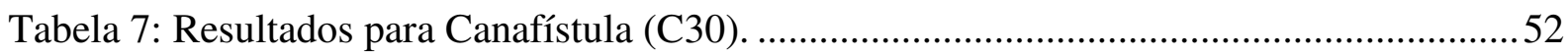

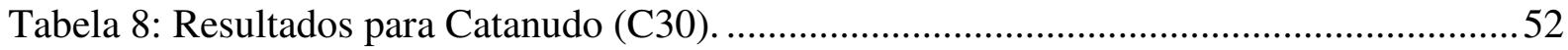

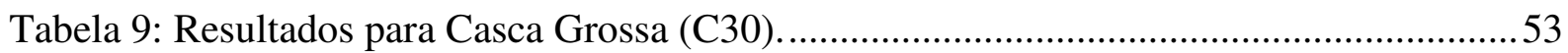

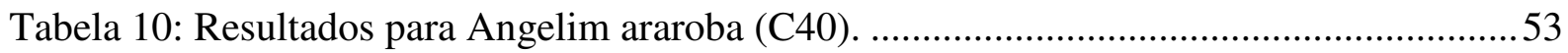

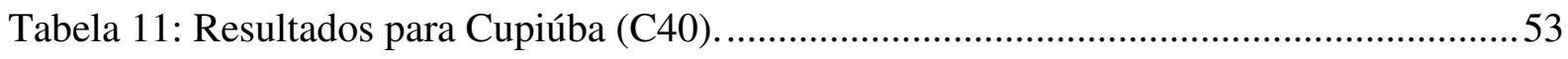

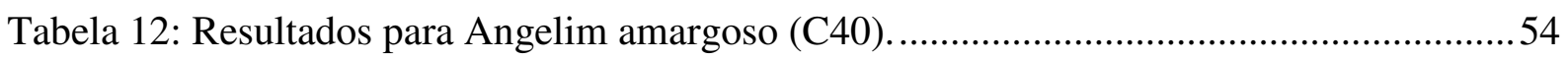

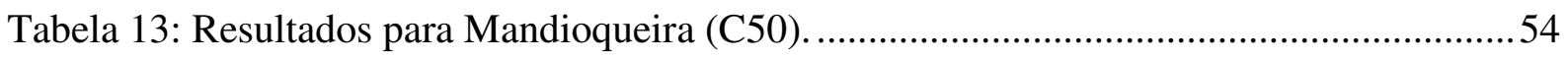

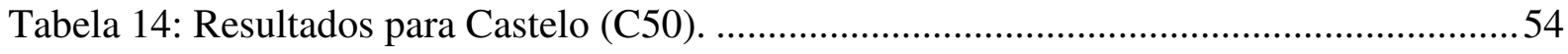

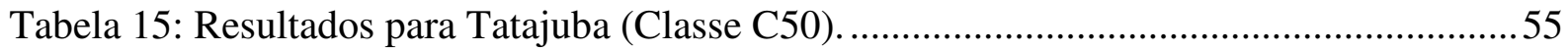

Tabela 16: Resultados para Angelim vermelho (C60) .........................................................55

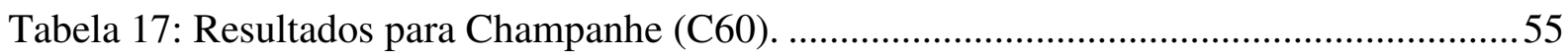

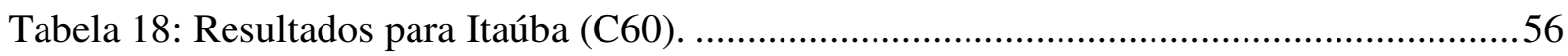

Tabela 19: Relações obtidas dos modelos de regressão entre a retração radial $\left(Y=\beta_{r}\right)$ e as

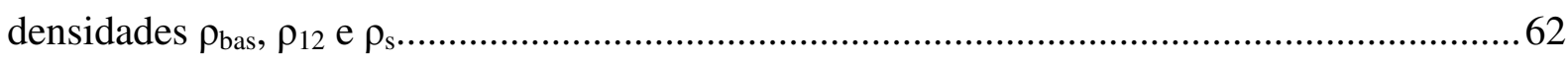

Tabela 20: Relações obtidas dos modelos de regressão entre a retração tangencial $\left(Y=\beta_{t}\right)$ e as

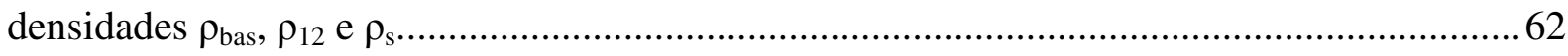

Tabela 21: Relações obtidas dos modelos de regressão entre a retração longitudinal $\left(Y=\beta_{l}\right)$ e as densidades $\rho_{\text {bas }}, \rho_{12}$ e $\rho_{\mathrm{s}}$.

Tabela 22: Relações obtidas dos modelos de regressão entre a retração volumétrica $\left(Y=\beta_{v}\right)$ e as densidades $\rho_{\text {bas }}, \rho_{12}$ e $\rho_{\mathrm{s}}$.

Tabela 23: Relações obtidas dos modelos de regressão entre o coeficiente de anisotropia $(Y=C A)$ e as densidades $\rho_{\text {bas }}, \rho_{12}$ e $\rho_{\mathrm{s}}$

Tabela 24: Relações obtidas dos modelos de regressão entre o coeficiente de inchamento volumétrico $\left(Y=\alpha_{v} / \mathrm{PSF}\right)$ e as densidades $\rho_{\mathrm{bas}}, \rho_{12}$ e $\rho_{\mathrm{s}}$. 
Tabela 25: Relações obtidas dos modelos de regressão entre o coeficiente de retratibilidade volumétrica $\left(Y=\beta_{\mathrm{v}} / \mathrm{PSF}\right)$ e as densidades $\rho_{\mathrm{bas}}, \rho_{12}$ e $\rho$ s.

Tabela 26: Modelos de regressão para a estimativa da densidade básica em função da densidade aparente. 69

Tabela 27: Resultados da ANOVA para validação da relação $\beta_{t}=1,65 * \beta_{r}$.......................... 70

Tabela 28: Resultados da ANOVA para validação da relação $\alpha_{t} / \alpha_{\mathrm{r}}=\beta_{t} / \beta_{r}$............................. 71

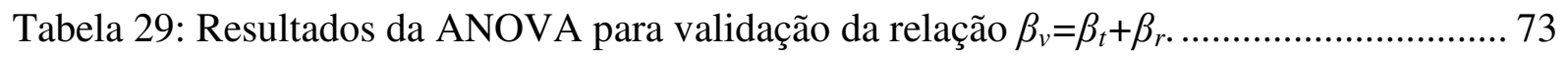

Tabela 30: Resultados da ANOVA para validação da relação $\alpha_{v}=\alpha_{t}+\alpha_{r} \ldots \ldots \ldots \ldots \ldots \ldots \ldots \ldots \ldots \ldots . . . . . . . . . . . . . . . . .73$

Tabela 31: Resultados da ANOVA do modelo de regressão multilinear para os valores dos

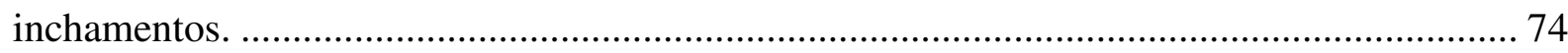

Tabela 32: Resultados da ANOVA para validação da relação $\alpha_{v} / P S F=0,84 * \rho_{s}$................... 75

Tabela 33: Resultados da ANOVA para validação da equação 14......................................... 76 


\section{LISTA DE EQUAÇÕES}

Equação 1: Determinação do teor de umidade da madeira. 33

Equação 2: Densidade Aparente da madeira em qualquer umidade.

Equação 3: Retração Volumétrica e Inchamento Volumétrico - relações. ...............................35

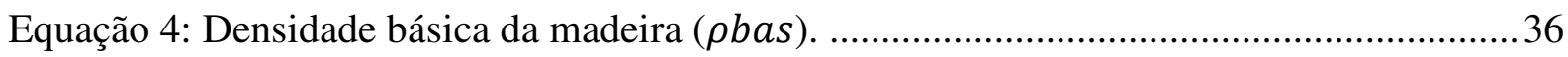

Equação 5: Coeficiente de Retratibilidade Volumétrica, Coeficiente de Inchamento

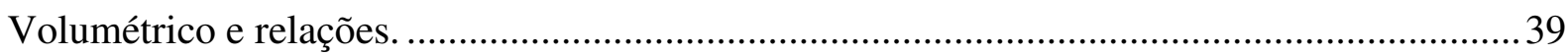

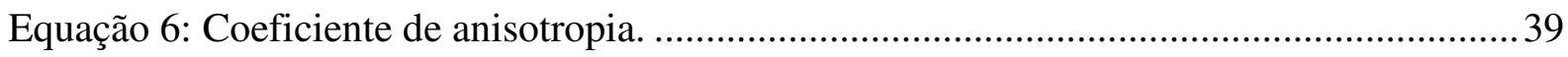

Equação 7: Inchamento volumétrico percentual total em função da densidade anidra da madeira. 40

Equação 8: Retração volumétrica percentual total em função da densidade básica da madeira....40 Equação 9: Relação entre Inchamento volumétrico máximo em função da densidade anidra da madeira como uma solução média.

Equação 10: Relação entre retração volumétrica máxima em função da densidade básica da madeira como uma solução média. 41

Equação 11: Relações importantes envolvendo coeficiente de anisotropia. 42

Equação 12: Coeficiente de anisotropia em função do inchamento - aproximação..................42

Equação 13: Retração volumétrica em função da retração linear e aproximação....................42

Equação 14: Densidade básica determinada pela densidade aparente. ...................................50 



\title{
LISTA DE SIGLAS E ABREVIATURAS
}

\author{
ABNT - Associação Brasileira de Normas Técnicas \\ EESC - Escola de Engenharia de São Carlos \\ LaMEM -Laboratório de Madeiras e de Estruturas de Madeira \\ IMAFLORA - Instituto de Manejo e Certificação Florestal e Agrícola \\ NBR - Norma Brasileira Registrada \\ PSF - Ponto de Saturação das Fibras \\ SET - Departamento de Engenharia de Estruturas \\ USP - Universidade de São Paulo
}





\section{LISTA DE SÍMBOLOS}

$\beta_{\mathrm{r}}$ - retração radial;

$\beta_{\mathrm{t}}$ - retração tangencial;

$\beta_{1}$ - retração longitudinal;

$\beta_{\mathrm{v}}$ - retração volumétrica;

CA $\left(\beta_{\mathrm{t}} / \beta_{\mathrm{r}}\right)$ - coeficiente de anisotropia;

$\alpha_{\mathrm{r}}$ - inchamento radial;

$\alpha_{\mathrm{t}}$ - inchamento tangencial;

$\alpha_{1}$ - inchamento longitudinal;

$\alpha_{v}$ - inchamento volumétrico;

$\alpha_{v} /$ PSF - coeficiente de retratibilidade volumétrica;

$\beta_{\mathrm{v}} / \mathrm{PSF}$ - coeficiente de inchamento volumétrico;

$\rho_{\text {bas }}$ (massa seca/volume saturado) - densidade básica;

$\rho_{12}$ - densidade aparente a $12 \%$ de umidade;

$\rho_{\mathrm{s}}$ - densidade da madeira seca;

$\mathrm{H}_{0}$ - hipótese nula;

$\mathrm{H}_{1}$ - hipótese alternativa;

$\mathrm{X}$ - variável independente;

Y - variável dependente;

a - parâmetro das correlações;

b - parâmetro das correlações;

$\sigma$ - coeficiente de correlação;

$\mathrm{R}^{2}$ (aj) - coeficiente determinação ajustado;

$\mathrm{f}_{\mathrm{c} 0 \mathrm{k}}$ - resistência à compressão paralela às fibras (valor característico);

$\mathrm{f}_{\mathrm{vk}}$ - resistência ao cisalhamento (valor característico);

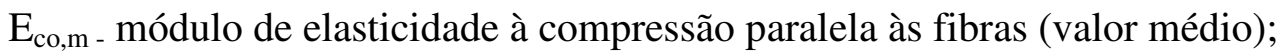

$\rho_{\text {bas,m }}$ - densidade básica (valor médio);

$\rho_{\text {aparente }}$ - densidade aparente (valor médio);

GL - graus de liberdade;

SQ - soma dos quadrados;

MS - média dos quadrados;

SQA - soma dos quadrados ajustada; 
MQA - média dos quadrados ajustada;

$\bar{x}_{\text {- média amostral; }}$

$C v(\%)$ - coeficiente de variação;

Mín. - valor mínimo;

Máx - valor máximo;

g - gramas;

$\mathrm{cm}$ - centímetros;

$\Delta \beta_{(P S F, 0)}$ - variação de retração entre $0 \%$ e PSF de umidade;

$\Delta u_{(P S F, 0)}$ - variação de umidade entre $0 \%$ e PSF de umidade;

$\alpha_{P S F}$ - inchamento máximo;

$\beta_{P S F}$ - retração máxima;

$\delta^{\prime} v$ - coeficiente de retratibilidade volumétrica;

$\alpha_{u}$ - inchamento volumétrico a $\mathrm{u} \%$ de umidade;

$\beta_{u}$ - retração volumétrica a $\mathrm{u} \%$ de umidade;

$V_{u}$ - volume do material a $\mathrm{u} \%$ de umidade;

$V_{\text {sat }}$ - volume saturado da madeira;

$V_{S}$ - volume do material a $0 \%$ de umidade;

$\rho_{u}$ - densidade aparente no teor de umidade desejado;

$\rho_{k}$ - densidade aparente no teor de umidade atual;

$\delta v$ - coeficiente de inchamento volumétrico da madeira;

$u$ - teor de umidade cujo qual a densidade aparente desejada está;

$k$ - teor de umidade cujo qual a amostra se encontra;

$m_{u}$ - massa da amostra contendo umidade em sua estrutura;

$m_{s}$ - massa da amostra isenta de umidade;

$T U$ - teor de umidade da amostra;

$\%$ - porcentagem;

$\% / \%$ - adimensional;

Estat. - estatística;

CR - classe de resistência;

F - estatística F;

$\gamma$ - coeficiente ótimo na regressão linear. 


\section{SUMÁRIO}

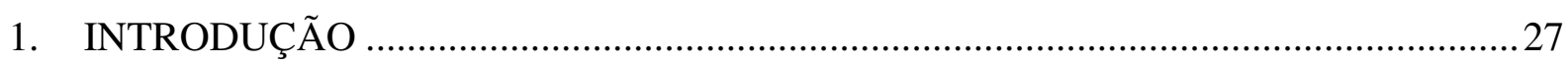

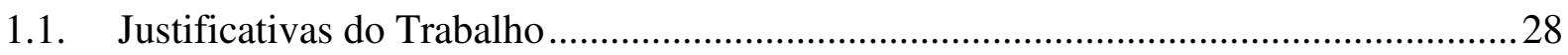

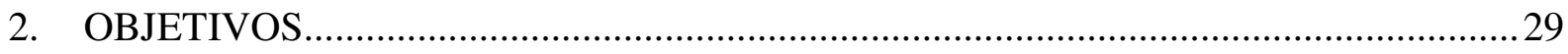

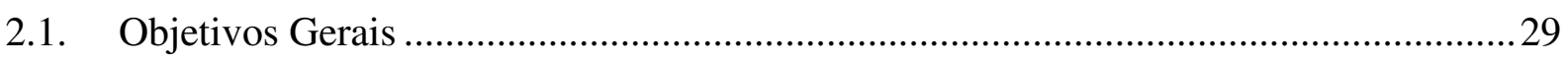

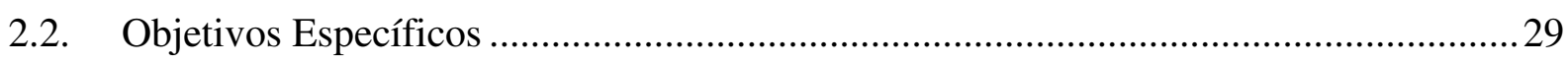

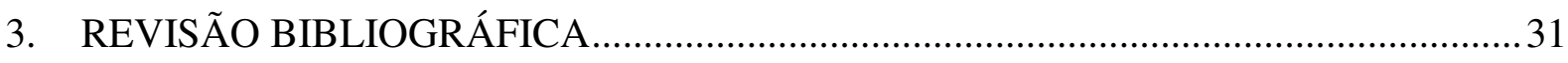

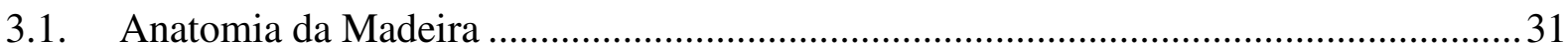

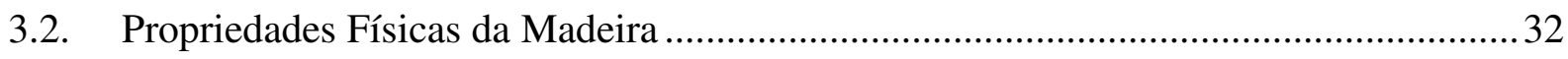

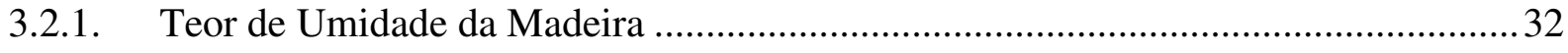

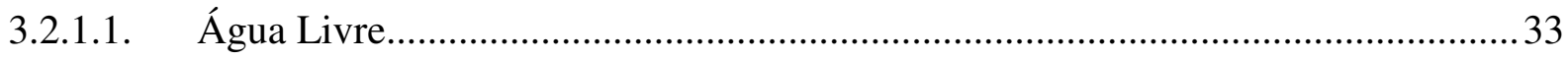

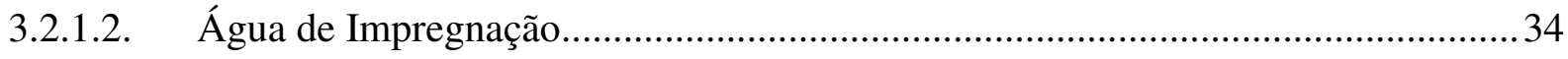

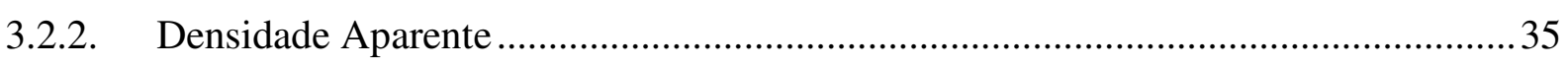

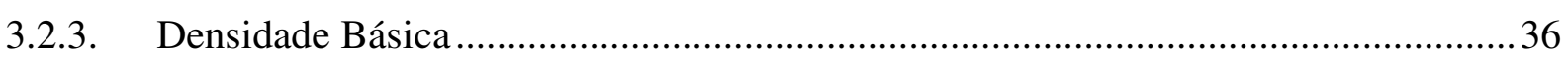

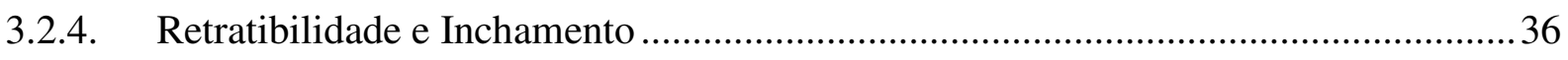

3.2.4.1. Coeficientes de Retratibilidade Volumétrica e de Inchamento Volumétrico .............38

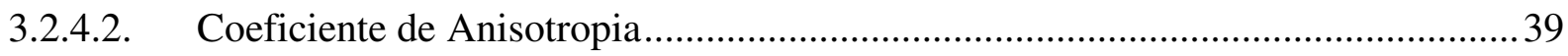

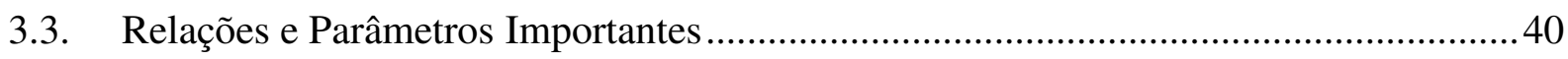

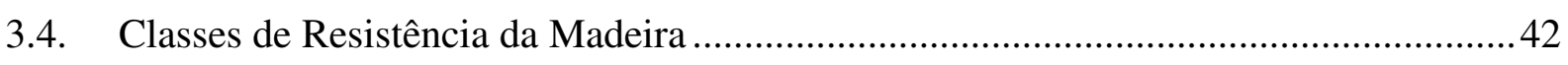

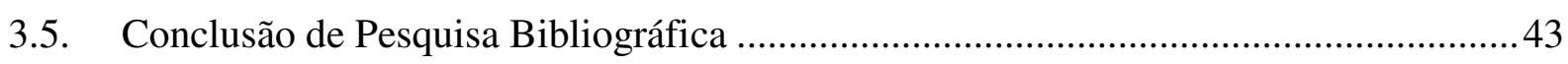

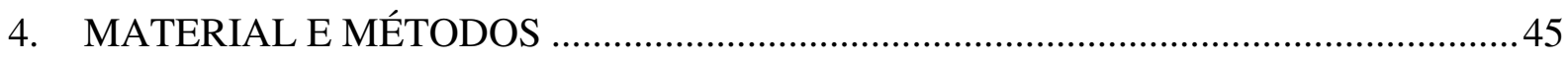

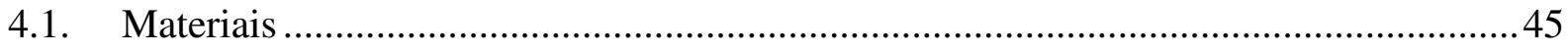

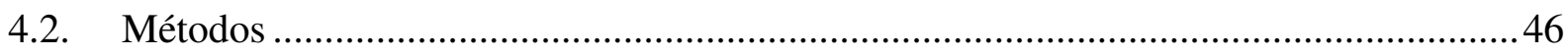

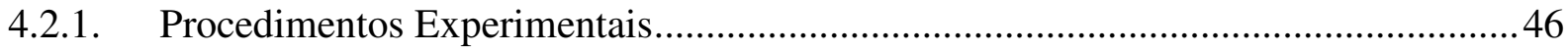

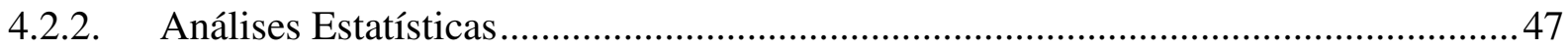

4.2.2.1. Análises de Precisão (Aderência)..........................................................................4

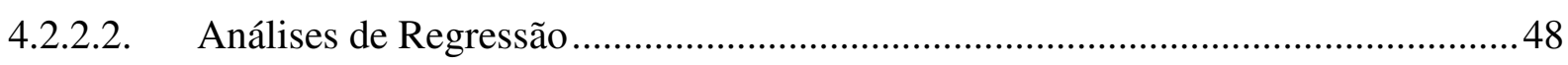

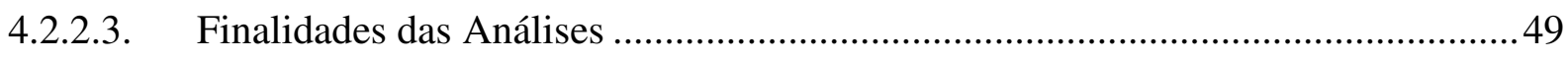

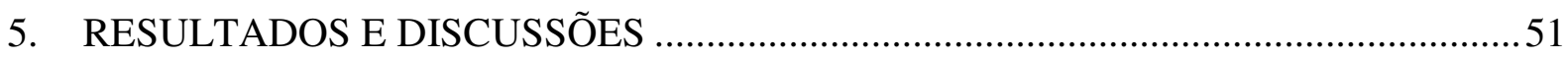

5.1. Apresentação dos Resultados Experimentais ................................................................51

5.1.1. Diagramas dos Resultados por Classe de Resistência ................................................56

5.2. Resultados dos Testes de Regressão...........................................................................61 


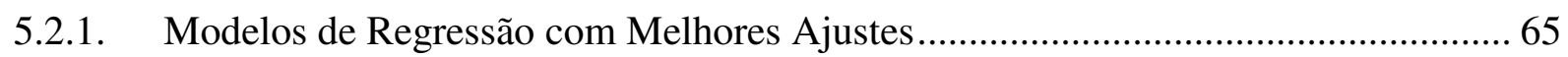

5.2.2. Correlação entre Densidade básica e Densidade aparente a 12\% de umidade ................... 68

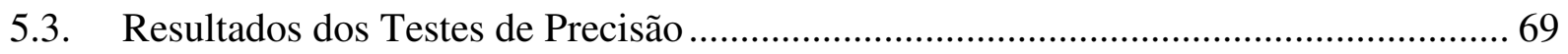

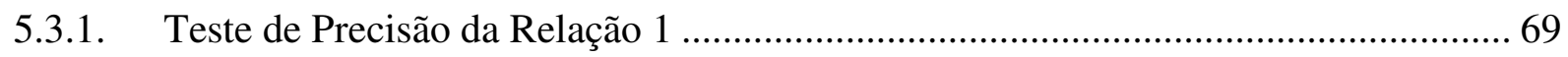

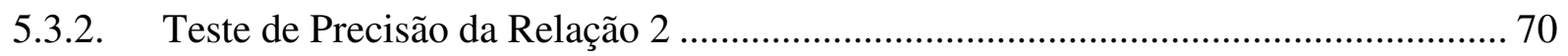

5.3.3. Teste de Precisão da Relação 3 ............................................................................... 71

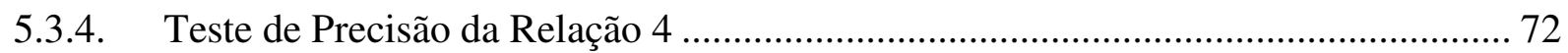

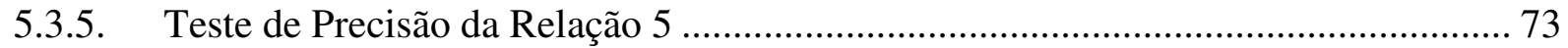

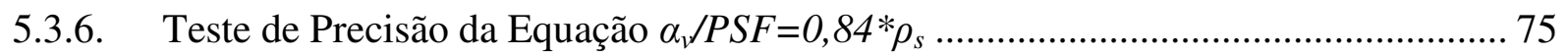

5.3.7. Teste de Precisão da Desenvolvida neste Trabalho (Equação 14) ............................ 75

6. CONCLUSÕES E SUGESTÕES PARA TRABALHOS FUTUROS ............................ 79

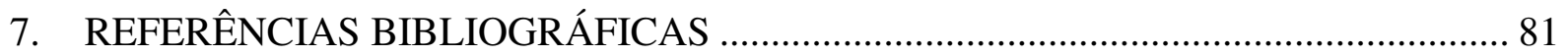

APÊNDICE - DEDUÇÃO DA RELAÇÃO ENTRE DENSIDADE BÁSICA E DENSIDADE APARENTE VIA INCHAMENTO E RETRATIBILIDADE................................................. 85

ANEXO - BREVE DESCRIÇÃO DAS ESPÉCIES UTILIZADAS ...................................... 89 


\section{INTRODUÇÃO}

A madeira é um material que há tempos é utilizado pelo ser humano para satisfazer suas carências. Fibroso, é proveniente do lenho de árvores, que por sua vez é formado pela reação básica da fisiologia das plantas: a fotossíntese. Por isso é tido como um material renovável, com papel importante no ciclo do carbono, que é sequestrado da atmosfera na fotossíntese formando monômeros (glicose), e se polimerizam em cadeias longas dando forma as substâncias que formam o conteúdo do material (ou a sua parte estrutural): celulose e polioses. Além destes polímeros, o material apresenta lignina (que são macromoléculas) e extrativos (CHRISTOFORO et al., 2014; CORADIN \& CAMARGOS, 2002).

De origem biológica, apresenta alta vascularização uma vez que a fotossíntese ocorre nas folhas. Os mecanismos de transporte de seiva na árvore elevam o teor de umidade antes do abate, podendo chegar à proporção em massa de água e material madeira maior que um (ou seja, a árvore antes de ser abatida pode apresentar mais água que polímeros em sua estrutura). Em resumo a água é um componente indispensável na formação do material (ALMEIDA et al., 2015).

A relação entre água e propriedades físicas do material é importante, pois influenciam diretamente no desempenho do material nas diversas fases do seu beneficiamento, processamento e utilização. Beneficiamento refere-se à extração, transporte e desdobro primário; processamento refere-se à secagem, usinagem (inclusive para produção de painéis de madeira reconstituída), além de processos que envolvem colagem; e utilização refere-se à qualidade e desempenho do produto final (KOLLMANN \& CÔTÉ, 1968; GALVÃO \& JANKOWSKY, 1985; PRATT, 1974).

No Brasil, o emprego de madeira da floresta amazônica alcança números significativos. Por exemplo, de acordo com o IMAFLORA (2013), anualmente são extraídos e rastreados 600 mil metros cúbicos de madeira da Amazônia, correspondendo a aproximadamente $15 \%$ do total extraído, que em sua maioria é comercializada no mercado interno nos mais diversos seguimentos.

As madeiras extraídas nessas regiões são muito apreciadas por suas características organolépticas e resistência mecânica, porém muitas vezes são comercializadas com nomes genéricos, e assim, sem qualquer caracterização, o que pode influenciar negativamente em seu desempenho em serviço. 
As propriedades físicas, principalmente a umidade e sua influência na madeira, têm sido objeto de vários estudos. Conhecê-las é fundamental para melhorar o desempenho do material quando aplicado. A literatura internacional há muito registra informações na tentativa de relacionar as propriedades físicas da madeira, considerando preponderantemente resultados de ensaios de coníferas.

\subsection{Justificativas do Trabalho}

As contribuições de Kollmann \& Côté, entre os anos 1930 e 1960, foram importantes para o inicio da estruturação do conhecimento a respeito das propriedades físicas e mecânicas da madeira, funcionando como um compêndio de informações, provenientes de suas pesquisas e de vários outros autores contemporâneos a eles. Nesse aspecto, foram apresentadas as primeiras sugestões para relacionar as propriedades da madeira, em uma época em que os conhecimentos nas áreas da estatística e da tecnologia da informação ainda eram incipientes.

Algumas das expressões citadas por estes autores têm sido admitidas até hoje como satisfatórias para estimar o comportamento da madeira de espécies tropicais brasileiras, mesmo tendo sido desenvolvidas a partir dos resultados, em sua maioria, de espécies de coníferas do hemisfério norte.

Assim este trabalho trata das propriedades físicas relacionadas com as variações dimensionais causadas pela alteração da umidade de madeiras tropicais brasileiras, e visa fornecer parâmetros mais específicos para tais madeiras, contribuindo para sua mais completa caracterização e para sua utilização mais racional. 


\section{OBJETIVOS}

\subsection{Objetivos Gerais}

Este trabalho tem como objetivo geral aprofundar o estudo da estabilidade dimensional, trabalhando com propriedades físicas de madeiras tropicais brasileiras, com ênfase nas densidades, ponto de saturação das fibras, retratibilidade e inchamento. Obter estes parâmetros, bem como determinar modelos que os relacionem, é importante para a melhor utilização destas espécies de madeira, que em muitos casos são comercializadas por nomes populares e sem caracterização prévia.

\subsection{Objetivos Específicos}

Este trabalho tem como objetivos específicos:

- $\quad$ Determinação de propriedades referentes à estabilidade dimensional para espécies de madeira tropicais brasileiras visando abranger toda a gama de classes de resistência de acordo com o documento normativo ABNT NBR 7190/97;

- Análise descritiva e construção de diagramas de: densidade aparente a $0 \%$ e $12 \%$ de umidade; densidade básica; retração e inchamento nas direções tangencial, radial e longitudinal (além de volumétricos); ponto de saturação das fibras; coeficiente de retratibilidade volumétrica e coeficiente de anisotropia;

- Estudo das relações entre as variáveis: densidade aparente a $0 \%$ de umidade; densidade aparente a 12\% de umidade; densidade básica; coeficiente de retratibilidade volumétrica; coeficiente de inchamento volumétrico; coeficiente de anisotropia; e retrações.

- $\quad$ Testes de precisão (aderência) de relações desenvolvidas em pesquisas correlatas;

- Desenvolvimento e teste de precisão de uma relação envolvendo densidade básica e densidade aparente via retratibilidade/inchamento. 
3. REVISÃO BIBLIOGRÁFICA

\subsection{Anatomia da Madeira}

Árvores são plantas superiores, de elevada complexidade anatômica e fisiológica. Botanicamente, estão contidas na divisão das Fanerógamas. Estas, por sua vez, se subdividem em Gimnospermas e Angiospermas. Nas Gimnospermas, a classe que mais se destaca é a de coníferas (softwoods). Com maior incidência em climas temperados e frios, constitui grande quantidade de florestas no hemisfério norte, e é utilizada em larga escala na construção civil e indústrias do setor. As árvores das coníferas apresentam folhas perenes com formato de escamas ou agulhas. No Brasil, os dois exemplos mais importantes são: Pinho do Paraná (Araucaria angustifolia) e as espécies do gênero Pinus. Os elementos anatômicos preponderantes são os traqueóides e os raios medulares (CALIL JR et al., 2003).

As Dicotiledôneas (hardwoods ou folhosas) representam as Angiospermas, vegetais mais evoluídos e com numerosas espécies no país. Apresentam vasta gama de densidades e aclimatam-se melhor em regiões de clima quente. Como exemplos, citam-se as espécies da região amazônica. Também pertencem às Dicotiledôneas os gêneros Eucalyptus, Corymbia e Tectona, com suas centenas de espécies (BURGER e RICHTER, 1991). A madeira é um meio capilar poroso, composto de fibras. Em dicotiledôneas $80 \%$ do volume de madeira é composto de fibras longitudinal, e o restante de células radiais (parênquima radial) (MOREY,1980). Na figura 1 estão ilustrados os dois tipos de lenho.

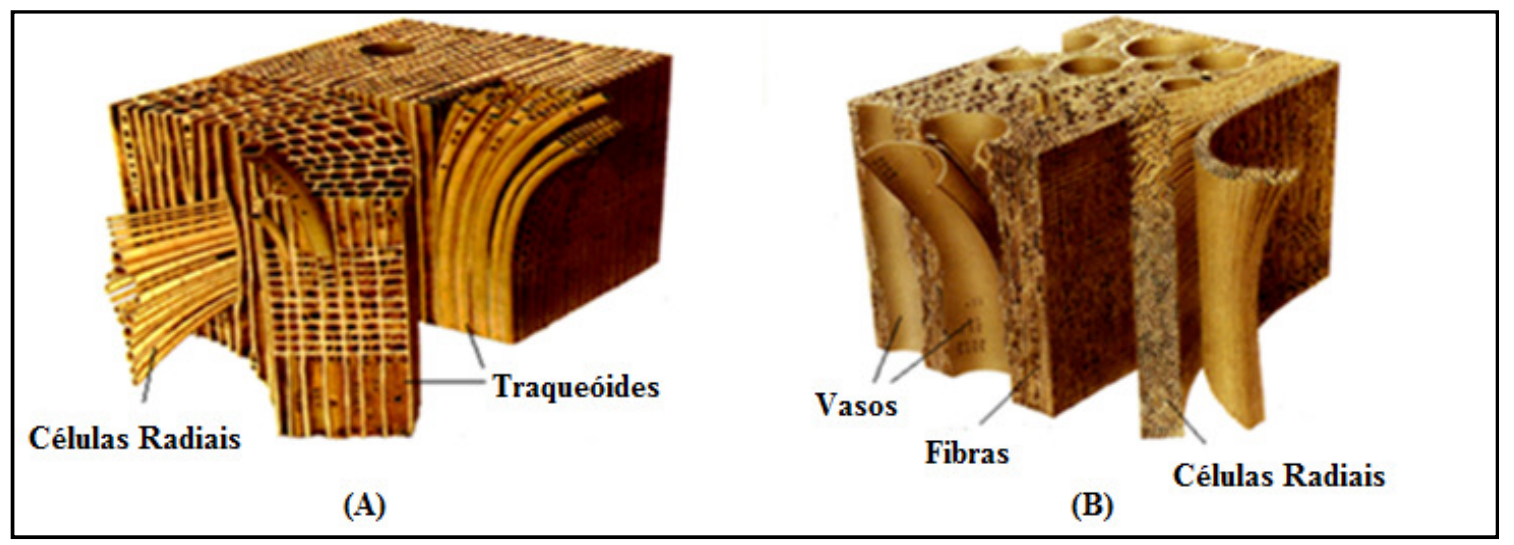

Figura 1: Lenhos de (A) Conífera e (B) Dicotiledônea. Fonte: TAYLOR (1978). 
Estrutura macroscópica é toda estrutura que se pode enxergar com aumento de até dez vezes. Nesta óptica podem ser percebidas três direções de orientações preferenciais na madeira, ou seja, o material, que é anisotrópico, para fins de estudo é considerado ortotrópico. A Figura 2 ilustra as três direções convencionadas de orientação da madeira.

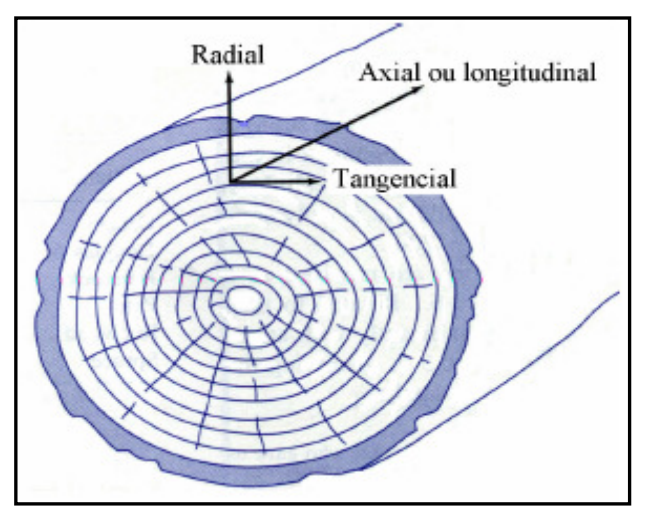

Figura 2: Representação das direções de orientação da madeira.

Fonte: SHACKELFORD (1996).

Estas direções são denominadas tangencial, radial e axial/longitudinal, e são determinadas em relação à disposição das fibras que constituem o lenho (CALIL JR et al., 2003; GALVÃO \& JANKOWSKY, 1985; BODIG \& JAYNE, 1982).

\subsection{Propriedades Físicas da Madeira}

As propriedades físicas são o objeto de estudo deste trabalho, então será dado enfoque maior para tais. Densidade aparente, densidade básica, teor de umidade e estabilidade dimensional (retração, inchamento, coeficiente de retratibilidade e coeficiente de anisotropia) serão as propriedades tratadas neste trabalho.

\subsubsection{Teor de Umidade da Madeira}

A árvore tem como atividade biológica básica o transporte de seiva, sendo elas: bruta e elaborada. A seiva bruta é constituída de água e sais minerais enquanto a elaborada é uma solução de carboidrato e água produtos da reação que ocorre na fotossíntese. Percebe-se então que a madeira, quando em pé, está o tempo todo contendo uma quantidade considerável de água na sua estrutura. Com a extração da madeira, pouco a pouco o teor de umidade tende a diminuir até a umidade de equilíbrio com o ambiente (LOGSDON, 2002). 
O teor de umidade é a relação entre o acréscimo em massa devido à presença de água em sua estrutura e a massa desta mesma amostra caso ela estivesse seca, em outras palavras é a relação entre a massa de água presente na amostra e a massa de material madeira da mesma amostra (KOLLMANN \& CÔTÉ, 1968). A equação 1 elucida como deve ser calculado o teor de umidade de acordo com a ABNT NBR 7190:97: Projeto de Estruturas de Madeira.

Equação 1: Determinação do teor de umidade da madeira.

$$
T U=\frac{m_{u}-m_{s}}{m_{s}} * 100
$$

Onde:

$m_{u}$ : massa da amostra contendo umidade em sua estrutura;

$m_{s}$ : massa da amostra isenta de umidade;

$T U$ : teor de umidade da amostra.

A partir de agora se introduz o conceito de teor de umidade correspondente ao ponto de saturação das fibras (PSF). O PSF é o teor de umidade a partir do qual, mesmo que a madeira ganhe massa devido ao ganho de umidade, o seu volume (volume saturado) permanece constante (GALVÃO \& JANKOWSKY, 1985).

Estudos classificam, de acordo com a localização da água no material no processo de secagem convencional, duas condições: água livre e água de impregnação. (COUTO \& BARCELLOS, 2011). Adiante, cada um destes conceitos será elucidado.

\subsubsection{1. $\quad$ Água Livre}

É contabilizada em teores de umidade acima do ponto de saturação das fibras e se localiza no lume das células, ou seja, na cavidade dos elementos constituintes da planta. Com o abate da árvore, a água livre é aos poucos liberada pela extremidade onde ocorreu o corte, assim no processo global de secagem, por definição as moléculas de água livre são as mais fáceis (e as primeiras) a serem extraídas da estrutura do material (HELLMEISTER, 1973). Na figura 3 está a ilustração. 


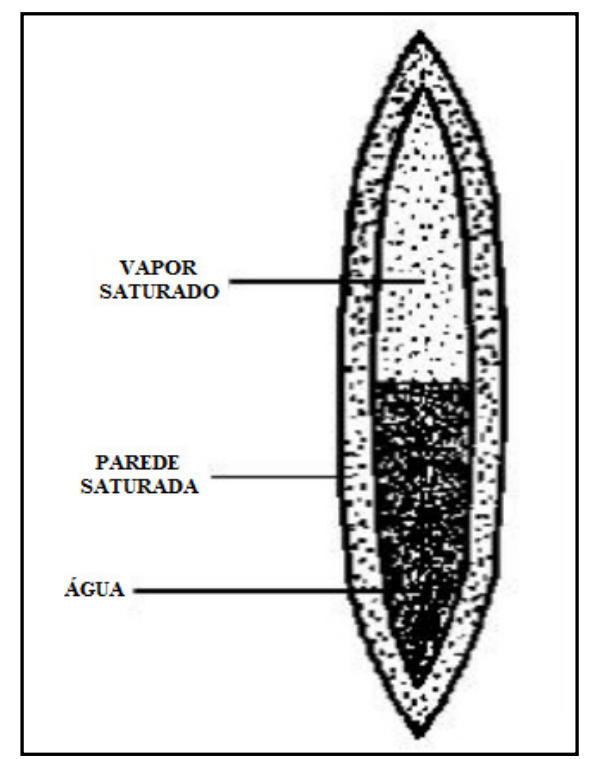

Figura 3: Representação de uma célula contendo água livre no lume. Fonte: Adaptado de REZENDE (2009)

\subsubsection{2. $\quad$ Água de Impregnação}

Presente nas paredes dos elementos anatômicos, retirada exige mais energia, dada a retração decorrente. A umidade de equilíbrio higroscópico (equilíbrio ao ar) depende temperatura do ambiente e da umidade relativa do ar. Ligações de hidrogênio são responsáveis por esta umidade impregnada no material. Com a saída das moléculas de água de impregnação, qualquer retirada de água posterior causa degradação da estrutura química do material (LOGSDON, 1999), figura 4.

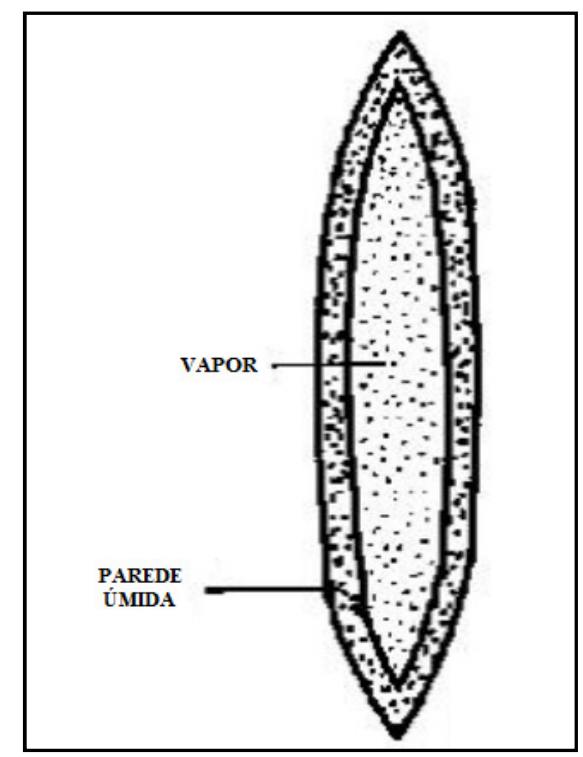

Figura 4: Representação da água de impregnação na estrutura do material. Fonte: Adaptado de REZENDE (2009) 
Segundo Logsdon (2002) e Bodig \& Jayne (1982), as ligações de hidrogênio entre as cadeias poliméricas são responsáveis pelo aumento da resistência mecânica do material com a diminuição do teor de umidade.

\subsubsection{Densidade Aparente}

A densidade é dada pela relação entre a massa de um corpo e o volume que ocupa no espaço. Para o material deste estudo não é diferente. Porém a madeira é um material higroscópico e o teor de umidade influencia significativamente em tal propriedade, tanto no âmbito mássico quanto no volumétrico. Assim, o valor da densidade aparente da madeira deve ser acompanhado do valor do teor de umidade em que aquele resultado foi obtido (REZENDE et al., 1988). Logsdon (2002) desenvolveu uma expressão para conversão da densidade aparente da madeira em diferentes umidades (equação 2).

Equação 2: Densidade Aparente da madeira em qualquer umidade.

$$
\rho_{u}=\rho_{k}+\rho_{k} *\left[(1-\delta v) * \frac{(u-k)}{100}\right]
$$

Onde:

$\rho_{u}$ : densidade aparente no teor de umidade desejado;

$\rho_{k}$ : densidade aparente no teor de umidade atual;

$\delta v$ : coeficiente de inchamento volumétrico da madeira;

$u$ : teor de umidade cujo qual a densidade aparente desejada está;

$k$ : teor de umidade cujo qual a amostra se encontra.

Na equação 3, introduzem-se os conceitos de retratibilidade volumétrica e inchamento volumétrico, parâmetros importantes do estudo da estabilidade dimensional da madeira.

Equação 3: Retração Volumétrica e Inchamento Volumétrico - relações.

$$
\alpha_{u}=\frac{V_{u}-V_{s}}{V_{s}}[\%] ; \beta_{u}=\frac{V_{s a t}-V_{u}}{V_{s a t}}[\%] ; \alpha_{u}=\frac{\beta_{u}}{1-\beta_{u}} ; \beta_{u}=\frac{\alpha_{u}}{1+\alpha_{u}}
$$

Onde:

$\alpha_{u}$ : inchamento volumétrico a $\mathrm{u} \%$ de umidade;

$\beta_{u}$ : retração volumétrica a $\mathrm{u} \%$ de umidade; 
$V_{u}$ : volume do material a u $\%$ de umidade;

$V_{\text {sat }}$ : volume saturado da madeira;

$V_{s}$ : volume do material a $0 \%$ de umidade.

\subsubsection{Densidade Básica}

Trata-se da relação entre a massa anidra (menor massa possível para uma amostra de madeira sem sofrer degradação), e o volume saturado (também chamado de volume verde, que é o maior volume que a mesma amostra de madeira pode ocupar, visto que para valores de umidade maiores que o ponto de saturação das fibras a variação de volume é considerada nula) (KOLLMANN \& CÔTÉ, 1968). A equação 4 representa esta relação.

Equação 4: Densidade básica da madeira $\left(\rho_{\text {bas }}\right)$.

$$
\rho_{\text {bas }}=\frac{m_{s}}{V_{\text {sat }}}
$$

A densidade básica é o menor valor possível de densidade para uma determinada amostra, pois é o valor correspondente ao quociente entre a menor massa (massa seca) e o maior volume (volume saturado).

\subsubsection{Retratibilidade e Inchamento}

A madeira é um material que, independentemente da espécie (algumas com maior e outras com menor magnitude), quando submetido à secagem em níveis de umidade inferiores ao ponto de saturação das fibras sofre gradual redução de volume, ação denominada Retratibilidade. Nestas condições, o ganho de umidade provoca o processo contrário, denominado Inchamento (REZENDE, 2009). Estes são os dois sentidos do fenômeno denominado Estabilidade Dimensional.

Estes ocorrem nas três direções principais da madeira. Na direção axial é onde ocorre a menor variação dimensional, seguida pela radial e pela tangencial. Nas figuras 5 e 6 estão representados os fenômenos da retratibilidade e inchamento, respectivamente.

Na continuidade do texto, são utilizadas as seguintes notações:

$\alpha_{l}$ : inchamento na direção longitudinal;

$\alpha_{r}$ : inchamento na direção radial; 
$\alpha_{t}$ : inchamento na direção tangencial;

$\alpha_{v}$ : inchamento volumétrico;

$\beta_{l}$ : retração na direção longitudinal;

$\beta_{r}$ : retração na direção radial;

$\beta_{t}$ : retração na direção tangencial;

$\beta_{v}$ : retração volumétrica.

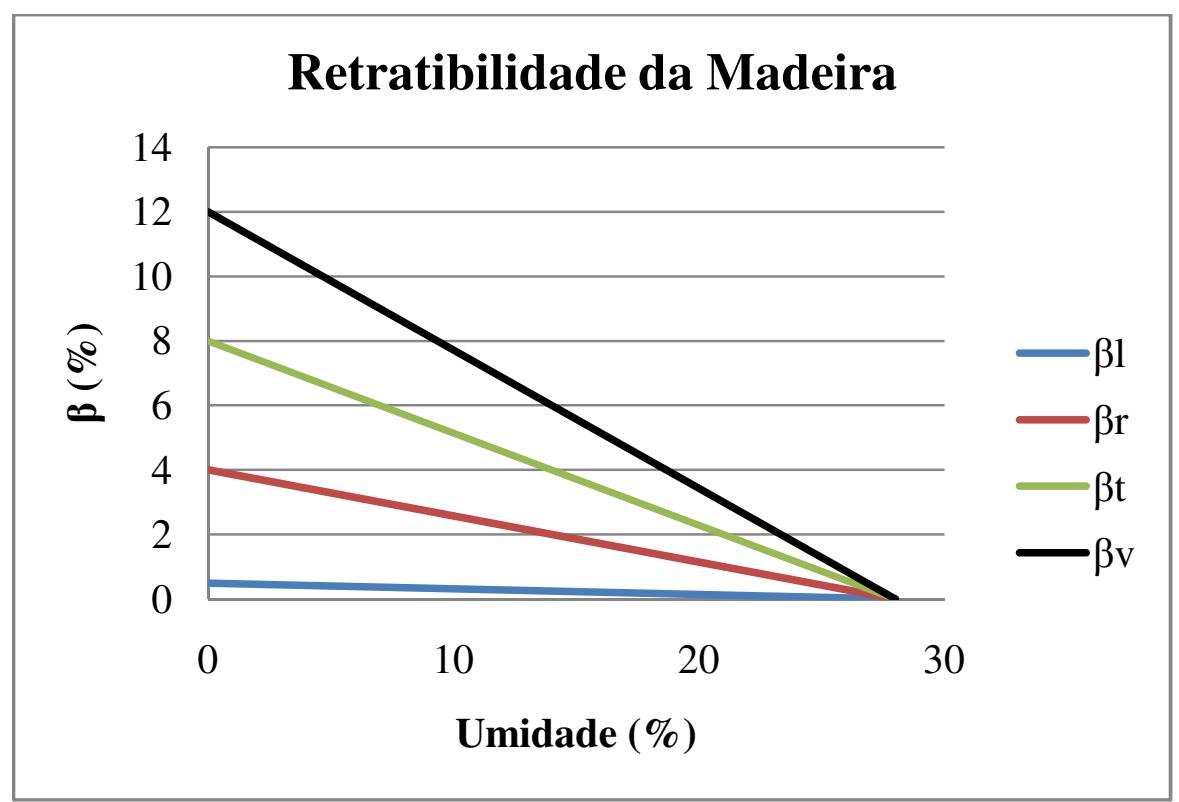

Figura 5: Retratibilidade da madeira nas três direções convencionadas e volumétrica. Fonte: Adaptado de GALVÃO \& JANKOWSKY(1985)

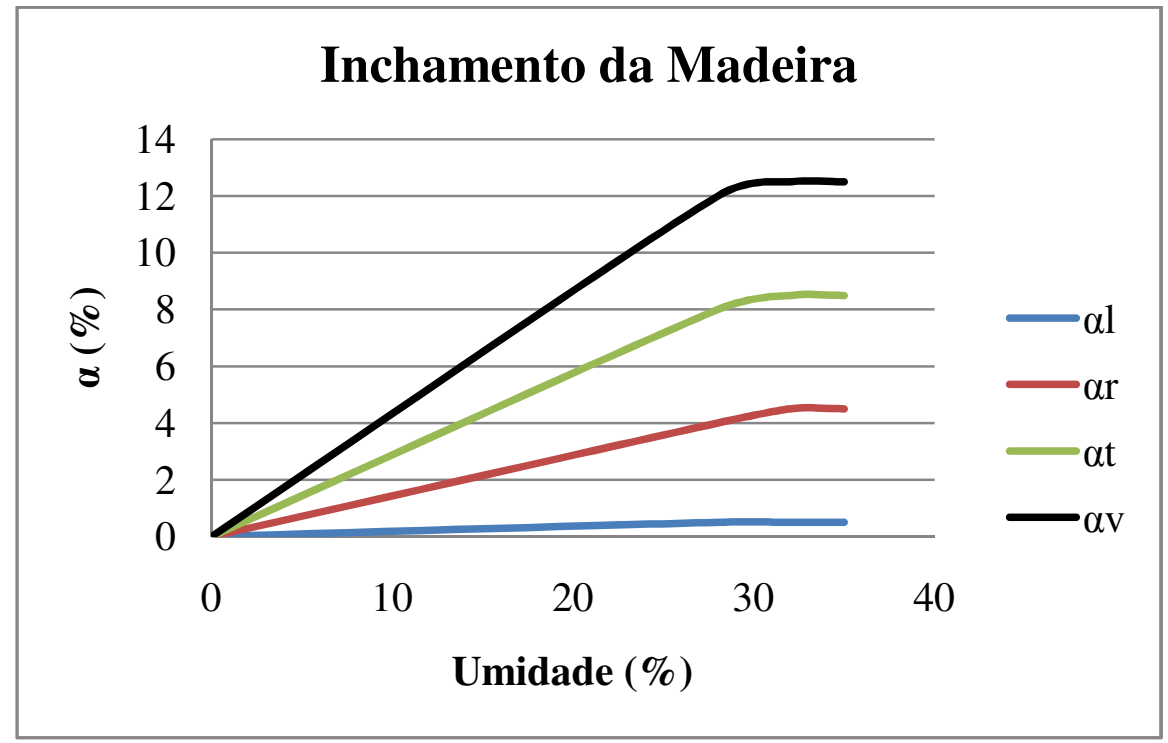

Figura 6: Inchamento da madeira nas três direções convencionadas e volumétrico. Fonte: Adaptado de KOLLMANN \& CÔTÉ(1968) 
A direção axial é a direção da altura das fibras, menos suscetível à variação dimensional devido à presença de umidade, e ocorre por existirem regiões cristalinas e amorfas no polímero (Figura 7) e pela existência de um ângulo de aproximadamente 10 graus entre as microfibrilas e o eixo longitudinal da fibra, ao contrário das demais direções que são transversais que são mais suscetíveis (KOLLMANN \& CÔTÉ, 1968).

A menor variação dimensional da direção radial em relação à tangencial pode ser explicada pela presença do parênquima radial, que melhora a estabilidade nesta direção; pela presença de maior número de pontoações (comunicações entre as fibras) na parede das células radiais que, ao obrigar as microfibrilas contorná-las, provocando desvios em suas orientações; e pela alternância entre lenho inicial e tardio (anéis de crescimento) (WALKER et al., 1993).

A figura 7 representa também a disposição do polímero nas microfibrilas, que formam a parede celular da árvore. (KOLLMANN \& CÔTÉ, 1968; GALVÃO \& JANKOWSKY, 1985).

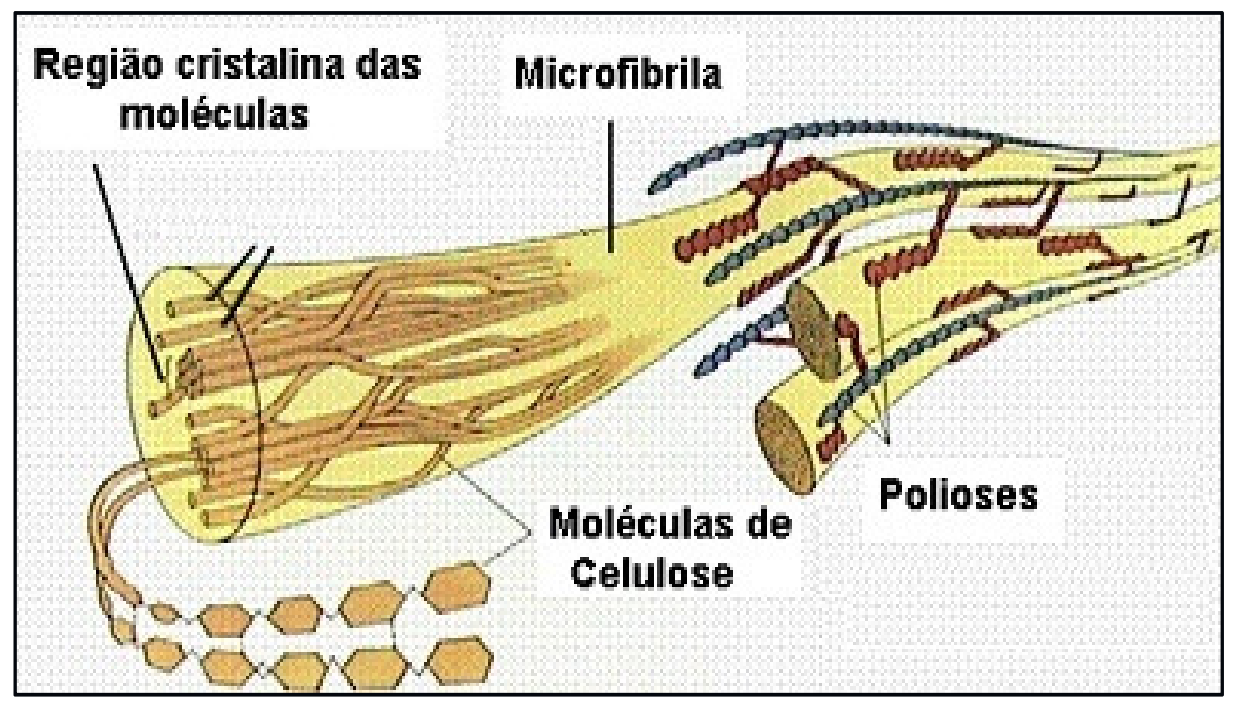

Figura 7: Polímero disposto nas microfibrilas da madeira. Fonte: SEVERIANO (2010).

\subsubsection{Coeficientes de Retratibilidade Volumétrica e de Inchamento Volumétrico}

O Coeficiente de Retratibilidade Volumétrica é um parâmetro adimensional que representa a perda percentual de volume em relação à perda percentual de massa de uma amostra de madeira sujeita à secagem partindo do PSF. O Coeficiente de Inchamento Volumétrico é análogo, porém dado em um inchamento partindo de $0 \%$ de umidade. A equação 5 mostra a relação a que este parâmetro corresponde. 
Equação 5: Coeficiente de Retratibilidade Volumétrica, Coeficiente de Inchamento

Volumétrico e relações.

$$
\begin{gathered}
\delta^{\prime} v=\frac{\left|\Delta \beta_{(P S F, 0)}\right|}{\left|\Delta u_{(P S F, 0)}\right|}=\frac{\beta_{P S F}}{P S F}[\% / \%] ; \delta v=\frac{\left|\Delta \alpha_{(P S F, 0)}\right|}{\left|\Delta u_{(P S F, 0)}\right|}=\frac{\alpha_{P S F}}{P S F}[\% / \%] ; \\
\delta v=\frac{\delta^{\prime} v}{1-\delta^{\prime} v * P S F} ; \delta^{\prime} v=\frac{\delta v}{1+\delta v * P S F}
\end{gathered}
$$

Onde:

$\Delta \beta_{(P S F, 0)}$ : variação de retração entre $0 \%$ e PSF de umidade;

$\Delta u_{(P S F, 0)}$ : variação de umidade entre $0 \%$ e PSF de umidade;

$\alpha_{P S F}:$ inchamento máximo;

$\beta_{P S F}$ : retração máxima;

$\delta^{\prime} v$ : coeficiente de retratibilidade volumétrica.

Estes parâmetros são utilizados nas relações que envolvem as propriedades físicas da madeira, pois demonstram numericamente a movimentação dimensional provocada pela variação no teor de umidade.

\subsubsection{Coeficiente de Anisotropia}

Analisando a estabilidade dimensional da madeira percebe-se a diferença entre as retrações nas direções radial e longitudinal da madeira que, como citado anteriormente, é fruto da atuação das células radiais do material e da influência das zonas amorfas no polímero. A equação 6 mostra o coeficiente de anisotropia.

Equação 6: Coeficiente de anisotropia.

$$
C A=\frac{\beta_{t}}{\beta_{r}}
$$

Onde:

$C A$ : coeficiente de anisotropia.

O coeficiente de anisotropia é um parâmetro importante da madeira quando se processa sua classificação para empregá-la in natura (ou seja, sem sofrer processamento mecânico total 
em picadores e moinhos). Sendo ele a relação entre a variação dimensional percentual nas direções tangencial e radial, e que essas deformações ocorrem de maneira diferente, quanto maior esta relação, mais suscetível a defeitos de secagem é a madeira (defeitos como tortuosidade, encanoamento e rachaduras) (GALVÃO \& JANKOWSKY, 1985).

\subsection{Relações e Parâmetros Importantes}

Para efeito de caracterização e utilização da madeira, suas propriedades são estudadas no sentido de desenvolvimento de parâmetros e relações matemáticas envolvendo estas variáveis.

No tocante ao Ponto de Saturação das Fibras, Trendelenburg (1939) citado por Kollmann \& Côté (1968), expõe sua variação com a composição química e a estrutura anatômica da madeira.

Para Kollmann \& Côté (1968), Durlo \& Marchiori (1992), entre outros, um valor médio correspondente a esse parâmetro é $28 \%$ de umidade.

Cisternas (1994), Severiano (2010), entre outros, registram que este parâmetro apresenta como valor médio $30 \%$ de umidade.

O documento normativo brasileiro ABNT NBR 7190/1997 utiliza como valor médio para este parâmetro, $25 \%$ de umidade.

Quando se trata de relações entre propriedades, estes autores defendem a existência das correlações lineares mostradas nas equações 7 e 8 , sendo elas: entre "Inchamento volumétrico máximo" e "Densidade aparente a $0 \%$ de umidade" e entre "Retratibilidade volumétrica máxima" e "Densidade Básica da madeira".

Equação 7: Inchamento volumétrico percentual total em função da densidade anidra da madeira.

$$
\alpha_{P S F}=P S F * \rho_{S} \rightarrow \frac{\alpha_{P S F}}{P S F}=f\left(\rho_{S}\right)
$$

Onde:

$\rho_{s}:$ densidade aparente da madeira anidra.

Equação 8: Retração volumétrica percentual total em função da densidade básica da madeira.

$$
\beta_{P S F}=P S F * \rho_{b a s} \rightarrow \frac{\beta_{P S F}}{P S F}=f\left(\rho_{\text {bas }}\right)
$$


Estes autores salientam que as equação 7 e 8 podem ser melhor descritas nas formas das equações 9 e 10, inserindo um fator para melhor ajuste dos pontos.

Equação 9: Relação entre Inchamento volumétrico máximo em função da densidade anidra da madeira como uma solução média.

$$
\frac{\alpha_{P S F}}{P S F}=0,84 * \rho_{S}
$$

Equação 10: Relação entre retração volumétrica máxima em função da densidade básica da madeira como uma solução média.

$$
\frac{\beta_{P S F}}{P S F}=0,84 * \rho_{\text {bas }}
$$

Logsdon (2005) utilizou a equação 9 em seus estudos para estabelecer uma relação entre a densidade aparente em qualquer umidade e a densidade aparente anidra das madeiras de Paricá, Cedrinho, Justa conta, Angico-cascudo e Gonçaleiro. Concluiu que o modelo proposto por Kollmann \& Côté (1968) parte de uma lógica irrepreensível, ao se imaginar o umedecimento de uma amostra de madeira, mas as aproximações utilizadas por ele parecem não se aplicar às folhosas brasileiras.

Existem vários estudos a respeito da correlação entre inchamento volumétrico total e densidade aparente da madeira anidra, além da correlação entre a retração volumétrica total e densidade básica da madeira. Estes consideram existir alguma correlação entre a densidade e a variação dimensional do material devido à mudança em seu teor de umidade (BATISTA et al., 2005; GREEN, 1989; MELO \& SIQUEIRA, 1992; PLIURA et al., 2005).

Em seus estudos Almeida et al.(2015) comprovaram existir correlação entre a retratibilidade volumétrica percentual total e densidade aparente da madeira anidra para Cedrella sp., Cassia ferruginea e Vataireopsis araroba, sendo elas espécies tropicais brasileiras.

Keylwerth (1943), citado por Kollmann \& Côté (1968), desenvolveu as relações contidas na equação 11. A primeira mostra a magnitude da retração na direção longitudinal em relação à retração na direção tangencial. A segunda foi desenvolvida em uma tentativa de regressão linear em um gráfico da retração total na direção tangencial em função da retração total na direção radial, generalizando assim o coeficiente de 
42

anisotropia das amostras utilizadas como sendo 1,65. De acordo com Kollmann \& Côté (1968), o coeficiente de anisotropia é influenciado pela densidade do material.

Equação 11: Relações importantes envolvendo coeficiente de anisotropia.

$$
\left\{\begin{array}{c}
\beta_{l}=\frac{\beta_{t}}{23} \\
\beta_{t}=1,65 * \beta_{r}
\end{array}\right.
$$

Da primeira relação, equação 11, que mostra ser desprezível a retração na direção longitudinal, os autores desenvolveram as equações 12 e 13 com aproximações.

Equação 12: Coeficiente de anisotropia em função do inchamento - aproximação.

$$
\frac{\alpha_{t}}{\alpha_{r}} \cong \frac{\beta_{t}}{\beta_{r}}
$$

Equação 13: Retração volumétrica em função da retração linear e aproximação.

$$
\left\{\begin{array}{c}
\alpha_{v}=\left(1+\alpha_{t}\right)\left(1+\alpha_{r}\right)\left(1+\alpha_{l}\right)-1 \cong \alpha_{t}+\alpha_{r} \\
\beta_{v}=1-\left(1-\beta_{t}\right)\left(1-\beta_{r}\right)\left(1-\beta_{l}\right) \cong \beta_{t}+\beta_{r}
\end{array}\right.
$$

\subsection{Classes de Resistência da Madeira}

Tratando-se das propriedades mecânicas da madeira, o documento normativo brasileiro divide-as entre coníferas e dicotiledôneas. Além disso, as Classes de Resistência (CR) predeterminadas.

Cabe comentar que os valores de resistência na compressão, assim como para outras solicitações mecânicas, são em média diretamente proporcionais aos valores da densidade das madeiras (CHRISTOFORO et al., 2013), ou seja, quão maior o valor da resistência, maiores são os valores das densidades, e visto que as madeiras neste trabalho foram escolhidas por meio do critério das classes de resistência, isso implica que as análises efetuadas, que englobam as quinze espécies de madeira em conjunto para cada propriedade investigada, representam bem a variabilidade na densidade das madeiras, o que permite investigar, com um nível maior de generalidade, a possibilidade da relação entre algumas propriedades físicas de interesse. 
$\mathrm{Na}$ tabela 1 as classes de resistência estabelecidas pelo projeto de norma PN02:126.10-001-1 (NBR 7190) para coníferas e dicotiledôneas.

Tabela 1: Classes de resistência da madeira previstas pela norma brasileira.

\begin{tabular}{|c|c|c|c|c|c|}
\hline \multicolumn{6}{|c|}{ CONÍFERAS } \\
\hline CLalores na condição padrão de referência TU=12\%) \\
\hline CLASSES & $\begin{array}{c}\mathrm{f}_{\mathrm{c} 0 \mathrm{k}} \\
(\mathrm{MPa})\end{array}$ & $\begin{array}{c}\mathrm{f}_{\mathrm{vk}} \\
(\mathrm{MPa})\end{array}$ & $\begin{array}{c}\mathrm{E}_{\mathrm{c} 0, \mathrm{~m}} \\
(\mathrm{MPa})\end{array}$ & $\begin{array}{c}\rho_{\text {bas,m }} \\
\left(\mathrm{kg} / \mathrm{m}^{3}\right)\end{array}$ & $\begin{array}{c}\rho_{\text {aparente }} \\
\left(\mathrm{kg} / \mathrm{m}^{3}\right)\end{array}$ \\
\hline C 20 & 20 & 4 & 3500 & 400 & 500 \\
\hline C 25 & 25 & 5 & 8500 & 450 & 550 \\
\hline C 30 & 30 & 6 & 14500 & 500 & 600 \\
\hline \multicolumn{6}{|c|}{ DICOTILEDÔNEAS } \\
\hline (Valores na condição padrão de referência TU=12\%) \\
\hline CLASSES & $\mathrm{f}_{\mathrm{c} 0 \mathrm{k}}$ & $\begin{array}{c}\mathrm{f}_{\mathrm{vk}} \\
(\mathrm{MPa})\end{array}$ & $\begin{array}{c}\mathrm{E}_{\mathrm{c} 0, \mathrm{~m}} \\
(\mathrm{MPa})\end{array}$ & $\begin{array}{c}\rho_{\text {bas, } \mathrm{m}} \\
\left(\mathrm{Mga} / \mathrm{m}^{3}\right)\end{array}$ & $\begin{array}{c}\rho_{\text {aparente }} \\
\left(\mathrm{kg} / \mathrm{m}^{3}\right)\end{array}$ \\
\hline C 20 & 20 & 4 & 9500 & 500 & 650 \\
\hline C 30 & 30 & 5 & 14500 & 650 & 800 \\
\hline C 40 & 40 & 6 & 19500 & 750 & 950 \\
\hline C 50 & 50 & 7 & 22000 & 775 & 975 \\
\hline C 60 & 60 & 8 & 24500 & 800 & 1000 \\
\hline
\end{tabular}

Na tabela acima:

$\mathrm{f}_{\mathrm{c} 0 \mathrm{k}}$ : Resistência à compressão paralela às fibras (valor característico);

$\mathrm{f}_{\mathrm{vk}}$ : Resistência ao cisalhamento (valor característico);

$\mathrm{E}_{\mathrm{co}, \mathrm{m}}$ : Módulo de elasticidade à compressão paralela às fibras (valor médio);

$\rho_{\text {bas,m: }}$ : Densidade básica (valor médio);

$\rho_{\text {aparente: }}$ Densidade aparente (valor médio).

\subsection{Conclusão de Pesquisa Bibliográfica}

No âmbito da estabilidade dimensional da madeira, parâmetros e relações foram desenvolvidas, não experimentadas para madeiras tropicais brasileiras, e mesmo assim assumidas como válidas até os dias atuais. Nota-se a necessidade de estudos dessas madeiras no que diz respeito à estabilidade dimensional, tendo em vista a caracterização e desenvolvimento de relações e parâmetros mais específicos para as mesmas. 


\section{MATERIAL E MÉTODOS}

Nesta seção são fornecidas as informações referentes aos materiais e métodos deste trabalho.

\subsection{Materiais}

Nesta pesquisa foi utilizada madeira de 15 espécies, relacionadas na Tabela 2, brevemente descritas no Anexo.

A escolha destas espécies baseou-se na abrangência das classes de resistência definidas pelo projeto de norma PN02:126.10-001-1 (ABNT NBR 7190). Todos os corpos de prova foram confeccionados com as peças de madeira com teor de umidade da ordem de $12 \%$, dispostas em lotes contendo 12 peças cada.

Tabela 2: Relação de espécies de madeira utilizadas no estudo.

\begin{tabular}{c|c|c}
\hline Nome Popular & Nome Científico & Classe de Resistência (CR) \\
\hline Cedro-doce & Pachira quinata & C20 \\
Cedro-amargo & Cedrela sp. & C20 \\
Cambará & Erisma sp. & C20 \\
\hline Canafístula & Cassia ferruginea & C30 \\
Catanudo & Calophyllum sp. & C30 \\
Casca grossa & Ocotea odorifera & C40 \\
\hline Angelim araroba & Vataieropsis araroba & $\mathrm{C} 40$ \\
Cupiúba & Goupia glabra & $\mathrm{C} 40$ \\
Angelim amargoso & Vatairea fusca & $\mathrm{C} 50$ \\
Mandioqueira & Qualea albiflora & $\mathrm{C} 50$ \\
Castelo & Gossypiospermun praecox & $\mathrm{C} 50$ \\
Tatajuba & Bagassa guianensis & $\mathrm{C} 60$ \\
Angelim Vermelho & Dinizia excelsa & $\mathrm{C} 60$ \\
Champanhe & Dipteryx sp. & $\mathrm{C} 60$ \\
Itaúba & Mezilaurus itauba &
\end{tabular}

Cabe ressaltar que todas estas madeiras são oriundas de áreas certificadas da Floresta Amazônica. 


\subsection{Métodos}

\subsubsection{Procedimentos Experimentais}

Os ensaios para determinação das propriedades foram conduzidos de acordo com as recomendações do anexo B da ABNT NBR 7190:97 "Determinação das Propriedades das Madeiras para Projetos Estruturais”. Para cada espécie foram realizadas 12 determinações, a partir de corpos de prova isentos de defeitos. Foi obtido um corpo de prova de cada uma das 12 peças citadas em 4.1. As propriedades determinadas foram: densidade aparente ( $0 \%$ e $12 \%$ de umidade), densidade básica, retração (longitudinal, radial, tangencial e volumétrica - valores máximos) e ponto de saturação das fibras.

Utilizando-se as equações 5 e 6, determinou-se os coeficientes de Retratibilidade volumétrica, de Inchamento Volumétrico e de Anisotropia, respectivamente.

As dimensões dos corpos de prova foram determinadas utilizando paquímetro (como o ilustrado na figura 8), bem como as massas foram determinadas utilizando balança analítica.
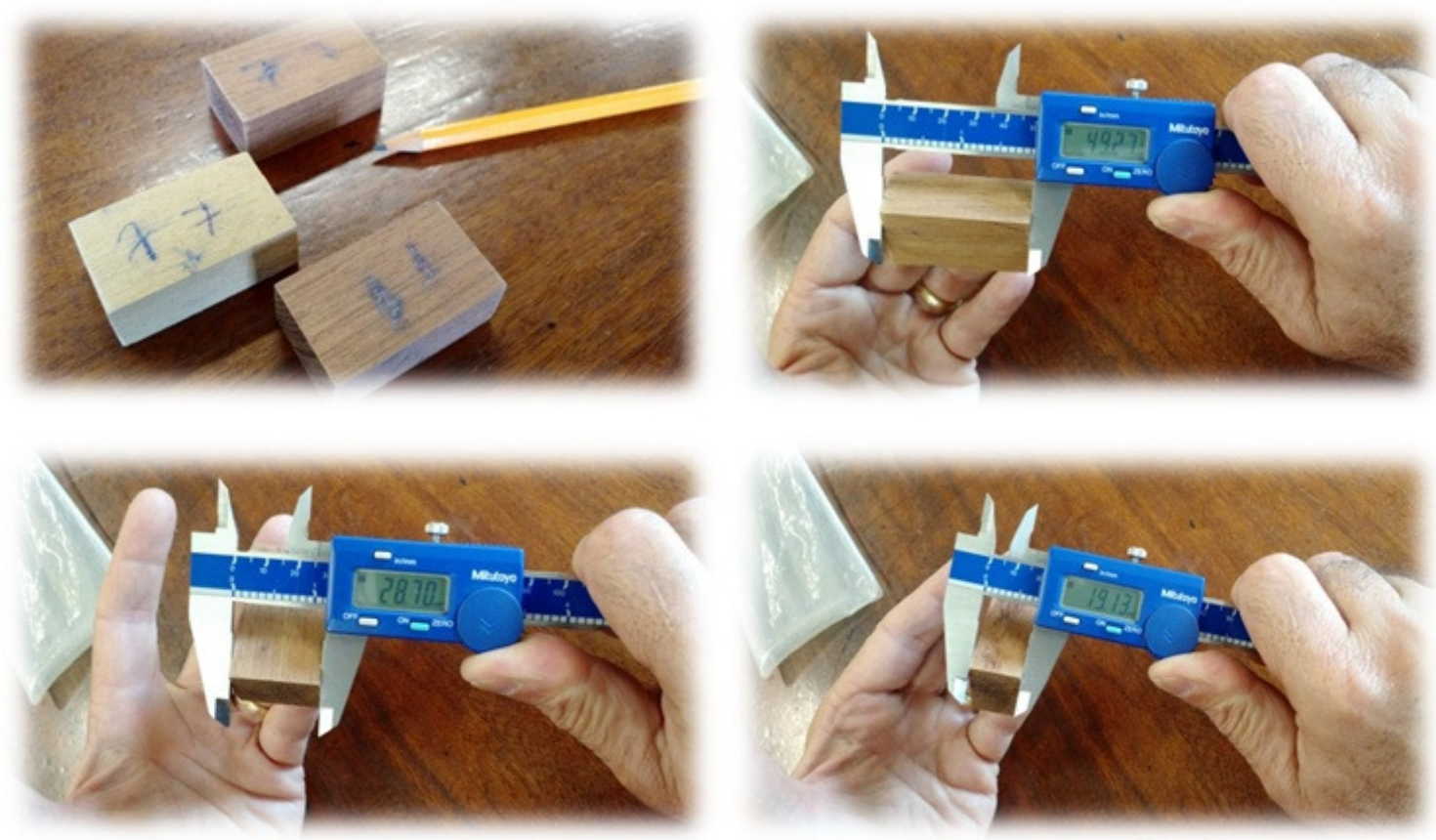

Figura 8: Determinação das dimensões dos corpos de prova. 


\subsubsection{Análises Estatísticas}

Como comentado anteriormente, as propriedades investigadas neste trabalho são:

$\checkmark \quad \beta_{\mathrm{r}}$ - retração radial;

$\checkmark \quad \beta_{\mathrm{t}}$ - retração tangencial;

$\checkmark \quad \beta_{1}$ - retração longitudinal;

$\checkmark \quad \beta_{\mathrm{v}}$ - retração volumétrica;

$\checkmark$ CA $\left(\beta_{t} / \beta_{\mathrm{r}}\right)$ - coeficiente de anisotropia;

$\checkmark \quad \alpha_{\mathrm{r}}$ - inchamento radial;

$\checkmark \quad \alpha_{\mathrm{t}}$ - inchamento tangencial;

$\checkmark \quad \alpha_{1}$ - inchamento longitudinal;

$\checkmark \quad \alpha_{\mathrm{v}}$ - inchamento volumétrico;

$\checkmark$ PSF - ponto de saturação das fibras;

$\checkmark \quad \alpha_{v} / \mathrm{PSF}$ - coeficiente de retratibilidade volumétrica;

$\checkmark \quad \beta_{\mathrm{v}} / \mathrm{PSF}$ - coeficiente de inchamento volumétrico;

$\checkmark \quad \rho_{\text {bas }}$ (massa seca/volume saturado) - densidade básica;

$\checkmark \quad \rho_{12}$ - densidade aparente a $12 \%$ de umidade;

$\checkmark \quad \rho_{\mathrm{s}}$ - densidade da madeira seca.

Em linhas gerais, procurou-se neste trabalho: investigar a possibilidade de estimar algumas propriedades físicas das madeiras por meio do conhecimento de outras, através de modelos de regressão; avaliar a precisão da relação entre algumas propriedades físicas apresentadas na literatura correlata (Kollmann \& Côté (1968) e Galvão \& Jankowsky (1985)), sugerindo-se, no caso da não adequação das relações da literatura para com os resultados do grupo das quinze espécies de madeira aqui utilizadas, os modelos matemáticos mais representativos; e também de avaliar a precisão de uma relação envolvendo densidade aparente e densidade básica desenvolvida neste trabalho.

\subsubsection{Análises de Precisão (Aderência)}

Para avaliar a precisão (adequação) das relações da literatura para com os resultados experimentais obtidos nesta pesquisa utilizou-se a análise de variância (ANOVA), com o auxílio do software Minitab® versão 14, considerada ao nível de 5\% 
de significância, consistindo a equivalência das médias dos dois grupos em análise como hipótese nula $\left(\mathrm{H}_{0}\right)$ e a não equivalência como hipótese alternativa $\left(\mathrm{H}_{1}\right)$. Dessa forma, se o P-valor (probabilidade $[\mathrm{P}]$ de se aceitar a hipótese nula $\left[\mathrm{H}_{0}\right]$ ) é superior ao nível de significância $(0,05)$, isso implica em se aceitar $\mathrm{H}_{0}$ (as médias dos dois grupos, estimada e obtida experimentalmente são equivalentes - modelo da literatura adere ao conjunto de dados desta pesquisa), e se menor (P-valor $<0,05)$, em refutar $\mathrm{H}_{0}$ ou aceitar $\mathrm{H}_{1}$ (as médias são significativamente diferentes - modelo da literatura não representativo).

Para validação da ANOVA faz-se necessário verificar a normalidade, homogeneidade dos resíduos por propriedade avaliada (MONTGOMERY, 2005). A normalidade e a homogeneidade dos resíduos foram investigadas com o uso dos testes de Anderson-Darling $[\mathrm{AD}]$ e $\mathrm{F}$ teste $[\mathrm{F}]$, respectivamente. Pela formulação de ambos os testes, avaliados também ao nível de 5\% de significância, P-valor superior a 5\% implica que os resíduos apresentam distribuição normal por variável-resposta e que as variâncias dos resíduos dos dois grupos são equivalentes, validando assim o modelo da ANOVA.

Quando da não normalidade nas distribuições dos resíduos, a transformada de Johnson foi utilizada, e no caso de não ter sido encontrada a função de transformação, na seqüência utilizou-se da Análise de Variância de Kruskal-Wallis (não paramétrica), considerada também ao nível de 5\% de significância.

Da ANOVA de Kruskal-Wallis, pela formulação das hipóteses, P-valor superior a 0,05 implica que as médias dos grupos são equivalentes (hipótese nula - $\mathrm{H}_{0}$ ), e inferior em caso contrário (hipótese alternativa - $\mathrm{H}_{1}$ ).

\subsubsection{Análises de Regressão}

Os modelos de regressão testados, também com o auxílio da ANOVA, estão apresentados na Tabela 3, sendo $\mathrm{X}$ a variável dependente, $\mathrm{Y}$ a variável independente e " $\mathrm{a}$ " e "b" as constantes (parâmetros) das funções ajustadas pelo método dos mínimos quadrados.

Pela ANOVA dos modelos de regressão, avaliados também ao nível de significância de 5\%, a hipótese nula estipulada consistiu na não representatividade dos modelos testados $\left(\mathrm{H}_{0}: \sigma=0\right)$, e na representatividade como hipótese alternativa $\left(\mathrm{H}_{1}: \sigma \neq 0\right)$. P-valor superior ao nível de significância considerado implica em aceitar $\mathrm{H}_{0}$ (o modelo testado não é representativo - variações de X são incapazes de explicar as variações em Y), refutando-a em caso contrário (o modelo testado é representativo). 
Tabela 3: Modelos de regressão utilizados na estimativa de propriedades físicas.

\begin{tabular}{cc}
\hline Tipo de Ajuste & Função $[Y=f(X)]$ \\
\hline Polinomial Linear [Lin] & $Y=a+b \cdot X$ \\
Exponencial [Exp] & $Y=a \cdot e^{b \cdot X}$ \\
Logarítmica [Log] & $Y=a+b \cdot \operatorname{Ln}(X)$ \\
Geométrica [Geo] & $Y=a \cdot X^{b}$ \\
\hline
\end{tabular}

Além do uso da ANOVA, que permite aceitar ou não a representatividade dos modelos testados, os valores do coeficiente de determinação ajustados $\left[R^{2}(a j)\right]$ foram obtidos como forma de avaliar a capacidade das variações da variável independente $\mathrm{X}$ em explicar a variável preditiva Y, possibilitando eleger, dentre os modelos considerados significativos, o de melhor ajuste por relação testada.

\subsubsection{Finalidades das Análises}

Com as análises de precisão, procura-se investigar:

- Com o auxílio da ANOVA, testar a precisão das relações de 1 a 5, provenientes da literatura em obras correlatas, sendo elas:

$$
\begin{array}{rlr}
\beta_{t} \cong 1,65 * \beta_{r} & \text { Relação 1 } \\
\frac{\alpha_{t}}{\alpha_{r}} \cong \frac{\beta_{t}}{\beta_{r}} & \text { Relação 2 } \\
\beta_{l} \cong \beta_{t} / 23 & \\
\beta_{v} \cong \beta_{t}+\beta_{r} & \text { Relação 3 } \\
\alpha_{v} \cong \alpha_{t}+\alpha_{r} & \text { Relação 4 } \\
& \text { Relação 5 }
\end{array}
$$

Para o caso das relações de 1 a 3, não sendo válidos (via ANOVA) os modelos testados sobre os valores das propriedades das madeiras aqui investigadas, modelos de regressão lineares (natureza das três equações) serão utilizados com o intuito de se investigar a precisão de tais relações. Para o caso das relações 4 e 5, acusada não equivalência das mesmas pela ANOVA, modelos de regressão lineares à duas variáveis independentes serão utilizados;

- $\quad$ Com o auxílio da ANOVA, testar a precisão da equação $\alpha_{v} / P S F=0,84 * \rho_{s}$, desenvolvida por Kollmann \& Côté (1968); 
- Com o auxílio da ANOVA, testar a precisão da equação 14, desenvolvida neste trabalho, abaixo apresentada. A dedução da mesma encontra-se no Apêndice.

Equação 14: Densidade básica determinada pela densidade aparente.

$$
\frac{T U}{\rho_{\text {bas }}}=\frac{\left(1+\frac{T U}{100}\right) * P S F}{\rho_{u}}-\frac{(P S F-T U)}{\rho_{s}}
$$

Para uso da Equação 14, o ponto de saturação das fibras, a densidade da madeira seca $\left(\rho_{0}\right)$ e a densidade aparente $\left(\rho_{12}\right)$, variáveis desta equação,foram utilizados todos os resultados das amostras das 15 espécies, e o teor de umidade TU [teor de umidade entre 0 e PSF\%] estipulado foi de $12 \%(0,12)$ [teor de umidade conhecido para uso da equação]. Como são 180 valores (12 determinações para cada uma das 15 espécies de madeira) das respectivas densidades, foram estimados 180 valores da densidade básica, a serem comparados com as densidades básicas das 180 amostras obtidas experimentalmente.

Com as análises de regressão, procura-se investigar:

- $\quad$ Em razão da relativa facilidade na obtenção dos valores de densidade aparente quando comparados com a obtenção das demais propriedades físicas das madeiras selecionadas, modelos de regressão (Tabela 3) foram utilizados como forma de se estimar as retrações $\left(\beta_{\mathrm{r}} ; \beta_{\mathrm{t}} ; \beta_{1} ; \beta_{\mathrm{v}}\right)$, o coeficiente de anisotropia (CA), o coeficiente de retratibilidade volumétrica $\left(\beta_{\mathrm{v}} / \mathrm{PSF}\right)$ e o coeficiente de inchamento volumétrico $\left(\alpha_{\mathrm{v}} / \mathrm{PSF}\right)$ em função da densidade básica $\left(\rho_{\text {bas }}\right)$, densidade aparente a $12 \%$ de umidade $\left(\rho_{12}\right)$ e densidade da madeira seca $\left(\rho_{\mathrm{s}}\right)$. Cabe ressaltar que os valores de inchamento $\left(\alpha_{\mathrm{r}} ; \alpha_{t} ; \alpha_{1} ; \alpha_{\mathrm{v}}\right)$ não são investigados nos modelos de regressão por serem dependentes dos valores das retrações, conferindo assim a mesma variabilidade;

- $\quad$ Pela relativa facilidade da obtenção dos valores da densidade aparente a $12 \%$ de umidade $\left(\rho_{12}\right)$, verificar a possibilidade de se estimar os valores da densidade básica $\left(\rho_{\mathrm{bas}}=\right.$ massa seca/volume saturado). 


\section{RESULTADOS E DISCUSSÕES}

\subsection{Apresentação dos Resultados Experimentais}

As Tabelas de 4 a 18 apresentam os valores médios $(\bar{x})$, os coeficientes de variação $(C v)$ e os menores (Mín.) e os maiores (Máx.) valores encontrados das propriedades físicas investigadas para as quinze espécies de madeira.

Tabela 4: Resultados para Cedro-doce (C20).

\begin{tabular}{|c|c|c|c|c|c|c|c|c|}
\hline Estat. & $\begin{array}{c}\rho_{12} \\
\left(\mathbf{g} / \mathbf{c m}^{3}\right)\end{array}$ & $\begin{array}{c}\rho_{\mathrm{s}} \\
\left(\mathrm{g} / \mathrm{cm}^{3}\right) \\
\end{array}$ & $\begin{array}{c}\rho_{\text {bas }} \\
\left(\mathrm{g} / \mathbf{c m}^{3}\right)\end{array}$ & $\begin{array}{l}\text { PSF } \\
(\%)\end{array}$ & $\beta_{\mathbf{r}}(\%)$ & $\beta_{\mathrm{t}}(\%)$ & $\beta_{\mathrm{v}}(\%)$ & $\beta_{1}(\%)$ \\
\hline$\overline{\bar{x}}$ & 0,50 & 0,48 & 0,42 & 25,34 & 3,44 & 5,00 & 8,67 & 0,43 \\
\hline$C v(\%)$ & 5,35 & 6,17 & 9,37 & 17,60 & 24,07 & 19,57 & 13,73 & 28,36 \\
\hline Mín. & 0,45 & 0,43 & 0,37 & 20,48 & 2,52 & 4,02 & 6,84 & 0,27 \\
\hline Máx & 0,55 & 0,53 & 0,52 & 36,00 & 5,51 & 6,64 & 11,05 & 0,72 \\
\hline Estat. & $\alpha_{1}(\%)$ & $\alpha_{\mathrm{r}}(\%)$ & $\alpha_{t}(\%)$ & $\alpha_{\mathrm{v}}(\%)$ & $\mathbf{C A}$ & $\alpha_{v} /$ PSF & $\beta_{\mathrm{v}} / \mathrm{PSF}$ & \\
\hline $\bar{x}$ & 0,43 & 3,57 & 5,28 & 9,51 & 1,53 & 0,39 & 0,35 & \\
\hline$C v(\%)$ & 28,51 & 25,14 & 20,70 & 15,12 & 32,36 & 22,25 & 21,41 & \\
\hline Mín. & 0,27 & 2,59 & 4,19 & 7,34 & 0,98 & 0,24 & 0,22 & \\
\hline Máx & 0,72 & 5,83 & 7,11 & 12,42 & 2,57 & 0,49 & 0,44 & \\
\hline
\end{tabular}

Tabela 5: Resultados para Cedro-amargo (C20).

\begin{tabular}{|c|c|c|c|c|c|c|c|c|}
\hline Estat. & $\begin{array}{c}\rho_{12} \\
\left(\mathrm{~g} / \mathrm{cm}^{3}\right)\end{array}$ & $\underset{\left(\mathrm{g} / \mathrm{cm}^{3}\right)}{\rho_{\mathrm{s}}}$ & $\begin{array}{c}\rho_{\text {bas }} \\
\left(\mathrm{g} / \mathbf{c m}^{3}\right)\end{array}$ & $\begin{array}{l}\text { PSF } \\
(\%)\end{array}$ & $\beta_{\mathbf{r}}(\%)$ & $\beta_{\mathrm{t}}(\%)$ & $\beta_{\mathrm{v}}(\%)$ & $\beta_{1}(\%)$ \\
\hline $\bar{x}$ & 0,50 & 0,47 & 0,42 & 18,00 & 3,99 & 5,57 & 9,94 & 0,66 \\
\hline$C v(\%)$ & 6,40 & 8,69 & 8,91 & 12,77 & 9,78 & 18,29 & 13,37 & 43,15 \\
\hline Mín. & 0,44 & 0,40 & 0,39 & 15,68 & 3,29 & 4,77 & 8,86 & 0,29 \\
\hline Máx & 0,57 & 0,55 & 0,53 & 24,46 & 4,91 & 8,52 & 13,96 & 1,09 \\
\hline Estat. & $\alpha_{1}(\%)$ & $\alpha_{r}(\%)$ & $\alpha_{t}(\%)$ & $\alpha_{\mathrm{v}}(\%)$ & $\mathbf{C A}$ & $\alpha_{v} /$ PSF & $\beta_{\mathrm{v}} / \mathrm{PSF}$ & \\
\hline $\bar{x}$ & 0,66 & 4,16 & 5,91 & 11,06 & 1,40 & 0,62 & 0,56 & \\
\hline$C v(\%)$ & 43,44 & 10,21 & 19,79 & 15,37 & 15,66 & 19,99 & 18,25 & \\
\hline Mín. & 0,30 & 3,40 & 5,01 & 9,72 & 1,23 & 0,44 & 0,40 & \\
\hline Máx & 1,10 & 5,16 & 9,31 & 16,23 & 1,94 & 0,95 & 0,82 & \\
\hline
\end{tabular}


Tabela 6: Resultados para Cambará (C20).

\begin{tabular}{ccccccccc}
\hline Estat. & $\begin{array}{c}\boldsymbol{\rho}_{\mathbf{1 2}} \\
\left(\mathbf{g} / \mathbf{c m}^{\mathbf{3}}\right)\end{array}$ & $\begin{array}{c}\boldsymbol{\rho}_{\mathbf{s}} \\
\left(\mathbf{g} / \mathbf{c m}^{\mathbf{3}}\right)\end{array}$ & $\begin{array}{c}\boldsymbol{\rho}_{\text {bas }} \\
\left(\mathbf{g} / \mathbf{c m}^{\mathbf{3}}\right)\end{array}$ & $\begin{array}{c}\mathbf{P S F} \\
(\boldsymbol{\%})\end{array}$ & $\boldsymbol{\beta}_{\mathbf{r}}(\boldsymbol{\%})$ & $\boldsymbol{\beta}_{\mathbf{t}}(\boldsymbol{\%})$ & $\boldsymbol{\beta}_{\mathbf{v}}(\boldsymbol{\%})$ & $\boldsymbol{\beta}_{\mathbf{l}}(\boldsymbol{\%})$ \\
\hline $\bar{x}$ & 0,68 & 0,64 & 0,51 & 22,32 & 5,91 & 10,63 & 16,77 & 1,04 \\
Cv $(\%)$ & 4,77 & 5,44 & 7,72 & 6,31 & 14,97 & 10,70 & 10,25 & 22,49 \\
Mín. & 0,62 & 0,58 & 0,45 & 19,67 & 4,72 & 8,85 & 13,87 & 0,51 \\
Máx & 0,74 & 0,69 & 0,58 & 24,15 & 7,92 & 12,91 & 19,59 & 1,34 \\
\hline Estat. & $\boldsymbol{\alpha}_{\mathbf{1}}(\boldsymbol{\%})$ & $\boldsymbol{\alpha}_{\mathbf{r}}(\boldsymbol{\%})$ & $\boldsymbol{\alpha}_{\mathbf{t}}(\boldsymbol{\%})$ & $\boldsymbol{\alpha}_{\mathbf{v}}(\boldsymbol{\%})$ & $\mathbf{C A}$ & $\boldsymbol{\alpha}_{\mathbf{v}} / \mathbf{P S F}$ & $\boldsymbol{\beta}_{\mathbf{v}} / \mathbf{P S F}$ & \\
\hline $\bar{x}$ & 1,05 & 6,28 & 11,91 & 20,20 & 1,81 & 0,91 & 0,75 & \\
Cv $(\%)$ & 22,67 & 16,01 & 12,00 & 12,27 & 7,32 & 12,54 & 10,78 & \\
Mín. & 0,51 & 4,95 & 9,71 & 16,10 & 1,47 & 0,75 & 0,64 & \\
Máx & 1,36 & 8,60 & 14,82 & 24,36 & 2,04 & 1,13 & 0,91 & \\
\hline
\end{tabular}

Tabela 7: Resultados para Canafístula (C30).

\begin{tabular}{|c|c|c|c|c|c|c|c|c|}
\hline Estat. & $\begin{array}{c}\rho_{12} \\
\left(\mathrm{~g} / \mathrm{cm}^{3}\right) \\
\end{array}$ & $\begin{array}{c}\rho_{\mathrm{s}} \\
\left(\mathrm{g} / \mathrm{cm}^{3}\right) \\
\end{array}$ & $\begin{array}{c}\rho_{\text {bas }} \\
\left(\mathrm{g} / \mathbf{c m}^{3}\right) \\
\end{array}$ & $\begin{array}{l}\text { PSF } \\
(\%)\end{array}$ & $\beta_{\mathbf{r}}(\%)$ & $\boldsymbol{\beta}_{\mathbf{t}}(\%)$ & $\beta_{\mathrm{v}}(\%)$ & $\beta_{1}(\%)$ \\
\hline $\bar{x}$ & 0,86 & 0,84 & 0,71 & 21,75 & 4,42 & 7,71 & 12,33 & 0,62 \\
\hline$C v(\%)$ & 8,80 & 9,56 & 5,15 & 7,66 & 16,70 & 15,61 & 15,07 & 23,32 \\
\hline Min. & 0,74 & 0,70 & 0,65 & 19,70 & 3,47 & 5,92 & 9,62 & 0,37 \\
\hline Máx & 0,95 & 0,93 & 0,78 & 25,62 & 6,08 & 9,47 & 15,61 & 0,86 \\
\hline Estat. & $\alpha_{1}(\%)$ & $\alpha_{\mathbf{r}}(\%)$ & $\alpha_{t}(\%)$ & $\alpha_{\mathrm{v}}(\%)$ & CA & $\alpha_{\mathrm{v}} / \mathrm{PSF}$ & $\beta_{\mathrm{v}} / \mathrm{PSF}$ & \\
\hline $\bar{x}$ & 0,62 & 4,63 & 8,37 & 14,11 & 1,75 & 0,65 & 0,57 & \\
\hline$C v(\%)$ & 23,46 & 17,57 & 16,92 & 17,27 & 8,22 & 18,28 & 16,26 & \\
\hline Mín. & 0,37 & 3,59 & 6,29 & 10,64 & 1,55 & 0,49 & 0,44 & \\
\hline Máx & 0,87 & 6,47 & 10,46 & 18,50 & 1,93 & 0,87 & 0,74 & \\
\hline
\end{tabular}

Tabela 8: Resultados para Catanudo (C30).

\begin{tabular}{|c|c|c|c|c|c|c|c|c|}
\hline Estat. & $\begin{array}{c}\rho_{12} \\
\left(\mathrm{~g} / \mathrm{cm}^{3}\right) \\
\end{array}$ & $\begin{array}{c}\rho_{\mathrm{s}} \\
\left(\mathrm{g} / \mathrm{cm}^{3}\right) \\
\end{array}$ & $\begin{array}{c}\rho_{\text {bas }} \\
\left(\mathrm{g} / \mathrm{cm}^{3}\right) \\
\end{array}$ & $\begin{array}{l}\text { PSF } \\
(\%)\end{array}$ & $\beta_{\mathbf{r}}(\%)$ & $\beta_{\mathrm{t}}(\%)$ & $\beta_{\mathrm{v}}(\%)$ & $\beta_{1}(\%)$ \\
\hline $\bar{x}$ & 0,80 & 0,78 & 0,63 & 23,32 & 5,41 & 8,37 & 14,19 & 1,00 \\
\hline$C v(\%)$ & 4,73 & 5,53 & 4,06 & 6,78 & 12,42 & 10,70 & 8,62 & 11,18 \\
\hline Mín. & 0,74 & 0,70 & 0,59 & 21,10 & 4,01 & 7,06 & 11,64 & 0,83 \\
\hline Máx & 0,87 & 0,86 & 0,69 & 25,87 & 6,35 & 9,61 & 15,97 & 1,20 \\
\hline Estat. & $\alpha_{1}(\%)$ & $\alpha_{\mathbf{r}}(\%)$ & $\alpha_{t}(\%)$ & $\alpha_{\mathrm{v}}(\%)$ & CA & $\alpha_{\mathrm{v}} /$ PSF & $\beta_{\mathrm{v}} / \mathrm{PSF}$ & \\
\hline $\bar{x}$ & 1,01 & 5,72 & 9,14 & 16,55 & 1,56 & 0,71 & 0,61 & \\
\hline$C v(\%)$ & 11,30 & 13,09 & 11,69 & 10,00 & 13,18 & 12,52 & 11,32 & \\
\hline Mín. & 0,84 & 4,18 & 7,60 & 13,17 & 1,13 & 0,60 & 0,53 & \\
\hline Máx & 1,22 & 6,78 & 10,63 & 19,01 & 1,87 & 0,85 & 0,72 & \\
\hline
\end{tabular}


Tabela 9: Resultados para Casca Grossa (C30).

\begin{tabular}{|c|c|c|c|c|c|c|c|c|}
\hline Estat. & $\begin{array}{c}\rho_{12} \\
\left(\mathrm{~g} / \mathrm{cm}^{3}\right)\end{array}$ & $\begin{array}{c}\rho_{\mathrm{s}} \\
\left(\mathrm{g} / \mathrm{cm}^{3}\right)\end{array}$ & $\begin{array}{c}\rho_{\text {bas }} \\
\left(\mathrm{g} / \mathbf{c m}^{3}\right)\end{array}$ & $\begin{array}{l}\text { PSF } \\
(\%)\end{array}$ & $\beta_{\mathrm{r}}(\%)$ & $\beta_{t}(\%)$ & $\beta_{\mathrm{v}}(\%)$ & $\beta_{1}(\%)$ \\
\hline$\overline{\bar{x}}$ & 1,08 & 1,07 & 0,62 & 17,67 & 6,08 & 11,51 & 17,87 & 1,19 \\
\hline$C v(\%)$ & 5,33 & 5,72 & 4,19 & 8,09 & 17,88 & 14,17 & 11,99 & 19,95 \\
\hline Mín. & 0,97 & 0,95 & 0,58 & 15,90 & 4,71 & 8,09 & 14,62 & 0,84 \\
\hline Máx & 1,15 & 1,15 & 0,67 & 21,02 & 7,86 & 13,97 & 20,84 & 1,65 \\
\hline Estat. & $\alpha_{1}(\%)$ & $\alpha_{\mathrm{r}}(\%)$ & $\alpha_{\mathrm{t}}(\%)$ & $\alpha_{\mathrm{v}}(\%)$ & $\mathbf{C A}$ & $\alpha_{v} /$ PSF & $\beta_{\mathrm{v}} / \mathrm{PSF}$ & \\
\hline$\overline{\bar{x}}$ & 1,21 & 6,49 & 13,04 & 21,84 & 1,93 & 1,24 & 1,02 & \\
\hline$C v(\%)$ & 20,20 & 19,07 & 15,80 & 14,47 & 19,06 & 17,38 & 15,19 & \\
\hline Mín. & 0,85 & 4,94 & 8,80 & 17,12 & 1,29 & 0,97 & 0,82 & \\
\hline Máx & 1,67 & 8,53 & 16,24 & 26,33 & 2,45 & 1,51 & 1,22 & \\
\hline
\end{tabular}

Tabela 10: Resultados para Angelim araroba (C40).

\begin{tabular}{|c|c|c|c|c|c|c|c|c|}
\hline Estat. & $\begin{array}{c}\rho_{12} \\
\left(\mathbf{g} / \mathbf{c m}^{3}\right)\end{array}$ & $\begin{array}{c}\rho_{\mathrm{s}} \\
\left(\mathrm{g} / \mathbf{c m}^{3}\right)\end{array}$ & $\begin{array}{c}\rho_{\text {bas }} \\
\left(\mathrm{g} / \mathbf{c m}^{3}\right)\end{array}$ & $\begin{array}{l}\text { PSF } \\
(\%)\end{array}$ & $\beta_{\mathrm{r}}(\%)$ & $\beta_{t}(\%)$ & $\beta_{\mathrm{v}}(\%)$ & $\beta_{1}(\%)$ \\
\hline $\bar{x}$ & 0,69 & 0,67 & 0,54 & 19,96 & 3,96 & 6,10 & 10,30 & 0,55 \\
\hline$C v(\%)$ & 9,62 & 10,40 & 7,97 & 12,47 & 20,76 & 16,72 & 17,90 & 38,90 \\
\hline Mín. & 0,60 & 0,56 & 0,49 & 17,30 & 3,03 & 4,88 & 8,15 & 0,30 \\
\hline Máx & 0,81 & 0,79 & 0,64 & 24,71 & 5,66 & 8,16 & 14,23 & 1,01 \\
\hline Estat. & $\alpha_{1}(\%)$ & $\alpha_{\mathrm{r}}(\%)$ & $\alpha_{t}(\%)$ & $\alpha_{\mathrm{v}}(\%)$ & CA & $\alpha_{v} /$ PSF & $\beta_{\mathrm{v}} / \mathrm{PSF}$ & \\
\hline $\bar{x}$ & 0,55 & 4,12 & 6,51 & 11,53 & 1,56 & 0,58 & 0,52 & \\
\hline$C v(\%)$ & 39,16 & 21,75 & 17,98 & 20,36 & 6,49 & 21,29 & 19,40 & \\
\hline Mín. & 0,30 & 3,12 & 5,13 & 8,87 & 1,42 & 0,40 & 0,37 & \\
\hline Máx & 1,02 & 6,00 & 8,89 & 16,59 & 1,77 & 0,84 & 0,72 & \\
\hline
\end{tabular}

Tabela 11: Resultados para Cupiúba (C40).

\begin{tabular}{|c|c|c|c|c|c|c|c|c|}
\hline Estat. & $\begin{array}{c}\rho_{12} \\
\left(\mathrm{~g} / \mathrm{cm}^{3}\right) \\
\end{array}$ & $\begin{array}{c}\rho_{\mathrm{s}} \\
\left(\mathrm{g} / \mathrm{cm}^{3}\right) \\
\end{array}$ & $\begin{array}{c}\rho_{\text {bas }} \\
\left(\mathrm{g} / \mathrm{cm}^{3}\right)\end{array}$ & $\begin{array}{l}\text { PSF } \\
(\%)\end{array}$ & $\beta_{\mathrm{r}}(\%)$ & $\boldsymbol{\beta}_{\mathbf{t}}(\%)$ & $\beta_{\mathrm{v}}(\%)$ & $\beta_{1}(\%)$ \\
\hline $\bar{x}$ & 0,84 & 0,82 & 0,54 & 21,75 & 4,12 & 7,37 & 11,55 & 0,41 \\
\hline$C v(\%)$ & 3,89 & 4,97 & 23,74 & 16,66 & 14,37 & 13,26 & 9,23 & 19,35 \\
\hline Mín. & 0,78 & 0,74 & 0,41 & 15,94 & 3,26 & 6,19 & 10,15 & 0,31 \\
\hline Máx & 0,88 & 0,87 & 0,75 & 27,51 & 5,12 & 9,92 & 13,90 & 0,58 \\
\hline Estat. & $\alpha_{1}(\%)$ & $\alpha_{\mathrm{r}}(\%)$ & $\alpha_{\mathrm{t}}(\%)$ & $\alpha_{\mathrm{v}}(\%)$ & CA & $\alpha_{v} /$ PSF & $\beta_{v} /$ PSF & \\
\hline $\bar{x}$ & 0,41 & 4,30 & 7,97 & 13,08 & 1,83 & 0,62 & 0,55 & \\
\hline$C v(\%)$ & 19,44 & 15,00 & 14,51 & 10,52 & 19,87 & 23,80 & 22,76 & \\
\hline Mín. & 0,31 & 3,37 & 6,60 & 11,30 & 1,27 & 0,46 & 0,41 & \\
\hline Máx & 0,59 & 5,40 & 11,01 & 16,15 & 2,52 & 0,87 & 0,75 & \\
\hline
\end{tabular}


Tabela 12: Resultados para Angelim amargoso (C40).

\begin{tabular}{|c|c|c|c|c|c|c|c|c|}
\hline Estat. & $\begin{array}{c}\rho_{12} \\
\left(\mathrm{~g} / \mathrm{cm}^{3}\right)\end{array}$ & $\begin{array}{c}\rho_{\mathrm{s}} \\
\left(\mathrm{g} / \mathrm{cm}^{3}\right)\end{array}$ & $\begin{array}{c}\rho_{\text {bas }} \\
\left(\mathrm{g} / \mathrm{cm}^{3}\right)\end{array}$ & $\begin{array}{l}\text { PSF } \\
(\%)\end{array}$ & $\beta_{\mathrm{r}}(\%)$ & $\beta_{t}(\%)$ & $\beta_{\mathrm{v}}(\%)$ & $\beta_{1}(\%)$ \\
\hline$\overline{\bar{x}}$ & 0,77 & 0,75 & 0,62 & 17,87 & 4,51 & 8,48 & 13,30 & 0,82 \\
\hline$C v(\%)$ & 4,72 & 5,84 & 4,81 & 5,60 & 28,79 & 20,86 & 22,17 & 32,73 \\
\hline Mín. & 0,72 & 0,69 & 0,57 & 16,31 & 1,97 & 5,92 & 8,35 & 0,44 \\
\hline Máx & 0,83 & 0,83 & 0,66 & 19,38 & 6,45 & 11,01 & 17,79 & 1,34 \\
\hline Estat. & $\alpha_{1}(\%)$ & $\alpha_{\mathrm{r}}(\%)$ & $\alpha_{t}(\%)$ & $\alpha_{\mathrm{v}}(\%)$ & CA & $\boldsymbol{\alpha}_{v} /$ PSF & $\beta_{v} /$ PSF & \\
\hline $\bar{x}$ & 0,83 & 4,74 & 9,30 & 15,46 & 1,96 & 0,87 & 0,75 & \\
\hline$C v(\%)$ & 33,01 & 29,99 & 22,67 & 25,35 & 20,97 & 24,85 & 21,88 & \\
\hline Mín. & 0,44 & 2,01 & 6,29 & 9,11 & 1,54 & 0,50 & 0,45 & \\
\hline Máx & 1,36 & 6,89 & 12,37 & 21,64 & 3,01 & 1,20 & 0,99 & \\
\hline
\end{tabular}

Tabela 13: Resultados para Mandioqueira (C50).

\begin{tabular}{ccccccccc}
\hline Estat. & $\begin{array}{c}\boldsymbol{\rho}_{\mathbf{1 2}} \\
\left(\mathbf{g} / \mathbf{c m}^{\mathbf{3}}\right)\end{array}$ & $\begin{array}{c}\boldsymbol{\rho}_{\mathbf{s}} \\
\left(\mathbf{g} / \mathbf{c m}^{\mathbf{3}}\right)\end{array}$ & $\begin{array}{c}\boldsymbol{\rho}_{\text {bas }} \\
\left(\mathbf{g} / \mathbf{c m}^{\mathbf{3}}\right)\end{array}$ & $\begin{array}{c}\mathbf{P S F} \\
(\boldsymbol{\%})\end{array}$ & $\boldsymbol{\beta}_{\mathbf{r}}(\boldsymbol{\%})$ & $\boldsymbol{\beta}_{\mathbf{t}}(\boldsymbol{\%})$ & $\boldsymbol{\beta}_{\mathbf{v}}(\boldsymbol{\%})$ & $\boldsymbol{\beta}_{\mathbf{l}}(\boldsymbol{\%})$ \\
\hline $\bar{x}$ & 0,86 & 0,83 & 0,67 & 23,29 & 4,63 & 9,23 & 14,02 & 0,68 \\
Cv $(\%)$ & 2,97 & 2,67 & 2,78 & 21,13 & 10,01 & 10,57 & 10,12 & 37,33 \\
Mín. & 0,82 & 0,79 & 0,65 & 18,64 & 3,97 & 7,24 & 11,21 & 0,26 \\
Máx & 0,90 & 0,87 & 0,71 & 36,04 & 5,61 & 10,94 & 16,84 & 1,08 \\
\hline Estat. & $\boldsymbol{\alpha}_{\mathbf{l}}(\boldsymbol{\%})$ & $\boldsymbol{\alpha}_{\mathbf{r}}(\boldsymbol{\%})$ & $\boldsymbol{\alpha}_{\mathbf{t}}(\boldsymbol{\%})$ & $\boldsymbol{\alpha}_{\mathbf{v}}(\boldsymbol{\%})$ & $\mathbf{C A}$ & $\boldsymbol{\alpha}_{\mathbf{v}} / \mathbf{P S F}$ & $\boldsymbol{\beta}_{\mathbf{v}} / \mathbf{P S F}$ & \\
\cline { 1 - 5 } & 0,69 & 4,86 & 10,18 & 16,33 & 2,00 & 0,73 & 0,63 & \\
Cv $(\%)$ & 37,56 & 10,51 & 11,59 & 11,75 & 8,23 & 24,22 & 23,06 & \\
Mín. & 0,26 & 4,13 & 7,81 & 12,63 & 1,75 & 0,35 & 0,31 & \\
Máx & 1,09 & 5,94 & 12,28 & 20,25 & 2,25 & 0,96 & 0,81 & \\
\hline
\end{tabular}

Tabela 14: Resultados para Castelo (C50).

\begin{tabular}{|c|c|c|c|c|c|c|c|c|}
\hline Estat. & $\begin{array}{c}\rho_{12} \\
\left(\mathrm{~g} / \mathrm{cm}^{3}\right) \\
\end{array}$ & $\begin{array}{c}\rho_{\mathrm{s}} \\
\left(\mathrm{g} / \mathrm{cm}^{3}\right) \\
\end{array}$ & $\begin{array}{c}\begin{array}{c}\rho_{\text {bas }} \\
\left(\mathrm{g} / \mathbf{c m}^{3}\right)\end{array} \\
\end{array}$ & $\begin{array}{l}\text { PSF } \\
(\%)\end{array}$ & $\beta_{\mathbf{r}}(\%)$ & $\boldsymbol{\beta}_{\mathbf{t}}(\%)$ & $\beta_{\mathrm{v}}(\%)$ & $\beta_{1}(\%)$ \\
\hline$\overline{\bar{x}}$ & 0,77 & 0,74 & 0,62 & 23,68 & 4,02 & 6,65 & 11,05 & 0,72 \\
\hline$C v(\%)$ & 7,10 & 7,87 & 5,46 & 12,61 & 14,21 & 9,94 & 9,32 & 13,39 \\
\hline Mín. & 0,69 & 0,66 & 0,56 & 16,03 & 3,17 & 5,72 & 9,62 & 0,59 \\
\hline Máx & 0,88 & 0,86 & 0,68 & 28,53 & 4,87 & 7,74 & 12,97 & 0,88 \\
\hline Estat. & $\alpha_{1}(\%)$ & $\alpha_{\mathbf{r}}(\%)$ & $\alpha_{t}(\%)$ & $\alpha_{\mathrm{v}}(\%)$ & CA & $\alpha_{\mathrm{v}} / \mathrm{PSF}$ & $\beta_{\mathrm{v}} / \mathrm{PSF}$ & \\
\hline $\bar{x}$ & 0,72 & 4,20 & 7,13 & 12,44 & 1,68 & 0,54 & 0,48 & \\
\hline$C v(\%)$ & 13,49 & 14,80 & 10,66 & 10,54 & 14,47 & 21,32 & 20,52 & \\
\hline Mín. & 0,59 & 3,27 & 6,07 & 10,64 & 1,37 & 0,40 & 0,36 & \\
\hline Máx & 0,89 & 5,12 & 8,39 & 14,90 & 2,14 & 0,78 & 0,70 & \\
\hline
\end{tabular}


Tabela 15: Resultados para Tatajuba (Classe C50).

\begin{tabular}{|c|c|c|c|c|c|c|c|c|}
\hline Estat. & $\begin{array}{c}\rho_{12} \\
\left(\mathrm{~g} / \mathrm{cm}^{3}\right)\end{array}$ & $\begin{array}{c}\rho_{\mathrm{s}} \\
\left(\mathrm{g} / \mathrm{cm}^{3}\right)\end{array}$ & $\begin{array}{c}\rho_{\text {bas }} \\
\left(\mathrm{g} / \mathbf{c m}^{3}\right)\end{array}$ & $\begin{array}{l}\text { PSF } \\
(\%)\end{array}$ & $\beta_{\mathrm{r}}(\%)$ & $\beta_{t}(\%)$ & $\beta_{\mathrm{v}}(\%)$ & $\beta_{1}(\%)$ \\
\hline$\overline{\bar{x}}$ & 0,95 & 0,93 & 0,72 & 22,80 & 4,29 & 6,12 & 10,81 & 0,74 \\
\hline$C v(\%)$ & 5,96 & 6,70 & 6,25 & 17,25 & 11,86 & 17,24 & 11,86 & 38,04 \\
\hline Mín. & 0,83 & 0,80 & 0,62 & 17,37 & 3,54 & 5,01 & 9,16 & 0,13 \\
\hline Máx & 1,06 & 1,06 & 0,77 & 27,83 & 5,37 & 8,45 & 12,80 & 1,20 \\
\hline Estat. & $\alpha_{1}(\%)$ & $\alpha_{\mathrm{r}}(\%)$ & $\alpha_{\mathrm{t}}(\%)$ & $\alpha_{\mathrm{v}}(\%)$ & $\mathbf{C A}$ & $\alpha_{v} /$ PSF & $\beta_{\mathrm{v}} / \mathrm{PSF}$ & \\
\hline$\overline{\bar{x}}$ & 0,75 & 4,49 & 6,54 & 12,15 & 1,44 & 0,56 & 0,49 & \\
\hline$C v(\%)$ & 38,25 & 12,43 & 18,53 & 13,36 & 18,48 & 28,02 & 26,72 & \\
\hline Mín. & 0,13 & 3,67 & 5,27 & 10,08 & 1,14 & 0,38 & 0,34 & \\
\hline Máx & 1,22 & 5,67 & 9,23 & 14,68 & 2,14 & 0,84 & 0,73 & \\
\hline
\end{tabular}

Tabela 16: Resultados para Angelim vermelho (C60).

\begin{tabular}{|c|c|c|c|c|c|c|c|c|}
\hline Estat. & $\begin{array}{c}\rho_{12} \\
\left(\mathrm{~g} / \mathrm{cm}^{3}\right) \\
\end{array}$ & $\begin{array}{c}\rho_{\mathrm{s}} \\
\left(\mathrm{g} / \mathrm{cm}^{3}\right)\end{array}$ & $\begin{array}{c}\rho_{\text {bas }} \\
\left(\mathrm{g} / \mathrm{cm}^{3}\right)\end{array}$ & $\begin{array}{l}\text { PSF } \\
(\%)\end{array}$ & $\beta_{\mathbf{r}}(\%)$ & $\beta_{t}(\%)$ & $\beta_{\mathbf{v}}(\%)$ & $\beta_{1}(\%)$ \\
\hline $\bar{x}$ & 1,13 & 1,12 & 0,89 & 25,53 & 5,10 & 8,38 & 13,63 & 0,66 \\
\hline$C v(\%)$ & 9,75 & 9,82 & 5,26 & 8,98 & 11,93 & 7,97 & 6,61 & 28,80 \\
\hline Mín. & 0,95 & 0,95 & 0,81 & 21,30 & 4,40 & 7,44 & 12,34 & 0,19 \\
\hline Máx & 1,25 & 1,24 & 0,97 & 29,84 & 6,54 & 9,68 & 14,98 & 0,88 \\
\hline Estat. & $\alpha_{1}(\%)$ & $\alpha_{\mathbf{r}}(\%)$ & $\alpha_{t}(\%)$ & $\alpha_{\mathrm{v}}(\%)$ & CA & $\boldsymbol{\alpha}_{v} / \mathrm{PSF}$ & $\beta_{\mathrm{v}} / \mathbf{P S F}$ & \\
\hline $\bar{x}$ & 0,67 & 5,37 & 9,15 & 15,79 & 1,66 & 0,63 & 0,54 & \\
\hline$C v(\%)$ & 28,91 & 12,66 & 8,71 & 7,67 & 13,35 & 16,66 & 15,60 & \\
\hline Mín. & 0,19 & 4,60 & 8,04 & 14,08 & 1,25 & 0,49 & 0,43 & \\
\hline Máx & 0,88 & 7,00 & 10,72 & 17,62 & 1,95 & 0,83 & 0,70 & \\
\hline
\end{tabular}

Tabela 17: Resultados para Champanhe (C60).

\begin{tabular}{|c|c|c|c|c|c|c|c|c|}
\hline Estat. & $\begin{array}{c}\rho_{12} \\
\left(\mathrm{~g} / \mathrm{cm}^{3}\right) \\
\end{array}$ & $\begin{array}{c}\rho_{\mathrm{s}} \\
\left(\mathrm{g} / \mathrm{cm}^{3}\right) \\
\end{array}$ & $\begin{array}{c}\rho_{\text {bas }} \\
\left(\mathrm{g} / \mathrm{cm}^{3}\right)\end{array}$ & $\begin{array}{l}\text { PSF } \\
(\%)\end{array}$ & $\beta_{\mathrm{r}}(\%)$ & $\beta_{t}(\%)$ & $\beta_{\mathrm{v}}(\%)$ & $\beta_{1}(\%)$ \\
\hline $\bar{x}$ & 1,09 & 1,08 & 0,91 & 21,16 & 3,95 & 6,37 & 10,70 & 0,70 \\
\hline$C v(\%)$ & 3,08 & 3,28 & 5,08 & 7,04 & 20,85 & 16,91 & 16,30 & 14,16 \\
\hline Mín. & 1,04 & 1,03 & 0,85 & 18,73 & 2,97 & 4,78 & 8,12 & 0,55 \\
\hline Máx & 1,14 & 1,14 & 0,98 & 23,28 & 5,33 & 7,95 & 13,36 & 0,85 \\
\hline Estat. & $\alpha_{1}(\%)$ & $\alpha_{\mathrm{r}}(\%)$ & $\alpha_{\mathrm{t}}(\%)$ & $\alpha_{\mathrm{v}}(\%)$ & CA & $\alpha_{\mathrm{v}} / \mathrm{PSF}$ & $\beta_{v} /$ PSF & \\
\hline $\bar{x}$ & 0,71 & 4,12 & 6,82 & 12,02 & 1,64 & 0,57 & 0,50 & \\
\hline$C v(\%)$ & 14,26 & 21,75 & 18,05 & 18,26 & 13,25 & 15,13 & 13,28 & \\
\hline Mín. & 0,56 & 3,06 & 5,02 & 8,84 & 1,27 & 0,46 & 0,42 & \\
\hline Máx & 0,85 & 5,63 & 8,64 & 15,42 & 1,92 & 0,70 & 0,61 & \\
\hline
\end{tabular}


Tabela 18: Resultados para Itaúba (C60).

\begin{tabular}{|c|c|c|c|c|c|c|c|c|}
\hline Estat. & $\begin{array}{c}\rho_{12} \\
\left(\mathbf{g} / \mathbf{c m}^{3}\right)\end{array}$ & $\begin{array}{c}\rho_{\mathrm{s}} \\
\left(\mathrm{g} / \mathrm{cm}^{3}\right)\end{array}$ & $\begin{array}{c}\rho_{\text {bas }} \\
\left(\mathbf{g} / \mathbf{c m}^{3}\right)\end{array}$ & $\begin{array}{l}\text { PSF } \\
(\%)\end{array}$ & $\beta_{\mathrm{r}}(\%)$ & $\beta_{\mathrm{t}}(\%)$ & $\beta_{\mathrm{v}}(\%)$ & $\beta_{1}(\%)$ \\
\hline$\overline{\bar{x}}$ & 0,91 & 0,90 & 0,78 & 19,62 & 3,04 & 8,13 & 11,53 & 0,68 \\
\hline$C v(\%)$ & 3,62 & 4,19 & 4,07 & 7,37 & 18,15 & 7,23 & 3,55 & 16,75 \\
\hline Mín. & 0,86 & 0,84 & 0,74 & 17,91 & 2,14 & 7,04 & 10,97 & 0,44 \\
\hline Máx & 0,97 & 0,95 & 0,83 & 23,03 & 3,84 & 8,94 & 12,48 & 0,82 \\
\hline Estat. & $\alpha_{1}(\%)$ & $\alpha_{\mathrm{r}}(\%)$ & $\alpha_{t}(\%)$ & $\alpha_{\mathrm{v}}(\%)$ & $\mathbf{C A}$ & $\alpha_{\mathrm{v}} / \mathrm{PSF}$ & $\beta_{\mathrm{v}} / \mathrm{PSF}$ & \\
\hline$\overline{\bar{x}}$ & 0,68 & 3,14 & 8,85 & 13,03 & 2,79 & 0,67 & 0,59 & \\
\hline$C v(\%)$ & 16,85 & 18,67 & 7,84 & 4,03 & 26,17 & 8,79 & 8,50 & \\
\hline Min. & 0,44 & 2,19 & 7,57 & 12,32 & 1,86 & 0,55 & 0,49 & \\
\hline Máx & 0,83 & 3,99 & 9,82 & 14,26 & 4,12 & 0,75 & 0,65 & \\
\hline
\end{tabular}

Os coeficientes de variação das propriedades determinadas alcançaram valores da mesma ordem de grandeza aos admitidos pela ABNT NBR 7190:1997 (18\%).

Como ainda são muito escassas as pesquisas a respeito da caracterização de espécies tropicais amazônicas, com base nos métodos contidos no Anexo B da norma brasileira, a comparação de resultados fica restrita.

Na bibliografia disponível, somente os trabalhos a seguir citados fazem referência a espécies aqui estudadas.

Baldin et al. (2008) obtiveram os seguintes resultados para Angelim amargoso: $\alpha_{\mathrm{v}} /$ PSF: $0,42 \% / \% ; \alpha_{\mathrm{r}}: 4,10 \% ; \alpha_{\mathrm{t}}: 8,00 \% ; \alpha_{\mathrm{v}}: 12,00 \% ; \beta_{\mathrm{r}}: 3,93 \% ; \beta_{\mathrm{t}}: 7,22 \% ; \beta_{\mathrm{v}}: 10,73$ $\% ; \rho_{12}: 0,62 \mathrm{~g} / \mathrm{cm}^{3} ; \rho_{\mathrm{s}}: 0,67 \mathrm{~g} / \mathrm{cm}^{3} ; \rho_{\text {bas }}: 0,55 \mathrm{~g} / \mathrm{cm}^{3}$. Tais resultados são compatíveis com os aqui obtidos.

Lubas et al. (2008) obtiveram os seguintes resultados para a Itaúba: $\alpha_{v} / \mathrm{PSF}: 0,39$ $\% / \% ; \alpha_{\mathrm{r}}: 2,23 \% ; \alpha_{\mathrm{t}}: 6,78 \% ; \alpha_{\mathrm{v}}: 9,65 \% ; \beta_{\mathrm{r}}: 2,18 \% ; \beta_{\mathrm{t}}: 6,42 \% ; \beta_{\mathrm{v}}: 8,80 \% ; \rho_{12}: 0,81$ $\mathrm{g} / \mathrm{cm}^{3} ; \rho_{\mathrm{s}}: 0,75 \mathrm{~g} / \mathrm{cm}^{3} ; \rho_{\text {bas }}: 0,69 \mathrm{~g} / \mathrm{cm}^{3}$. Tais resultados também são compatíveis com os aqui obtidos.

\subsubsection{Diagramas dos Resultados por Classe de Resistência}

As Figuras de 9 a 12 apresentam os gráficos (Boxplot) envolvendo densidades e pontos de saturação $\left(\rho_{12} ; \rho_{\mathrm{s}} ; \rho_{\text {bas }} ;\right.$ PSF $)$, retrações $\left(\beta_{\mathrm{r}} ; \beta_{\mathrm{t}} ; \beta_{\mathrm{v}} ; \beta_{1}\right)$, inchamentos $\left(\alpha_{\mathrm{r}} ; \alpha_{\mathrm{t}} ; \alpha_{\mathrm{v}} ; \alpha_{\mathrm{l}}\right)$ e coeficientes $\left(\mathrm{CA} ; \alpha_{\mathrm{v}} / \mathrm{PSF} ; \beta_{\mathrm{v}} / \mathrm{PSF}\right)$, respectivamente, com as espécies agrupadas nas classes de resistência (36 determinações por classe de resistência e por propriedade). Isto torna possível avaliar a variação das propriedades físicas com as classes de resistência. 


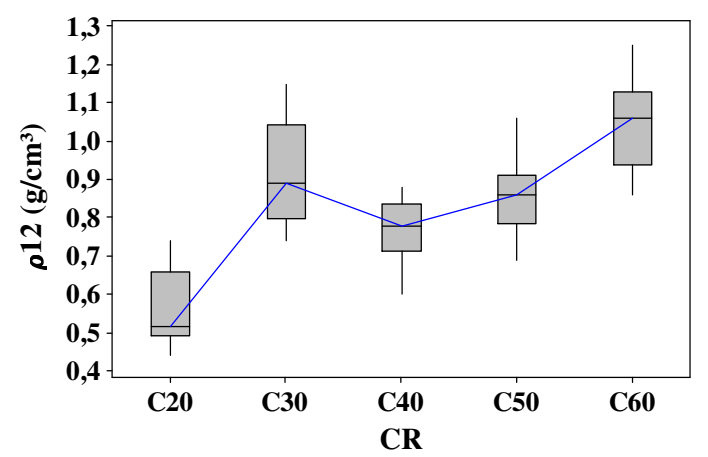

(a)

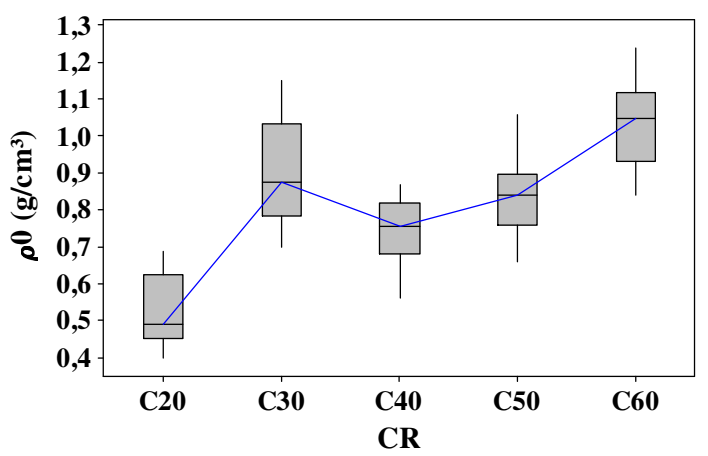

(b)

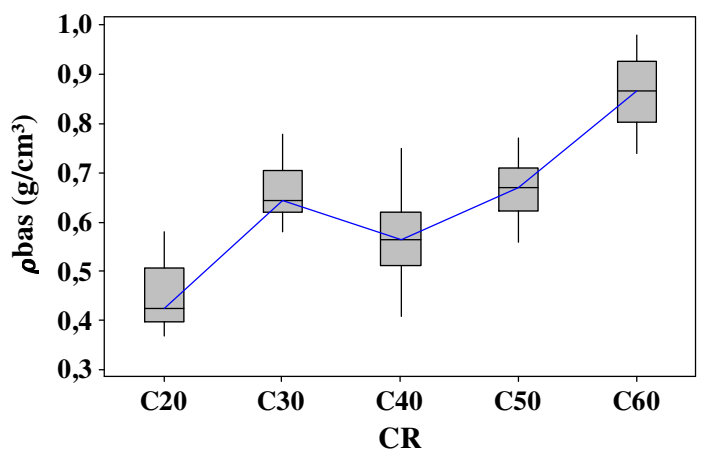

(c)

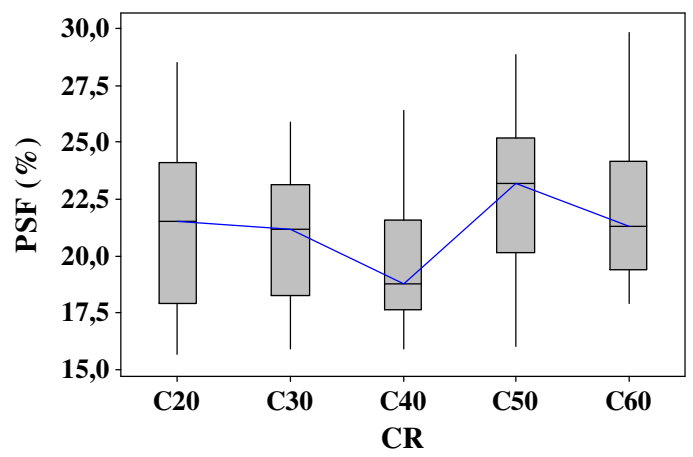

(d)

Figura 9: Boxplot das densidades e pontos de saturação referentes às cinco classes de resistência da norma brasileira: a) $\rho_{12}$, b) $\rho_{\mathrm{s}}$; c) $\rho_{\text {bas }}$ e d) PSF. 


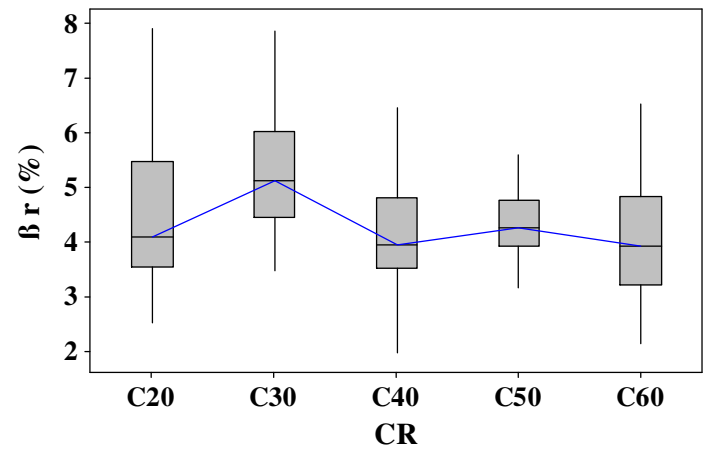

(a)

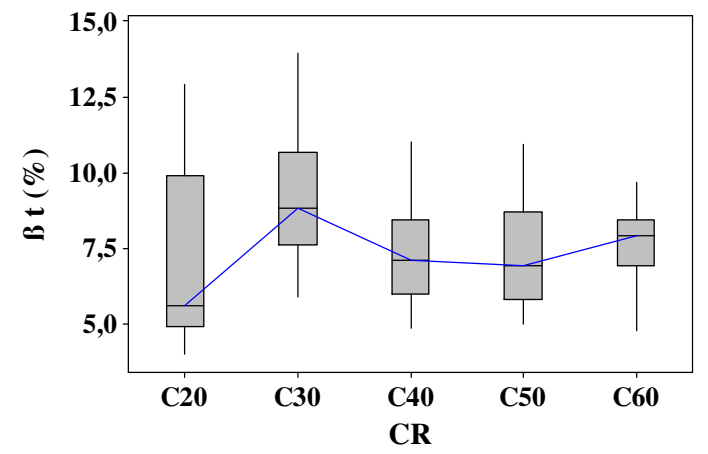

(b)

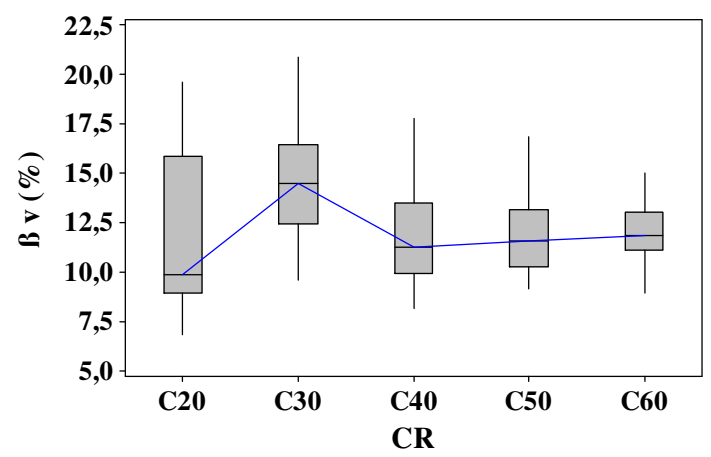

(c)

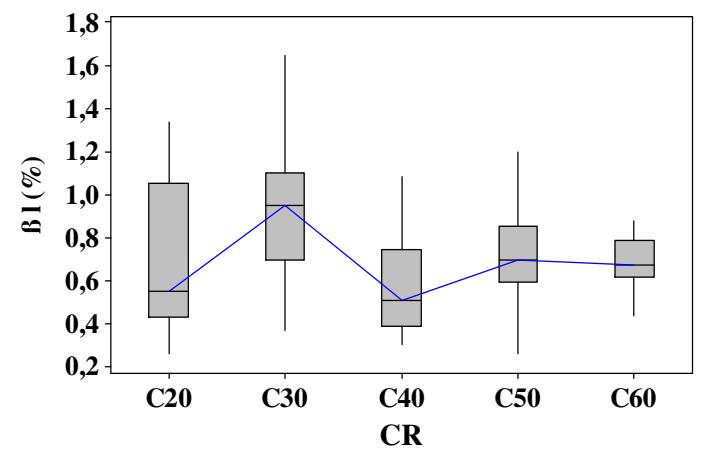

(d)

Figura 10: Boxplot das retrações referentes às cinco classes de resistência da norma brasileira: a) $\beta_{\mathrm{r}}$, b) $\beta_{\mathrm{t}}$; c) $\beta_{\mathrm{v}}$ e d) $\beta_{1}$. 


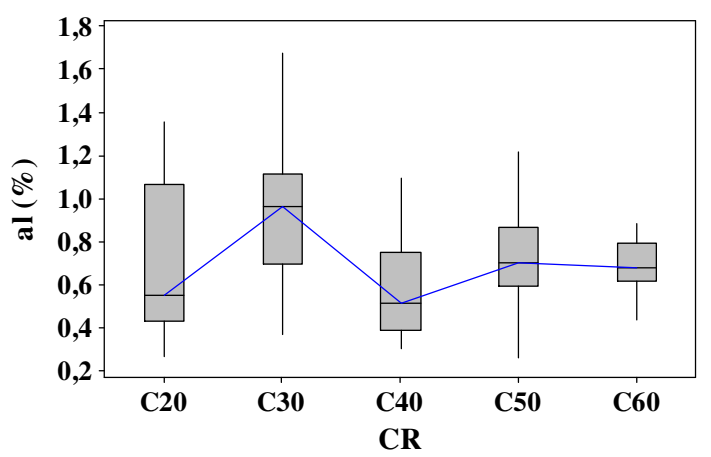

(a)

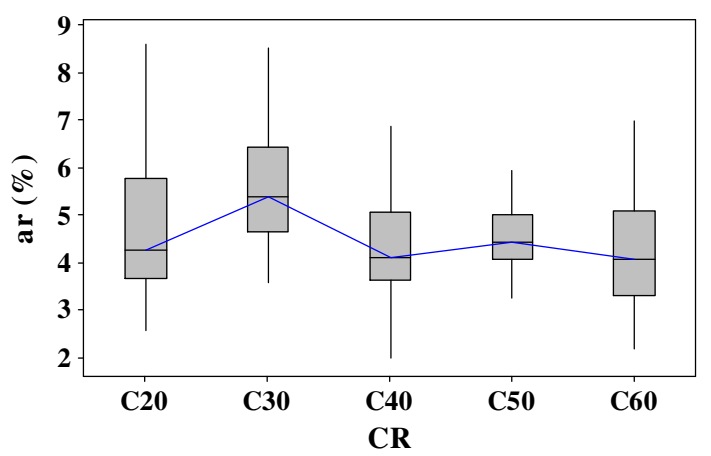

(b)

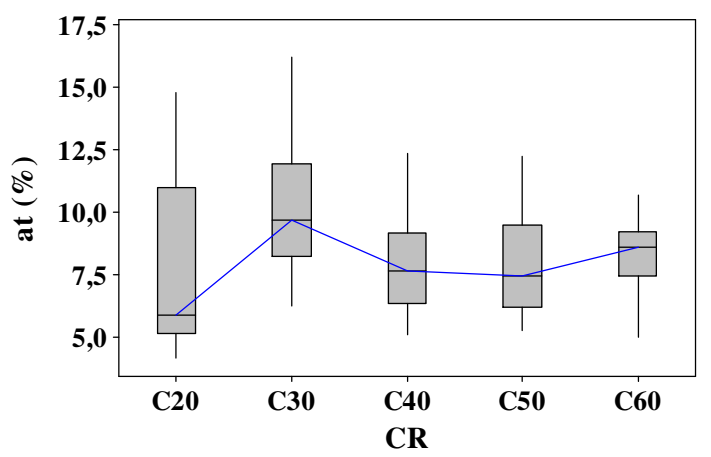

(c)

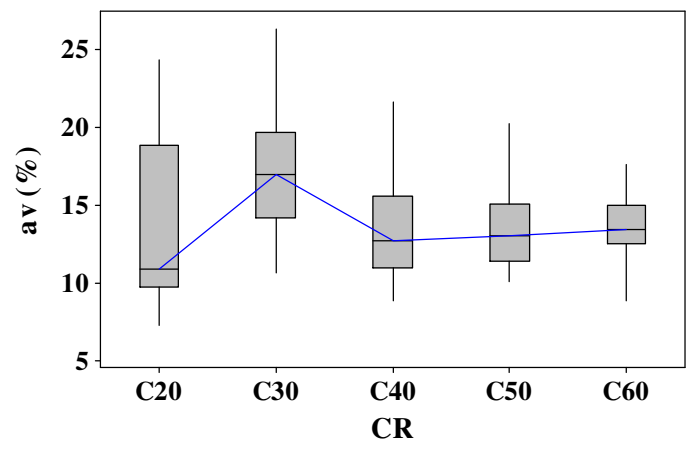

(d)

Figura 11: Boxplot dos valores de inchamento referentes às cinco classes de resistência da norma brasileira: a) $\alpha_{l}$, b) $\alpha_{r}$; c) $\alpha_{t}$ e d) $\alpha_{v}$. 


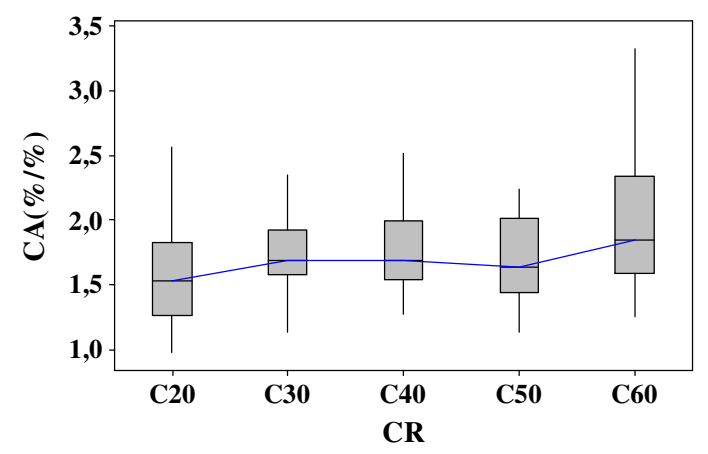

(a)

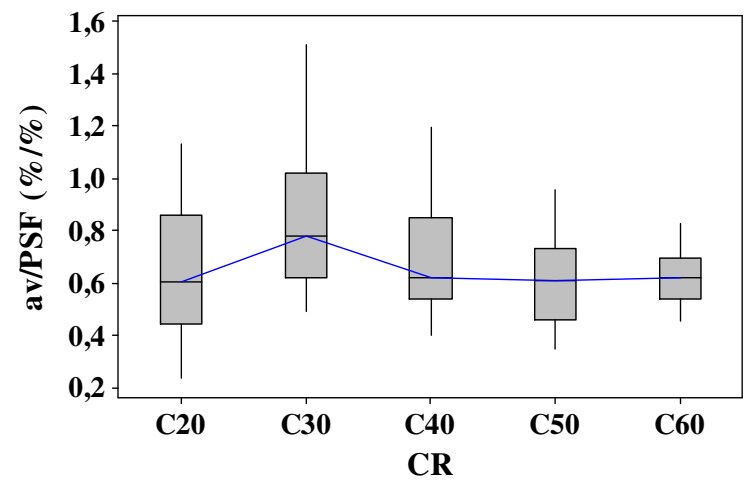

(b)

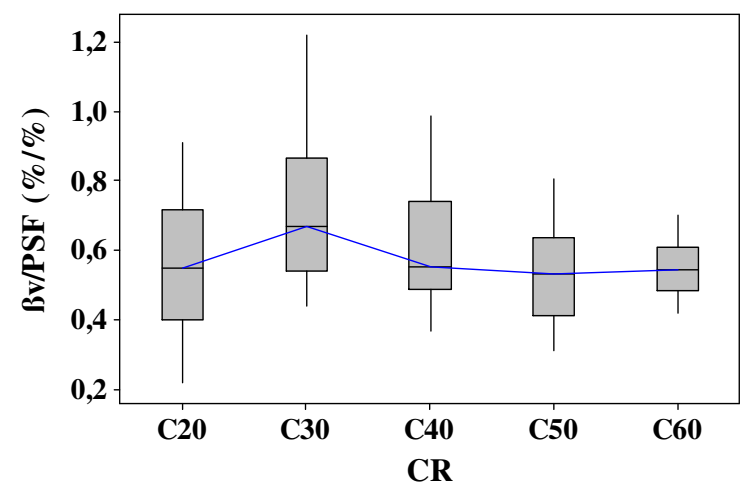

(c)

Figura 12: Boxplot dos coeficientes referentes às cinco classes de resistência da norma brasileira: a) CA, b) $\alpha_{v} / \mathrm{PSF}$ e c) $\beta_{\mathrm{v}} / \mathrm{PSF}$.

Como se sabe, a inclusão das espécies nas classes de resistência preconizadas pela ABNT NBR 7190:1997 se dá pelo valor característico da resistência da madeira à compressão paralela às fibras. Tal parâmetro é influenciado não somente pela densidade da madeira, como apontado por Dias (2000), entre outros, pois a direção da grã também se constitui em fator relevante.

Desse modo, os resultados obtidos para as propriedades físicas estudadas, divididos por classe de resistência, apresentam diferentes padrões de variação, 
evidenciando que a resistência à compressão paralela às fibras (embora considerada suficiente para estimar outras propriedades de resistência) não se constitui no único parâmetro necessário para a adequada categorização de propriedades físicas.

Esta constatação levou à definição que os próximos tópicos da análise dos resultados serão conduzidos sem a divisão dos resultados pelas chamadas classes de resistência da madeira.

Cabe ressaltar também que o Ponto de Saturação das Fibras para as madeiras estudadas apresentou como valor médio $21,60 \%$ de umidade e o coeficiente de variação $16,70 \%$.

\subsection{Resultados dos Testes de Regressão}

As Tabelas de 19 a 25 apresentam os resultados dos modelos de regressão via ANOVA para estimativa das retrações $\left(\beta_{\mathrm{r}} ; \beta_{\mathrm{t}} ; \beta_{\mathrm{l}} ; \beta_{\mathrm{v}}\right)$, coeficiente de anisotropia (CA), coeficiente de inchamento volumétrico $\left(\alpha_{v} / \mathrm{PSF}\right)$ e coeficiente de retratibilidade volumétrica $\left(\beta_{v} / \mathrm{PSF}\right)$ em função da densidade básica $\left(\rho_{\text {bas }}\right)$, densidade aparente $\left(\rho_{12}\right)$ e densidade da madeira seca $\left(\rho_{\mathrm{s}}\right)$ para todas as espécies de madeira (180 determinações por variável). Os modelos considerados significativos pela ANOVA (P-valor $<0,05)$ encontram-se sublinhados nestas tabelas, assim como o coeficiente de determinação $\left(\mathrm{R}^{2}(\mathrm{aj})\right)$ do melhor dentre os ajustes testados por propriedade física em relação aos valores de densidade. 
62

Tabela 19: Relações obtidas dos modelos de regressão entre a retração radial $\left(Y=\beta_{r}\right)$ e as densidades $\rho_{\text {bas }}, \rho_{12}$ e $\rho_{\mathrm{s}}$.

\begin{tabular}{|c|c|c|c|c|}
\hline$X=\rho_{\text {bas }}$ & \multicolumn{2}{|c|}{ Parâmetros } & \multirow[b]{2}{*}{ P-valor } & \multirow[b]{2}{*}{$\mathbf{R}^{2}(\mathbf{a j})$} \\
\hline Modelos & $a$ & $b$ & & \\
\hline$Y=a+b \cdot X$ & 4,3649 & 0,1453 & 0,7909 & $0,04 \%$ \\
\hline$Y=a \cdot e^{b \cdot X}$ & 4,1946 & 0,0476 & 0,7013 & $0,08 \%$ \\
\hline$Y=a+b \cdot \operatorname{Ln}(X)$ & 4,5749 & 0,2473 & 0,4697 & $0,29 \%$ \\
\hline$Y=a \cdot X^{b}$ & 4,4571 & 0,0639 & 0,4096 & $0,38 \%$ \\
\hline$X=\rho_{12}$ & \multicolumn{2}{|c|}{ Parâmetros } & & \\
\hline Modelos & $a$ & $b$ & P-valor & $\mathbf{R}^{2}(\mathbf{a j})$ \\
\hline$Y=a+b \cdot X$ & 3,3595 & 1,3251 & $\underline{0,0018}$ & $5,32 \%$ \\
\hline$Y=a \cdot e^{b \cdot X}$ & 3,3769 & 0,2984 & $\underline{0,0019}$ & $5,26 \%$ \\
\hline$Y=a+b \cdot \operatorname{Ln}(X)$ & 4,6888 & 1,0669 & $\underline{0,0012}$ & $\underline{5,70 \%}$ \\
\hline$Y=a \cdot X^{b}$ & 4,5565 & 0,2415 & $\underline{0,0012}$ & $5,53 \%$ \\
\hline$X=\rho_{s}$ & \multicolumn{2}{|c|}{ Parâmetros } & & \\
\hline Modelos & $a$ & $b$ & P-valor & $\mathbf{R}^{2}(\mathbf{a j})$ \\
\hline$Y=a+b \cdot X$ & 3,4798 & 1,2109 & $\underline{0,0031}$ & $4,81 \%$ \\
\hline$Y=a \cdot e^{b \cdot X}$ & 3,4733 & 0,2713 & $\underline{0,0034}$ & $4,71 \%$ \\
\hline$Y=a+b \cdot \operatorname{Ln}(X)$ & 4,6905 & 0,9437 & $\underline{0,0022}$ & $5,13 \%$ \\
\hline$Y=a \cdot X^{b}$ & 4,5575 & 0,2130 & $\underline{0,0023}$ & $5,10 \%$ \\
\hline
\end{tabular}

Tabela 20: Relações obtidas dos modelos de regressão entre a retração tangencial $\left(Y=\beta_{t}\right) \mathrm{e}$ as densidades $\rho_{\text {bas }}, \rho_{12}$ e $\rho_{\mathrm{s}}$.

\begin{tabular}{|c|c|c|c|c|}
\hline$X=\rho_{\text {bas }}$ & \multicolumn{2}{|c|}{ Parâmetros } & \multirow[b]{2}{*}{ P-valor } & \multirow[b]{2}{*}{$\mathbf{R}^{2}(\mathbf{a j})$} \\
\hline Modelos & $a$ & $b$ & & \\
\hline$Y=a+b \cdot X$ & 2327 & 2,3008 & $\underline{0,0237}$ & $2,84 \%$ \\
\hline$Y=a \cdot e^{b \cdot X}$ & 7516 & 0,4016 & 22 & $12 \%$ \\
\hline$Y=a+b \cdot \operatorname{Ln}(X)$ & 8,6040 & 1,8958 & $\underline{0,0027}$ & $4,94 \%$ \\
\hline$Y=a \cdot X^{b}$ & 6282 & 0,3133 & &, $00 \%$ \\
\hline$X=\rho_{12}$ & \multicolumn{2}{|c|}{ Parâmetros } & & \\
\hline Modelos & $a$ & $b$ & & $\mathbf{R}^{2}(\mathbf{a j})$ \\
\hline$Y=a+b \cdot X$ & 4,3916 & 4,0088 & $\underline{000}$ & $13,87 \%$ \\
\hline$Y=a \cdot e^{b \cdot X}$ & 4,6539 & 0,5661 & $\underline{0,0000}$ & $16,47 \%$ \\
\hline$Y=a+b \cdot \operatorname{Ln}(X)$ & 8,4304 & 3,3389 & $\underline{0,0000}$ & $15,97 \%$ \\
\hline$Y=a \cdot X^{b}$ & 2556 & 0,4802 & $\underline{\underline{00}}$ & $19,58 \%$ \\
\hline$X=\rho_{s}$ & \multicolumn{2}{|c|}{ Parâmetros } & & \\
\hline Modelos & $a$ & $b$ & P- & $\mathbf{R}^{2}(\mathbf{a j})$ \\
\hline$Y=a+b \cdot X$ & 4,6865 & 3,7404 & $\underline{0,0000}$ & $13,15 \%$ \\
\hline$Y=a \cdot e^{b \cdot X}$ & 4,8407 & 0,5302 & $\underline{0,0000}$ & $15,65 \%$ \\
\hline$Y=a+b \cdot \operatorname{Ln}(X)$ & 8,4568 & 3,0392 & $\underline{0,0000}$ & $15,23 \%$ \\
\hline$Y=a \cdot X^{b}$ & 8,2896 & 0,4383 & $\underline{0,0000}$ & $18,78 \%$ \\
\hline
\end{tabular}


Tabela 21: Relações obtidas dos modelos de regressão entre a retração longitudinal $\left(Y=\beta_{l}\right)$ e as densidades $\rho_{\text {bas }}, \rho_{12}$ e $\rho_{\text {s }}$.

\begin{tabular}{|c|c|c|c|c|}
\hline$X=\rho_{\text {bas }}$ & \multicolumn{2}{|c|}{ Parâmetros } & \multirow[b]{2}{*}{ P-valor } & \multirow[b]{2}{*}{$\mathbf{R}^{2}(\mathbf{a j})$} \\
\hline Modelos & $a$ & $b$ & & \\
\hline$Y=a+b \cdot X$ & 0,6429 & 0,1298 & 0,3513 & $0,49 \%$ \\
\hline$Y=a \cdot e^{b \cdot X}$ & 0,5264 & 0,3766 & 0,0685 & $1,85 \%$ \\
\hline$Y=a+b \cdot \operatorname{Ln}(X)$ & 0,7875 & 0,1299 & 0,1344 & $1,25 \%$ \\
\hline$Y=a \cdot X^{b}$ & 0,7725 & 0,3003 & 95 & $3,02 \%$ \\
\hline$X=\rho_{12}$ & \multicolumn{2}{|c|}{ Parâmetros } & & \\
\hline Modelos & $a$ & $b$ & P-valor & $\mathbf{R}^{2}(\mathbf{a j})$ \\
\hline$Y=a+b \cdot X$ & 0,4322 & 0,3545 & $\underline{0,0010}$ & $5,89 \%$ \\
\hline$Y=a \cdot e^{b \cdot X}$ & 0,4187 & 0,5674 & $\underline{0,0004}$ & $6,80 \%$ \\
\hline$Y=a+b \cdot \operatorname{Ln}(X)$ & 0,7870 & 0,2818 & $\underline{0,0008}$ & $6,15 \%$ \\
\hline$Y=a \cdot X^{b}$ & 0,7392 & 0,4524 & $\underline{0,0003}$ & $\underline{7,14 \%}$ \\
\hline$X=\rho_{s}$ & \multicolumn{2}{|c|}{ Parâmetros } & & \\
\hline Modelos & $a$ & $b$ & P-valor & $\mathbf{R}^{2}(\mathbf{a j})$ \\
\hline$Y=a+b \cdot X$ & 0,4551 & 0,3355 & $\underline{0,0012}$ & $5,72 \%$ \\
\hline$Y=a \cdot e^{b \cdot X}$ & 0,4336 & 0,5392 & $\overline{0,0005}$ & $6,65 \%$ \\
\hline$Y=a+b \cdot \operatorname{Ln}(X)$ & 0,7895 & 0,2575 & $\underline{0,0010}$ & $5,91 \%$ \\
\hline$Y=a \cdot X^{b}$ & 0,7424 & 0,4153 & $\underline{0,0004}$ & $6,93 \%$ \\
\hline
\end{tabular}

Tabela 22: Relações obtidas dos modelos de regressão entre a retração volumétrica $\left(Y=\beta_{v}\right)$ e as densidades $\rho_{\text {bas }}, \rho_{12}$ e $\rho_{\mathrm{s}}$.

\begin{tabular}{|c|c|c|c|c|}
\hline$X=\rho_{\text {bas }}$ & \multicolumn{2}{|c|}{ Parâmetros } & \multirow[b]{2}{*}{ P-valor } & \multirow[b]{2}{*}{$\mathbf{R}^{2}(\mathbf{a j})$} \\
\hline Modelos & $a$ & $b$ & & \\
\hline$Y=a+b \cdot X$ & 10,8477 & 2,4872 & 0,0827 & $1,68 \%$ \\
\hline$Y=a \cdot e^{b \cdot X}$ & 10,1993 & 0,2695 & $\underline{0,0163}$ & $3,19 \%$ \\
\hline$Y=a+b \cdot \operatorname{Ln}(X)$ & 13,4698 & 2,1736 & $\underline{0,0147}$ & $3,29 \%$ \\
\hline$Y=a \cdot X^{b}$ & 13,4472 & 0,2192 & $\underline{0,0016}$ & $5,42 \%$ \\
\hline$X=\rho_{12}$ & \multicolumn{2}{|c|}{ Parâmetros } & & \\
\hline Modelos & $a$ & $b$ & P-valor & $\mathbf{R}^{2}(\mathbf{a j})$ \\
\hline$Y=a+b \cdot X$ & 8,0273 & 5,3263 & $\underline{0,0000}$ & $12,46 \%$ \\
\hline$Y=a \cdot e^{b \cdot X}$ & 8,3181 & 0,4545 & $\underline{0,0000}$ & $14,68 \%$ \\
\hline$Y=a+b \cdot \operatorname{Ln}(X)$ & 13,3947 & 4,4011 & $\underline{0,0000}$ & $14,06 \%$ \\
\hline$Y=a \cdot X^{b}$ & 13,1643 & 0,3806 & $\underline{0,0000}$ & $\underline{17,01 \%}$ \\
\hline$X=\rho_{s}$ & \multicolumn{2}{|c|}{ Parâmetros } & & \\
\hline Modelos & $a$ & $\boldsymbol{b}$ & P-valor & $\mathbf{R}^{2}(\mathbf{a j})$ \\
\hline$Y=a+b \cdot X$ & 8,4374 & 4,9579 & $\underline{0,0000}$ & $11,70 \%$ \\
\hline$Y=a \cdot e^{b \cdot X}$ & 8,6100 & 0,4237 & $\underline{0,0000}$ & $13,82 \%$ \\
\hline$Y=a+b \cdot \operatorname{Ln}(X)$ & 13,4237 & 3,9826 & $\underline{0,0000}$ & $13,25 \%$ \\
\hline$Y=a \cdot X^{b}$ & 13,2004 & 0,3453 & $\underline{0,0000}$ & $16,12 \%$ \\
\hline
\end{tabular}


64

Tabela 23: Relações obtidas dos modelos de regressão entre o coeficiente de anisotropia $(Y=C A)$ e as densidades $\rho_{\text {bas }}, \rho_{12}$ e $\rho_{\mathrm{s}}$.

\begin{tabular}{|c|c|c|c|c|}
\hline$X=\rho_{\text {bas }}$ & \multicolumn{2}{|c|}{ Parâmetros } & \multirow[b]{2}{*}{ P-valor } & \multirow[b]{2}{*}{$\mathbf{R}^{2}$ (aj) } \\
\hline Modelos & $a$ & $b$ & & \\
\hline$Y=a+b \cdot X$ & 1,354 & 0,6451 & $\underline{0,0038}$ & $4,61 \%$ \\
\hline$Y=a \cdot e^{b \cdot X}$ & 1,3716 & 0,3533 & $\underline{0,0016}$ & $5,46 \%$ \\
\hline$Y=a+b \cdot \operatorname{Ln}(X)$ & 1,9819 & 0,4521 & $\underline{0,0011}$ & $5,81 \%$ \\
\hline$Y=a \cdot X^{b}$ & 1,9352 & 0,2490 & 0006 & $6,35 \%$ \\
\hline$X=\rho_{12}$ & \multicolumn{2}{|c|}{ Parâmetros } & & \\
\hline Modelos & $a$ & $\boldsymbol{b}$ & P-valor & $\mathbf{R}^{2}(\mathbf{a j})$ \\
\hline$Y=a+b \cdot X$ & 1,3298 & 0,4503 & $\underline{0,0099}$ & $3,68 \%$ \\
\hline$Y=a \cdot e^{b \cdot X}$ & 1,3786 & 0,2672 & 24 & $5,05 \%$ \\
\hline$Y=a+b \cdot \operatorname{Ln}(X)$ & 1,8561 & 0,4059 & $\underline{0,0029}$ & $4,88 \%$ \\
\hline$Y=a \cdot X^{b}$ & 1,8114 & 0,2382 & 0001 & $\underline{6,83 \%}$ \\
\hline$X=\rho_{s}$ & \multicolumn{2}{|c|}{ Parâmetros } & & \\
\hline Modelos & $a$ & $\boldsymbol{b}$ & P-valor & $\mathbf{R}^{2}(\mathbf{a j})$ \\
\hline$Y=a+b \cdot X$ & 1,4103 & 0,4432 & $\underline{0,0085}$ & $3,82 \%$ \\
\hline$Y=a \cdot e^{b \cdot X}$ & 1,3964 & 0,2584 & $\underline{0,0022}$ & $5,11 \%$ \\
\hline$Y=a+b \cdot \operatorname{Ln}(X)$ & 1,8637 & 0,3872 & $\underline{0,0023}$ & $5,10 \%$ \\
\hline$Y=a \cdot X^{b}$ & 1,8185 & 0,2250 & $\underline{0,0003}$ & $6,70 \%$ \\
\hline
\end{tabular}

Tabela 24: Relações obtidas dos modelos de regressão entre o coeficiente de inchamento volumétrico $\left(Y=\alpha_{\mathrm{v}} / \mathrm{PSF}\right)$ e as densidades $\rho_{\mathrm{bas}}, \rho_{12}$ e $\rho_{\mathrm{s}}$.

\begin{tabular}{|c|c|c|c|c|}
\hline$X=\rho_{\text {bas }}$ & \multicolumn{2}{|c|}{ Parâmetros } & \multirow[b]{2}{*}{ P-valor } & \multirow[b]{2}{*}{$\mathbf{R}^{2}(\mathbf{a j})$} \\
\hline Modelos & $a$ & $b$ & & \\
\hline$Y=a+b \cdot X$ & 0,6552 & 0,0471 & 0,6861 & $0,09 \%$ \\
\hline$Y=a \cdot e^{b \cdot X}$ & 0,5765 & 0,1870 & 0,2469 & $0,75 \%$ \\
\hline$Y=a+b \cdot \operatorname{Ln}(X)$ & 0,7236 & 0,0808 & 0,2659 & $0,69 \%$ \\
\hline$Y=a \cdot X^{b}$ & 0,7111 & 0,1906 & 0,0579 & $2,00 \%$ \\
\hline$X=\rho_{12}$ & \multicolumn{2}{|c|}{ Parâmetros } & & \\
\hline Modelos & $a$ & $b$ & P-valor & $\mathbf{R}^{2}(\mathbf{a j})$ \\
\hline$Y=a+b \cdot X$ & 0,4070 & 0,3358 & $\underline{0,0002}$ & $7,56 \%$ \\
\hline$Y=a \cdot e^{b \cdot X}$ & 0,4339 & 0,4873 & $\underline{0,0001}$ & $8,26 \%$ \\
\hline$Y=a+b \cdot \operatorname{Ln}(X)$ & 0,7442 & 0,2718 & $\underline{0,0001}$ & $8,19 \%$ \\
\hline$Y=a \cdot X^{b}$ & 0,7099 & 0,4080 & $\underline{0,0000}$ & $9,57 \%$ \\
\hline$X=\rho_{s}$ & \multicolumn{2}{|c|}{ Parâmetros } & & \\
\hline Modelos & $a$ & $b$ & P-valor & $\mathbf{R}^{2}(\mathbf{a j})$ \\
\hline$Y=a+b \cdot X$ & 0,4293 & 0,3171 & $\underline{0,0002}$ & $7,31 \%$ \\
\hline$Y=a \cdot e^{b \cdot X}$ & 0,4480 & 0,4604 & $\underline{0,0001}$ & $7,99 \%$ \\
\hline$Y=a+b \cdot \operatorname{Ln}(X)$ & 0,7465 & 0,2480 & $\underline{0,0001}$ & $7,85 \%$ \\
\hline$Y=a \cdot X^{b}$ & 0,7125 & 0,3731 & $\underline{0,0000}$ & $9,21 \%$ \\
\hline
\end{tabular}


Tabela 25: Relações obtidas dos modelos de regressão entre o coeficiente de retratibilidade volumétrica $\left(Y=\beta_{\mathrm{v}} / \mathrm{PSF}\right)$ e as densidades $\rho_{\text {bas }}, \rho_{12}$ e $\rho$ s.

\begin{tabular}{|c|c|c|c|c|}
\hline$X=\rho_{\text {bas }}$ & \multicolumn{2}{|c|}{ Parâmetros } & \multirow[b]{2}{*}{ P-valor } & \multirow[b]{2}{*}{$R^{2}(\mathbf{a j})$} \\
\hline Modelos & $a$ & $b$ & & \\
\hline$Y=a+b \cdot X$ & 0,5715 & 0,0348 & 0,7004 & $0,08 \%$ \\
\hline$Y=a \cdot e^{b \cdot X}$ &, 5143 & 0,1554 & 924 & $0,62 \%$ \\
\hline$Y=a+b \cdot \operatorname{Ln}(X)$ & 0,6231 & 0,0620 & 0,2721 & $0,68 \%$ \\
\hline$Y=a \cdot X^{b}$ & 0,6141 & 0,1641 & $0,($ & $1,78 \%$ \\
\hline$X=\rho_{12}$ & \multicolumn{2}{|c|}{ Parâmetros } & & \\
\hline Modelos & $a$ & $b$ & P-valor & $\mathbf{R}^{2}(\mathbf{a j})$ \\
\hline$Y=a+b \cdot X$ & 0,3859 & 0,2508 & $\underline{0,0003}$ & $6,99 \%$ \\
\hline$Y=a \cdot e^{b \cdot X}$ & 0,4001 & 0,4232 & $\underline{0,0002}$ & $7,46 \%$ \\
\hline$Y=a+b \cdot \operatorname{Ln}(X)$ & 0,6380 & 0,2040 & $\underline{0,0002}$ & $7,64 \%$ \\
\hline$Y=a \cdot X^{b}$ & 0,6136 & 0,3552 & & $\underline{8,68 \%}$ \\
\hline$X=\rho_{s}$ & \multicolumn{2}{|c|}{ Parâmetros } & & \\
\hline Modelos & $a$ & $b$ & P-valor & $\mathbf{R}^{2}(\mathbf{a j})$ \\
\hline$Y=a+b \cdot X$ & 0,4021 & 0,2373 & $\underline{0,0004}$ & 6,78 \\
\hline$Y=a \cdot e^{b \cdot X}$ & 0,4111 & 0,4007 & $\underline{0,0003}$ & 7,25 \\
\hline$Y=a+b \cdot \operatorname{Ln}(X)$ & 0,6397 & 0,1865 & $\underline{0,0002}$ & 7,35 \\
\hline$Y=a \cdot X^{b}$ & 0,6157 & 0,3253 & $\underline{0,0001}$ & 8,38 \\
\hline
\end{tabular}

Observa-se que, embora vários P-valores apontem significância dos modelos, todos os coeficientes de determinação $\mathrm{R}^{2}$ (aj) são muito baixos, mostrando que os modelos podem não representar adequadamente os fenômenos estudados.

\subsubsection{Modelos de Regressão com Melhores Ajustes}

Com exceção da densidade básica ( $\rho_{\text {bas }}$ ) na estimativa de $\beta_{\mathrm{r}}, \beta_{\mathrm{l}}, \alpha_{\mathrm{v}} / \mathrm{PSF}$ e $\beta_{\mathrm{v}} / \mathrm{PSF}$, as duas demais densidades forneceram ajustes significativos na estimativa das propriedades investigadas. O modelo geométrico associado aos valores da densidade aparente (12\%) levou aos melhores ajustes, com exceção da estimativa da retração radial, em que as melhores aproximações foram provenientes do modelo logarítmico.

O maior valor do coeficiente de determinação ajustado $\left(R^{2}(a j)=19,58 \%\right)$ foi proveniente do ajuste dos valores da retração tangencial em função da densidade aparente, fazendo-se uso do modelo geométrico.

Ressalta-se que o modelo de regressão ser significativo pela ANOVA implica que existe um comportamento entre as duas variáveis delineado pela curva de ajuste (as 
66

variações de Y são significativamente afetadas pelas variações de X), entretanto, a grande dispersão dos dados afeta diretamente os valores dos coeficientes de determinação.

As Figuras de 13 a 19 apresentam os gráficos contendo os melhores ajustes (Tabelas de 19 a 25) de cada propriedade física em função da combinação das densidades e dos modelos de regressão utilizados, possibilitando visualizar a dispersão dos dados no redor das curvas-ajustes.

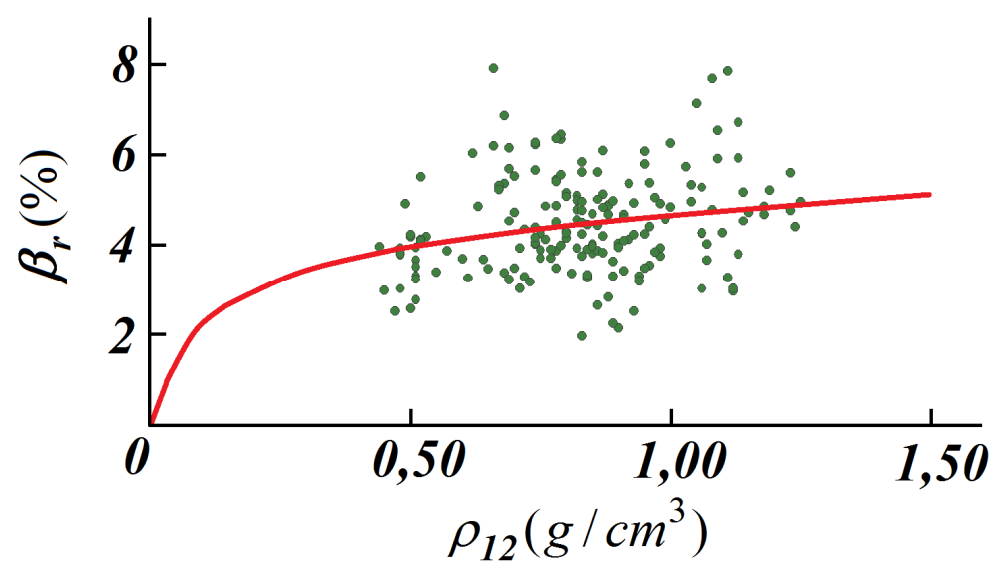

Figura 13: Ajuste do modelo logarítmico entre a retração radial $\left(\beta_{\mathrm{r}}\right)$ e a densidade aparente $\left(\rho_{12}\right)$.

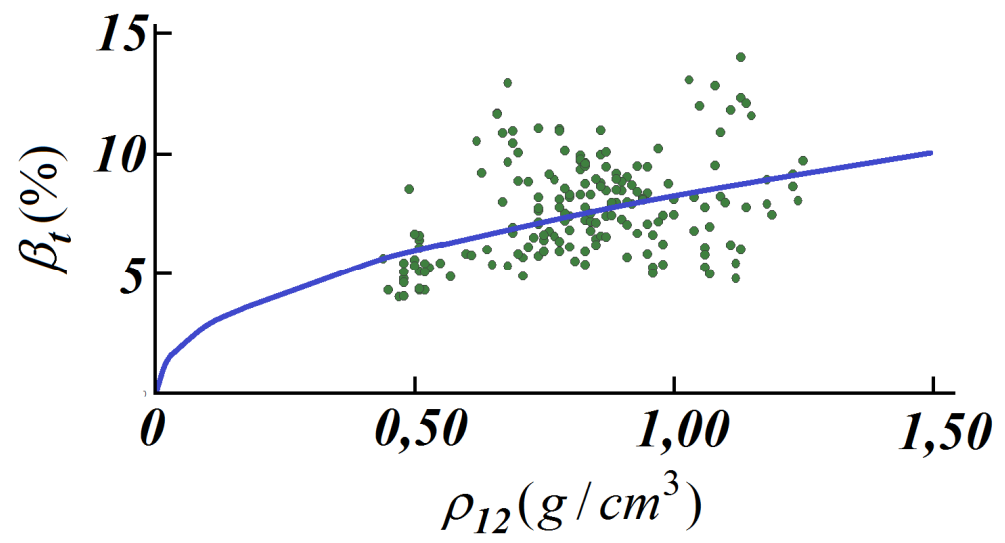

Figura 14: Ajuste do modelo geométrico entre a retração tangencial $\left(\beta_{\mathrm{t}}\right)$ e a densidade aparente $\left(\rho_{12}\right)$. 


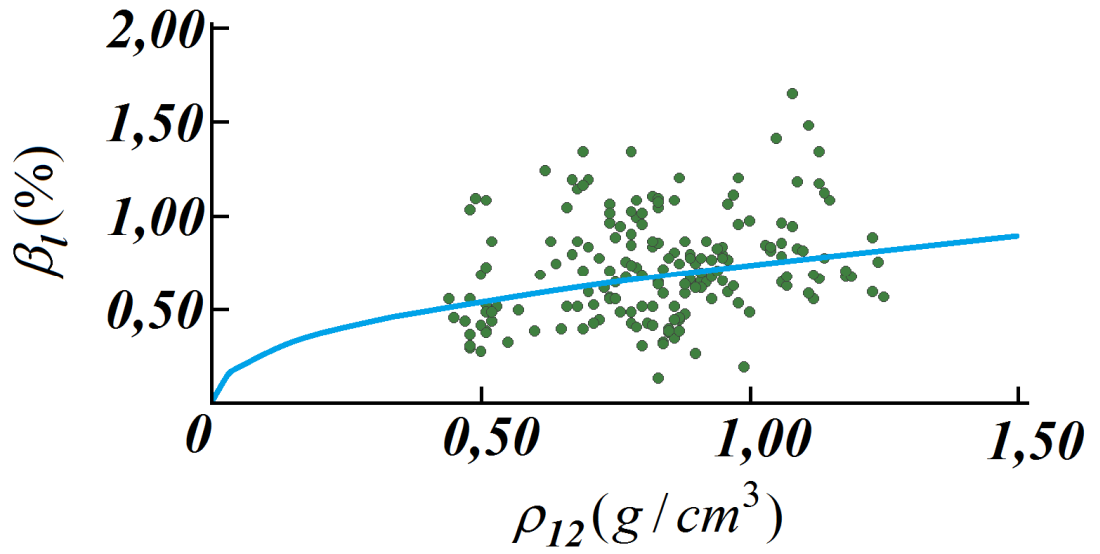

Figura 15: Ajuste do modelo geométrico entre a retração longitudinal $\left(\beta_{1}\right)$ e a densidade aparente $\left(\rho_{12}\right)$.

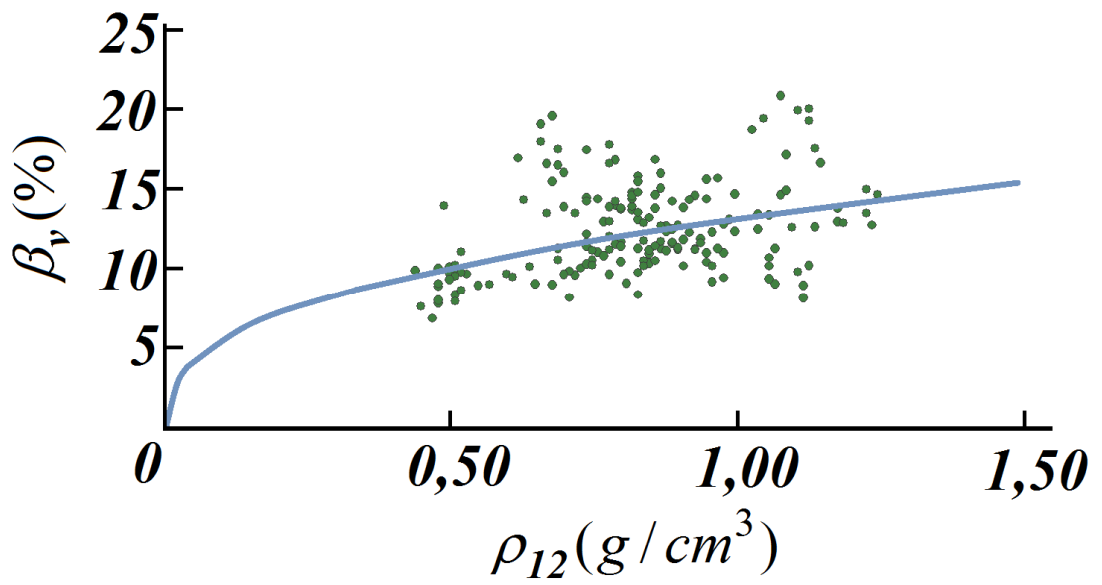

Figura 16: Ajuste do modelo geométrico entre a retração volumétrica $\left(\beta_{\mathrm{v}}\right)$ e a densidade aparente $\left(\rho_{12}\right)$.

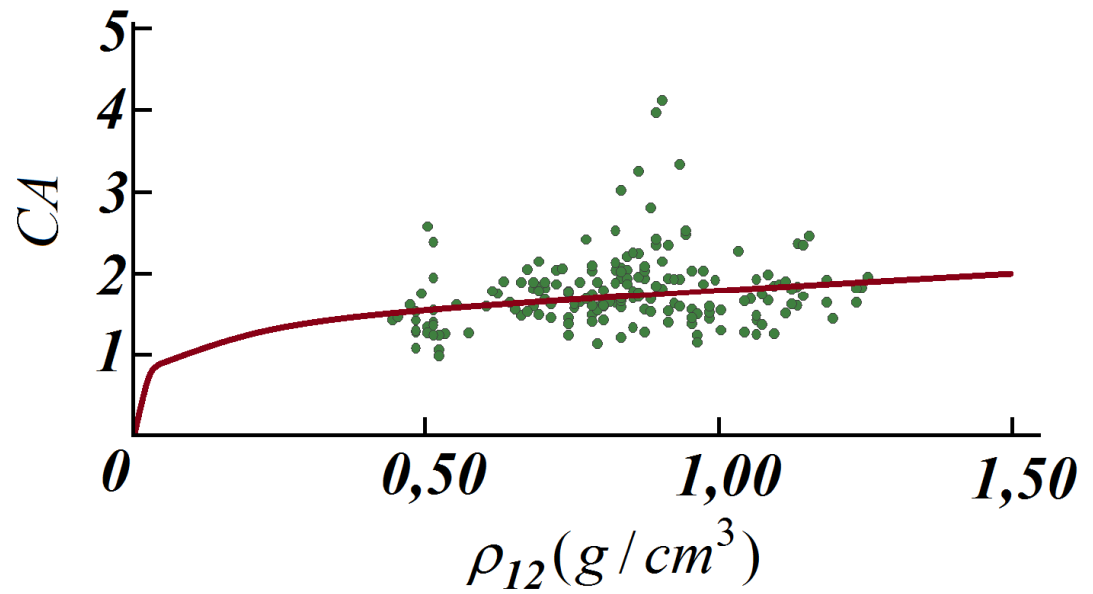

Figura 17: Ajuste do modelo geométrico entre o coeficiente de anisotropia (CA) e a densidade aparente $\left(\rho_{12}\right)$. 
68

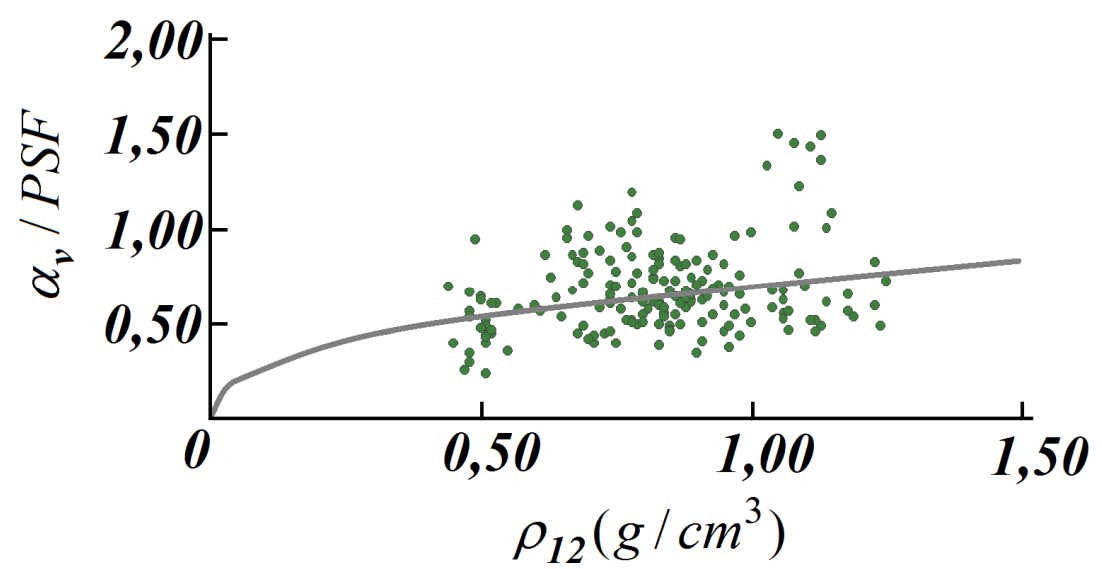

Figura 18: Ajuste do modelo geométrico entre o coeficiente de retratibilidade volumétrica e a densidade aparente $\left(\rho_{12}\right)$.

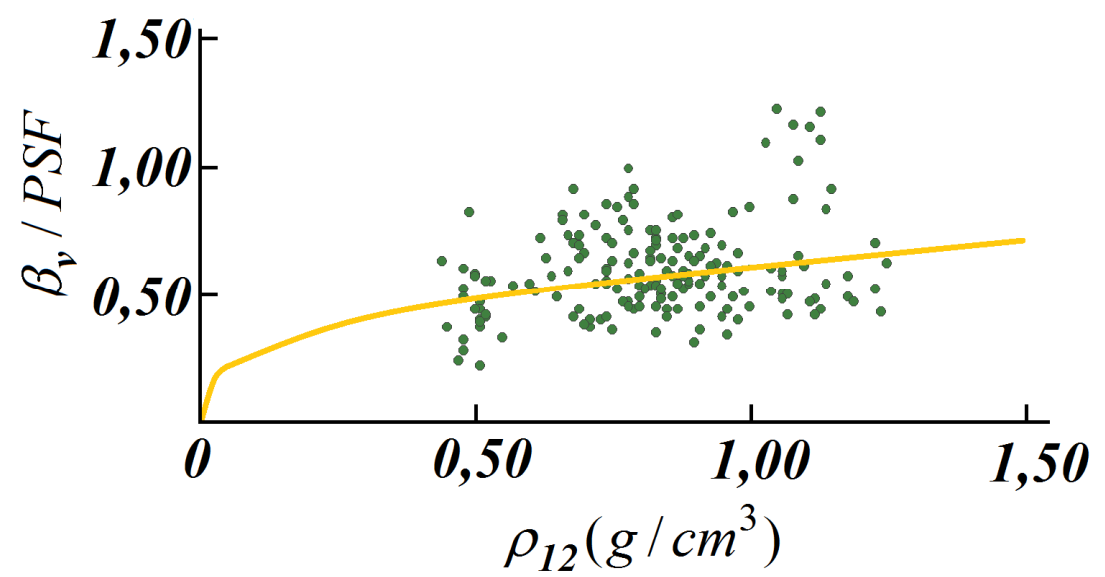

Figura 19: Ajuste do modelo geométrico entre o coeficiente de inchamento volumétrico e a densidade aparente $\left(\rho_{12}\right)$.

Os gráficos apresentados evidenciam as expressivas dispersões dos resultados, mostrando que não é conveniente adotar tais modelos para representar os fenômenos aqui estudados. Não foram encontradas na bibliografia referências que permitam a comparação com os resultados do presente trabalho.

\subsubsection{Correlação entre Densidade básica e Densidade aparente a $12 \%$ de umidade}

$\mathrm{Na}$ Tabela 26 constam os resultados dos modelos de regressão na estimativa da densidade básica por meio dos valores da densidade aparente a $12 \%$ de umidade, considerando-se o grupo com as quinze espécies de madeira investigadas. Estão sublinhados os P-valores $<0,05$ (modelos considerados significativos pela ANOVA). 
Tabela 26: Modelos de regressão para a estimativa da densidade básica em função da densidade aparente.

\begin{tabular}{ccccc}
\hline $\boldsymbol{X}=\boldsymbol{\rho}_{\text {I2 }} ; \boldsymbol{Y}=\boldsymbol{\rho}_{\text {bas }}$ & \multicolumn{2}{c}{ Parâmetros } & & \\
\cline { 1 - 4 } Modelos & $\boldsymbol{a}$ & $\boldsymbol{b}$ & $\mathbf{P}$-valor & $\mathbf{R}^{2}(\mathbf{a j})$ \\
\hline$Y=a+b \cdot X$ & 0,0967 & 0,6570 & $\underline{0,0000}$ & $69,79 \%$ \\
$Y=a \cdot e^{b \cdot X}$ & 0,2594 & 1,0581 & $\underline{0,0000}$ & $70,57 \%$ \\
$Y=a+b \cdot \operatorname{Ln}(X)$ & 0,7517 & 0,5098 & $\underline{0,0000}$ & $69,44 \%$ \\
$Y=a \cdot X^{b}$ & 0,7472 & 0,8366 & $\underline{0,0000}$ & $\underline{72,92 \%}$ \\
\hline
\end{tabular}

Nota-se, Tabela 26, que o melhor ajuste na estimativa dos valores da densidade básica por meio da densidade aparente foi referente ao uso do modelo de regressão geométrico, por apresentar o maior dentre os valores do coeficiente de determinação ajustado (72,92\%). A Figura 12 apresenta o ajuste por meio do modelo de regressão geométrico.

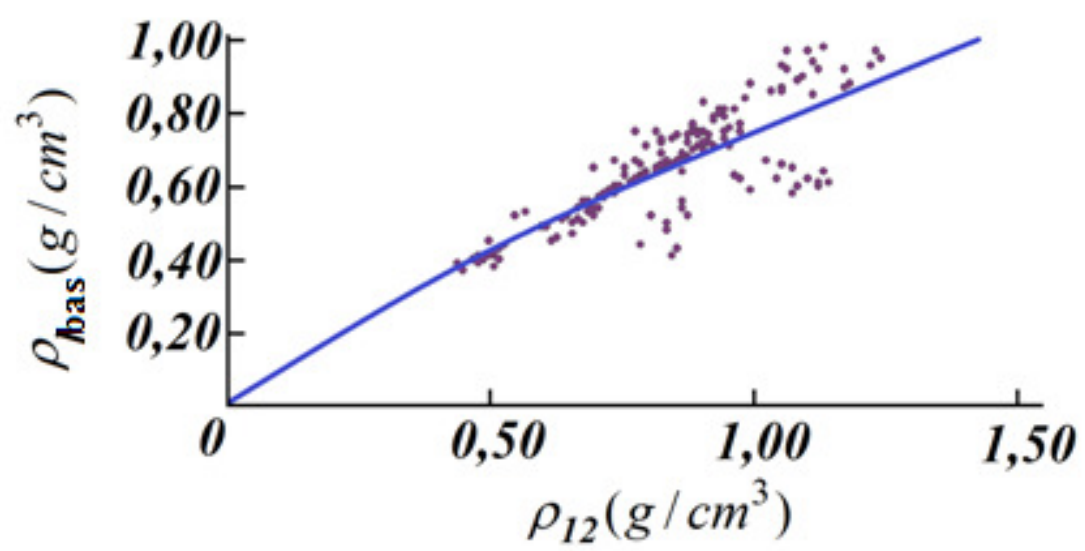

Figura 20: Modelo de regressão geométrico ajustado na estimativa da densidade básica $\left(\rho_{\text {bas }}\right)$ em função da densidade aparente $\left(\rho_{12}\right)$.

A alta correlação observada permite admitir a possibilidade de estimar a densidade básica a partir dos valores da densidade aparente a $12 \%$ de umidade.

\subsection{Resultados dos Testes de Precisão}

\subsubsection{Teste de Precisão da Relação 1}

Os resultados da ANOVA da relação $\beta_{t}=1,65 * \beta_{r}$ são apresentados na Tabela 27 sendo GL os graus de liberdade, SQ a soma dos quadrados, MS a média dos quadrados, F a estatística considerada, $\mathrm{P}$-valor a probabilidade $\mathrm{P}$ e FC o fator forma de cálculo dos valores da retração tangencial (Experimental [Exper]; 1,65* $\beta_{r}$ ). Os P-valores (teste de 
70

normalidade de Anderson Darling e de homogeneidade de variâncias, teste $\mathrm{F}$, dos resíduos) foram iguais a 0,827 (Figura 21a) e 0,632 (Figura 21b), respectivamente, validando o modelo de ANOVA.

Tabela 27: Resultados da ANOVA para validação da relação $\beta_{t}=1,65 * \beta_{r}$.

\begin{tabular}{cccccc}
\hline Fonte & GL & SQ & MS & F & P-valor \\
\hline FC & 1 & 11,19 & 11,19 & 2,97 & 0,086 \\
Erro & 358 & 1349,63 & 3,77 & & \\
Total & 359 & 1360,83 & & & \\
\hline
\end{tabular}

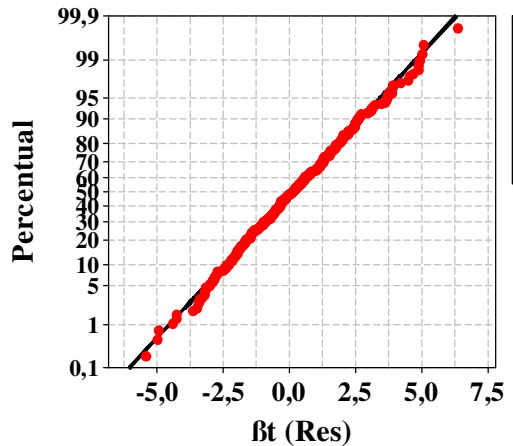

(a)

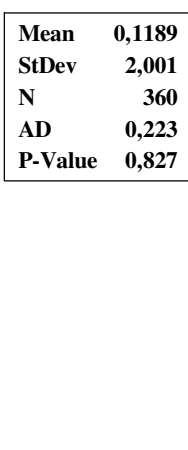

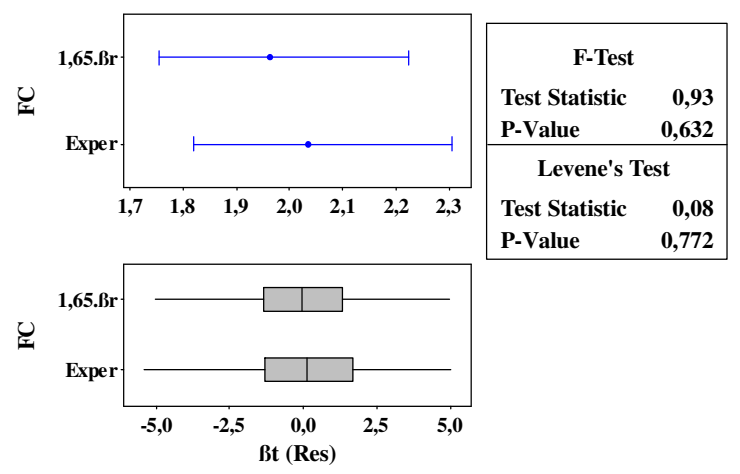

(b)

Figura 21: Resultados dos testes de normalidade (a) e de homogeneidade de variâncias (b) dos resíduos da ANOVA para a relação $\beta_{t}=1,65 * \beta_{r}$.

Como o P-valor da ANOVA (Tabela 27) é superior a 0,05, constata-se que a relação entre $\beta_{\mathrm{t}}$ e $1,65 * \beta_{\mathrm{r}}$ é de equivalência, validando o uso desta equação também sobre os valores das retrações obtidas experimentalmente nesta pesquisa.

\subsubsection{Teste de Precisão da Relação 2}

Os resultados da ANOVA da relação $\alpha_{t} / \alpha_{r}=\beta_{t} / \beta_{r}$ são apresentados na Tabela 28, sendo GL os graus de liberdade, SQ a soma dos quadrados, MS a média dos quadrados, F a estatística F, P-valor a probabilidade P e RR o fator razão das retrações $\left(\alpha_{t} / \alpha_{r} ; \beta_{t} / \beta_{r}\right)$. Os P-valores do teste de normalidade de Anderson Darling e de homogeneidade de variâncias (teste F) dos resíduos foram iguais a 0,742 (Figura 22a) e 0,278 (Figura 22b), respectivamente, validando o modelo de ANOVA. 
Tabela 28: Resultados da ANOVA para validação da relação $\alpha_{t} / \alpha_{r}=\beta_{t} / \beta_{r}$.

\begin{tabular}{cccccc}
\hline Fonte & GL & SQ & MS & F & P-valor \\
\hline$R R$ & 1 & 0,429 & 0,429 & 1,89 & 0,171 \\
Erro & 358 & 81,357 & 0,227 & & \\
Total & 359 & 81,786 & & & \\
\hline
\end{tabular}

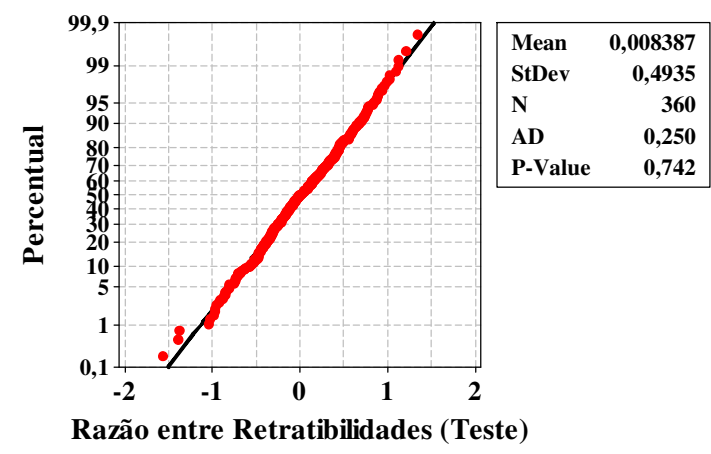

(a)

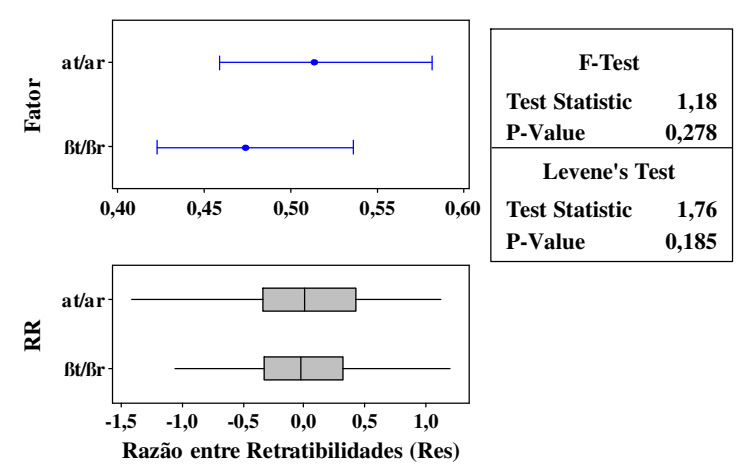

(b)

Figura 22: Resultados dos testes de normalidade (a) e de homogeneidade de variâncias (b) dos resíduos da ANOVA para a relação $\alpha_{t} / \alpha_{\mathrm{r}}=\beta_{t} / \beta_{r}$.

Como o P-valor da ANOVA (Tabela 28) é superior a 0,05, constata-se que a relação entre $\alpha_{t} / \alpha_{r}$ e $\beta_{t} / \beta_{r}$ é de equivalência, validando o uso desta equação também sobre os valores das retrações obtidas experimentalmente nesta pesquisa.

\subsubsection{Teste de Precisão da Relação 3}

Para a ANOVA da relação $\beta_{l}=\beta_{t} / 23$, a distribuição dos resíduos não apresentou normalidade, e a transformada de Johnson não foi capaz de encontrar uma função de transformação.

O emprego da ANOVA de Kruskal-Wallis forneceu P-valor igual a 0,0000, e por ser inferior ao nível de significância, constata-se que as médias dos grupos são estatisticamente diferentes, e que a relação em estudo não apresenta aderência aos conjuntos dos valores das retrações obtidas experimentalmente nesta pesquisa.

O modelo de mínimos quadrados (Figura 23) para esta relação (reta ajustada passando pela origem) forneceu a relação $\beta_{l}=\beta_{t} / 9,84$, com coeficiente de determinação ajustado igual a 47,23\%. O coeficiente ótimo $(\gamma)$, encontrado do ajuste foi igual a 1/9,84 (por simplicidade, sugere-se adotar 1/10), é significativamente diferente do estabelecido pela relação estudada $(1 / 23)$. 


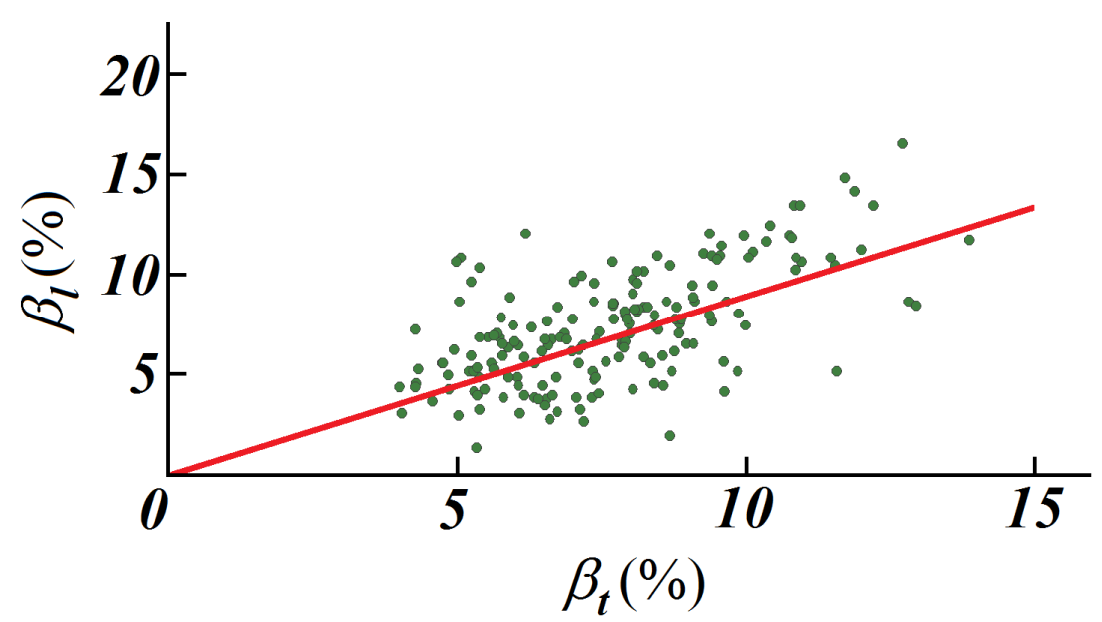

Figura 23: Ajuste do coeficiente ótimo $(\gamma)$ da relação entre as retrações $\beta_{l}=\gamma^{*} \beta_{t}$.

Sendo o coeficiente da relação consagrada 1/23 e o coeficiente ótimo encontrado neste trabalho $1 / 9,84$, e a incidência de variação dimensional na direção longitudinal da madeira está intimamente relacionada com a existência de zonas amorfas no polímero que constitui o material, conclui-se que as dicotiledôneas parecem apresentar maior incidência de zonas amorfas em sua constituição.

\subsubsection{Teste de Precisão da Relação 4}

Os resultados da ANOVA da relação $\beta_{v}=\beta_{t}+\beta_{r}$ são apresentados na Tabela 29, sendo GL os graus de liberdade, SQ a soma dos quadrados, MS a média dos quadrados, $\mathrm{F}$ a estatística $\mathrm{F}$, P-valor a probabilidade $\mathrm{P}$ e $\beta$ o fator retratibilidade $\left(\beta_{v} ; \beta_{t}+\beta_{r}\right)$. Os $\mathrm{P}-$ valores (teste de normalidade de Anderson Darling e de homogeneidade de variâncias, teste F, dos resíduos) foram iguais a 0,495 (Figura 24a) e 0,803 (Figura 24b), respectivamente, validando o modelo de ANOVA. 
Tabela 29: Resultados da ANOVA para validação da relação $\beta_{v}=\beta_{t}+\beta_{r}$.

\begin{tabular}{cccccc}
\hline Fonte & GL & SQ & MS & F & P-valor \\
\hline$\beta$ & 1 & 6,88 & 6,88 & 0,82 & 0,367 \\
Erro & 358 & 3032,81 & 8,44 & & \\
Total & 359 & 3027,69 & & & \\
\hline
\end{tabular}

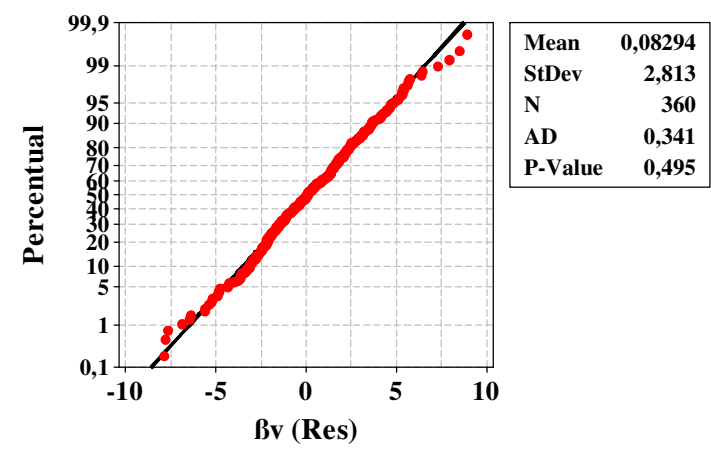

(a)

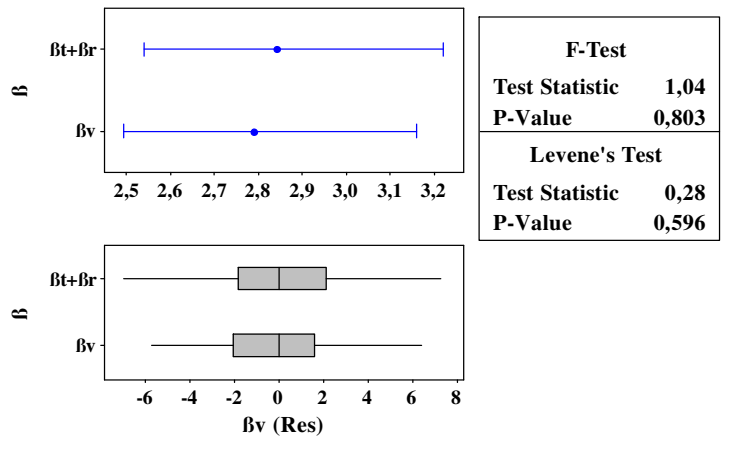

(b)

Figura 24: Resultados dos testes de normalidade (a) e de homogeneidade de variâncias (b) dos resíduos da ANOVA para a relação $\beta_{v}=\beta_{t}+\beta_{r}$.

Como o P-valor da ANOVA (Tabela 29) é superior a 0,05, constata-se que a relação entre $\beta_{v} e \beta_{t}+\beta_{r}$ é de equivalência, validando o uso desta equação também sobre os valores das retratibilidades obtidas experimentalmente nesta pesquisa.

\subsubsection{Teste de Precisão da Relação 5}

Os resultados da ANOVA da relação $\alpha_{v}=\alpha_{t}+\alpha_{r}$ são apresentados na Tabela 30, sendo GL os graus de liberdade, SQ a soma dos quadrados, MS a média dos quadrados, F a estatística F, P-valor a probabilidade $\mathrm{P}$ e $\alpha$ o fator inchamento $\left(\alpha_{v} ; \alpha_{t}+\alpha_{r}\right)$. Os P-valores do teste de normalidade de Anderson Darling e de homogeneidade de variâncias (teste F) dos resíduos foram iguais a 0,569 (Figura 16a) e 0,829 (Figura 16b), respectivamente, validando o modelo de ANOVA.

Tabela 30: Resultados da ANOVA para validação da relação $\alpha_{v}=\alpha_{t}+\alpha_{r}$.

\begin{tabular}{cccccc}
\hline Fonte & GL & SQ & MS & F & P-valor \\
\hline$\alpha$ & 1 & 141,0 & 141,10 & 10,64 & 0,001 \\
Erro & 358 & 4745,5 & 13,30 & & \\
Total & 359 & 4886,6 & & & \\
\hline
\end{tabular}




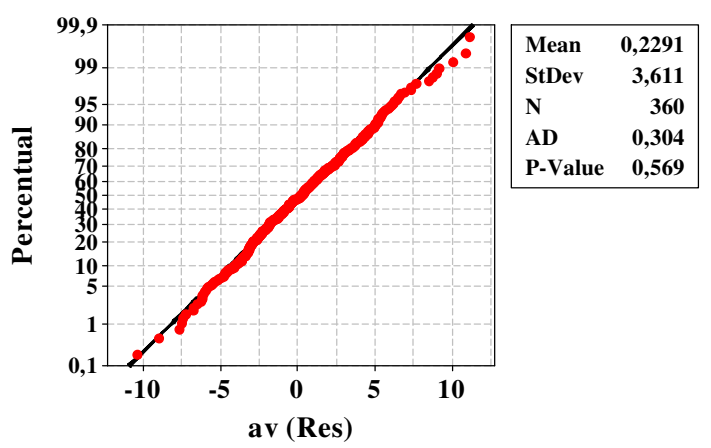

(a)

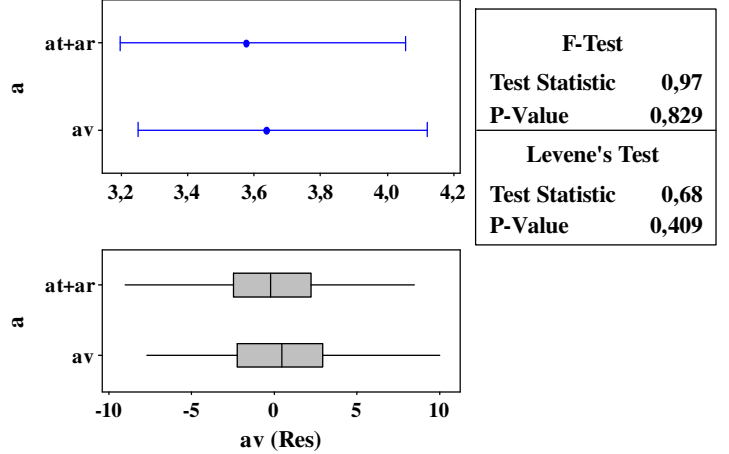

(b)

Figura 25: Resultados dos testes de normalidade (a) e de homogeneidade de variâncias (b) dos resíduos da ANOVA para a relação $\alpha_{v}=\alpha_{t}+\alpha_{r}$.

Como o P-valor da ANOVA (Tabela 30) é inferior a 0,05, constata-se que a relação entre $\alpha_{v}$ e $\alpha_{t}+\alpha_{r}$ não é de equivalência, invalidando o uso desta equação também sobre os valores dos inchamentos obtidos experimentalmente nesta pesquisa.

Esta constatação é distinta da registrada por Kollmann e Côté (1968) e também assumida por Galvão e Jankowsky (1985).

A Tabela 31 apresenta os resultados da ANOVA do modelo linear a duas variáveis independentes na determinação dos valores de inchamentos volumétricos, sendo GL os graus de liberdade, SQ a soma dos quadrados, SQA a soma dos quadrados ajustada, MQA é a média dos quadrados ajustada, F é a estatística de Fisher e P-valor é a probabilidade $\mathrm{P}$.

Tabela 31: Resultados da ANOVA do modelo de regressão multilinear para os valores dos inchamentos.

\begin{tabular}{ccccccc}
\hline Fonte & GL & SQ & SQA & MQA & F & P-valor \\
\hline Regressão & 2 & 2671,71 & 2671,71 & 1335,86 & 22202,4 & $\underline{0,0000}$ \\
$\alpha_{t}$ & 1 & 2464,45 & 708,70 & 708,70 & 11778,8 & $\underline{0,0000}$ \\
$\alpha_{r}$ & 1 & 207,26 & 207,26 & 207,26 & 3444,7 & $\underline{0,0000}$ \\
Erro & 177 & 10,65 & 10,65 & 0,06 & & \\
Total & 179 & 2682,36 & & & & \\
\hline Equação: & $\boldsymbol{\alpha}_{\boldsymbol{v}}=\mathbf{- 0 , 6 2 2 5 5 2 + 1 , 1 0 7 3 2 * \boldsymbol { \alpha } _ { t } + \mathbf { + 1 , 2 0 7 7 4 } * \boldsymbol { \alpha } _ { \boldsymbol { r } }}$ & $\mathrm{R}^{2}(\mathrm{aj})=99,60 \%$ \\
\hline
\end{tabular}

O modelo de regressão multilinear $\left(\alpha_{v}=-0,622552+1,10732 * \alpha_{t}+1,20774 * \alpha_{r}\right)$ testado foi considerado significativo pela ANOVA, fornecendo um coeficiente de determinação ajustado igual a 99,60\%, evidenciando a excelente precisão alcançada. 


\subsubsection{Teste de Precisão da Equação $\alpha_{v} / P S F=0,84 * \rho_{s}$}

Os resultados da ANOVA da relação $\alpha_{v} / P S F=0,84^{*} \rho_{s}$ são apresentados na Tabela 32, sendo GL os graus de liberdade, SQ a soma dos quadrados, MS a média dos quadrados, F a estatística $\mathrm{F}, \mathrm{P}$-valor a probabilidade $\mathrm{P}$ e $F C$ o fator forma de obtenção [FO] $\left(\alpha_{v} / P S F ; 0,84 \cdot \rho_{s}\right)$. Os P-valores do teste de normalidade de Anderson Darling e de homogeneidade de variâncias (teste F) dos resíduos foram iguais a 0,102 (Figura 26a) e 0,285 (Figura 26b), respectivamente, validando o modelo de ANOVA.

Tabela 32: Resultados da ANOVA para validação da relação $\alpha_{v} / P S F=0,84 * \rho_{s}$.

\begin{tabular}{cccccc}
\hline Fonte & GL & SQ & MS & F & P-valor \\
\hline FO & 1 & 0,0041 & 0,0041 & 0,10 & 0,753 \\
Erro & 358 & 14,8618 & 0,0415 & & \\
Total & 359 & 14,8659 & & & \\
\hline
\end{tabular}

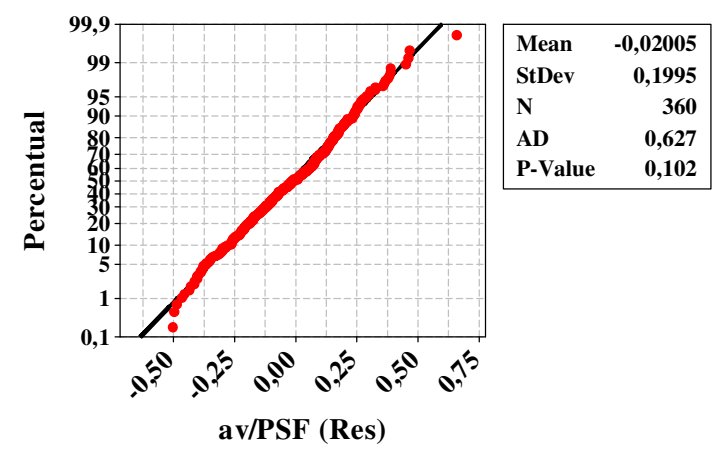

(a)

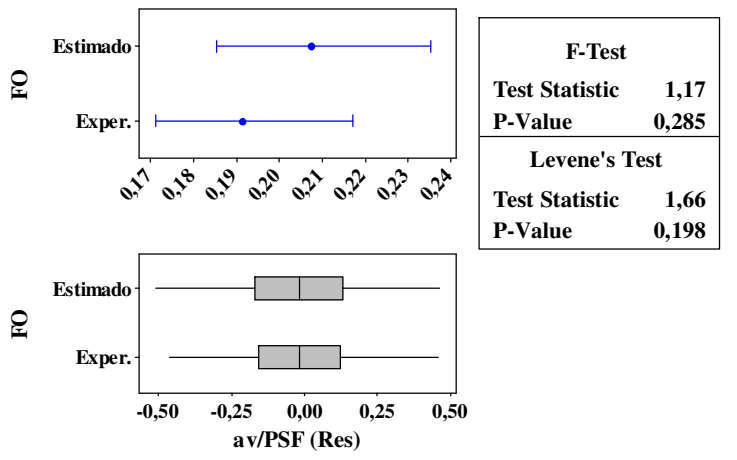

(b)

Figura 26: Resultados dos testes de normalidade (a) e de homogeneidade de variâncias (b) dos resíduos da ANOVA para a relação $\alpha_{v} / P S F=0,84 * \rho_{s}$.

Como o P-valor da ANOVA (Tabela 32) é superior a 0,05, constata-se que a relação entre $\alpha_{v} / P S F e \quad 0,84 * \rho_{s}$ é de equivalência, validando o uso desta equação também sobre os valores obtidos experimentalmente nesta pesquisa.

\subsubsection{Teste de Precisão da Desenvolvida neste Trabalho (Equação 14)}

Os resultados da ANOVA da equação:

$$
\frac{T U}{\rho_{\text {bas }}}=\frac{\left(1+\frac{T U}{100}\right) \cdot P S F}{\rho_{u}}-\frac{(P S F-T U)}{\rho_{s}}
$$


são apresentados na Tabela 33, sendo GL os graus de liberdade, SQ a soma dos quadrados, MS a média dos quadrados, $\mathrm{F}$ a estatística $\mathrm{F}, \mathrm{P}$-valor a probabilidade $\mathrm{P}$ e $F O$ o fator forma de obtenção da densidade básica (Experimental [Exp]; analítico). Os Pvalores do teste de normalidade de Anderson Darling e de homogeneidade de variâncias (teste F) dos resíduos foram iguais a 0,383 (Figura 27a) e 0,797 (Figura 27b), respectivamente, validando o modelo de ANOVA.

Tabela 33: Resultados da ANOVA para validação da equação 14.

\begin{tabular}{cccccc}
\hline Fonte & GL & SQ & MS & F & P-valor \\
\hline$\alpha$ & 1 & 0,2542 & 0,2542 & 10,97 & 0,001 \\
Erro & 358 & 8,2962 & 0,0232 & & \\
Total & 359 & 8,5504 & & & \\
\hline
\end{tabular}

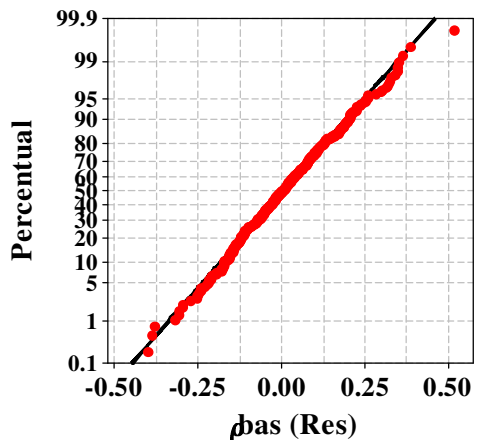

(a)

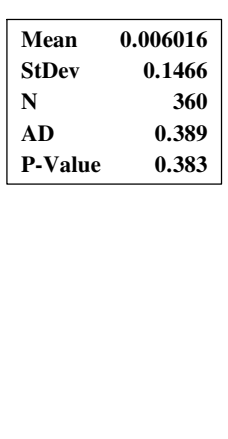

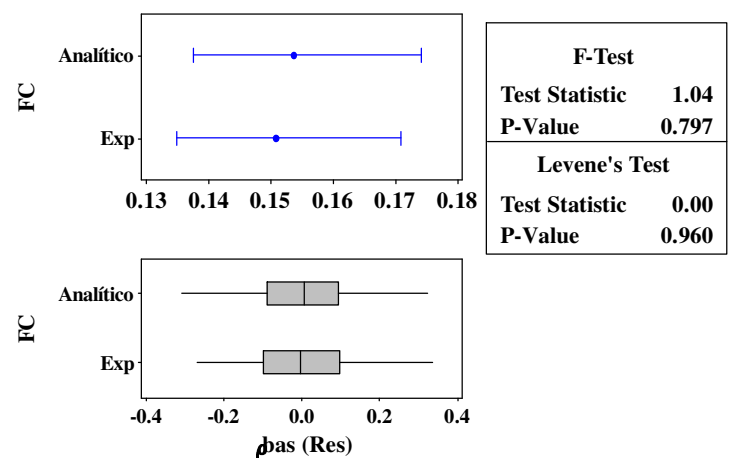

(b)

Figura 27: Resultados dos testes de normalidade (a) e de homogeneidade de variâncias (b) dos resíduos da ANOVA para a equação 14.

Da Tabela 33, o P-valor obtido da ANOVA foi inferior ao nível de significância estipulado, implicando que a presente relação não foi capaz de reproduzir as variações dos valores das densidades básicas das madeiras obtidos experimentalmente. Mesmo não sendo representativa a relação estudada, ressalta-se o valor médio e o coeficiente de variação das densidades básicas obtidas experimentalmente foram iguais a $0,64 \mathrm{~g} / \mathrm{cm}^{3} \mathrm{e}$ $23,50 \%$, respectivamente, sendo de $0,69 \mathrm{~g} / \mathrm{cm}^{3}$ e $22,13 \%$ a média e o coeficiente de variação dos valores da densidade básica, obtidos por meio da relação, o que fica evidente a proximidade da equação analítica na estimativa dos resultados experimentais. Aspectos específicos da anatomia, não abrangidos pela equação, certamente são responsáveis pela pequena diferença observada. Além disto, é possível se esperar que, com um número 
maior de espécies, eventuais influências dos aspectos anatômicos possam deixar de contribuir de modo relevante ao nível de $5 \%$.

A ausência, na literatura disponível sobre o assunto, de trabalhos semelhantes ao desenvolvido restringe a discussão dos resultados. Por outro lado, evidencia com mais clareza a originalidade da abordagem adotada. 


\section{CONCLUSÕES E SUGESTÕES PARA TRABALHOS FUTUROS}

A partir das análises dos resultados, registram-se as seguintes conclusões:

Sobre as Análises de Regressão:

- Com exceção da densidade básica, as demais densidades forneceram ajustes significativos na estimativa das propriedades investigadas;

- $\quad$ O modelo geométrico associado aos valores da densidade aparente a $12 \%$ de umidade levou aos melhores ajustes, com exceção da estimativa da retração radial, em que as melhores aproximações foram provenientes do modelo logarítmico;

- Embora vários P-valores apontem significância dos modelos, todos os coeficientes de determinação ajustados são muito baixos (maior valor do coeficiente de determinação ajustado foi 19,58\%), mostrando que os modelos podem não representar adequadamente os fenômenos estudados;

- $\quad$ melhor ajuste na estimativa dos valores da densidade básica por meio da densidade aparente foi referente ao uso do modelo de regressão geométrico, coeficiente de determinação ajustado 72,92\%. Assim, é possível admitir a estimativa da densidade básica a partir dos valores da densidade aparente a $12 \%$ de umidade.

Sobre as Análises de Precisão:

- A relação entre $\beta_{\mathrm{t}}$ e $1,65 * \beta_{\mathrm{r}}$ é de equivalência, validando o uso desta equação também sobre os valores obtidos experimentalmente nesta pesquisa;

- A relação entre $\alpha_{t} / \alpha_{r}$ e $\beta_{t} / \beta_{r}$ é de equivalência, validando o uso desta equação também sobre os valores obtidos experimentalmente nesta pesquisa;

- $\quad$ Relação entre $\beta_{1}$ e $\beta_{t} / 23$ não é de equivalência.

- $\quad$ O modelo de mínimos quadrados forneceu a relação $\beta_{1}=\beta_{\mathrm{t}} / 9,84$, com coeficiente de determinação ajustado $47,23 \%$ como solução ótima.

- $\quad$ A relação entre $\beta_{\mathrm{v}}$ e $\beta_{\mathrm{t}}+\beta_{\mathrm{r}}$ é de equivalência, validando o uso desta equação também sobre os valores obtidos experimentalmente nesta pesquisa;

- $\quad$ A relação entre $\alpha_{\mathrm{v}}$ e $\alpha_{\mathrm{t}}+\alpha_{\mathrm{r}}$ não é de equivalência;

- $\quad$ O modelo de regressão multilinear $\alpha_{\mathrm{v}}=-0,622552+1,10732 * \alpha_{\mathrm{t}}+1,20774 * \alpha_{\mathrm{r}}$ testado foi considerado significativo pela ANOVA, fornecendo um coeficiente de determinação ajustado igual a 99,60\%, evidenciando a excelente precisão alcançada; 
- $\quad$ A relação entre $\alpha_{v} /$ PSF e $0,84^{*} \rho_{\mathrm{s}}$ é de equivalência, validando o uso desta equação também sobre os valores obtidos experimentalmente nesta pesquisa;

- Que a relação $\frac{T U}{\rho_{\text {bas }}}=\frac{\left(1+\frac{T U}{100}\right) * P S F}{\rho_{u}}-\frac{(P S F-T U)}{\rho_{S}}$, proposta neste estudo, não foi capaz de reproduzir as variações dos valores das densidades básicas das madeiras obtidos experimentalmente. Cabe ressaltar que fica evidente a proximidade da equação analítica na estimativa dos resultados experimentais, e que a média do Ponto de Saturação das Fibras (parâmetro da equação) para as madeiras utilizadas difere do valor considerado na norma brasileira.

Para continuidade da pesquisa a respeito do assunto, sugere-se:

- $\quad$ Aumentar o número de espécies consideradas, para maior abrangência da amostragem e, com isto, otimização dos resultados.

- Ampliar os estudos que venham a contribuir para mais detalhada avaliação da influência dos aspectos anatômicos nos valores numéricos que representam as propriedades da madeira. 


\section{REFERÊNCIAS BIBLIOGRÁFICAS}

ALMEIDA, T. H.; ALMEIDA, D. H.; MARCOLIN, L. A.; GONÇALVES, D.; CHRISTOFORO, A. L. ; ROCCO, F. A. L.. Correlation between dry density and volumetric shrinkage coefficient of three brazilian tropical wood species. International Journal of Materials Engineering, v. 5, p. 1-4, 2015.

ASSOCIAÇÃO BRASILEIRA DE NORMAS TÉCNICAS (1997). NBR 7190: Projeto de Estruturas de Madeira. Rio de Janeiro.

BATISTA, D.C; KLITZKE, R.J AND TABORDA, C. V. S.. Densidade básica e retratibilidade da madeira de clones de três espécies de Eucalyptus. Ciência Florestal, Santa Maria, vol.20, Ed. 4, p.665-674, 2010.

BODIG, J.; JAYNE, B.A.. Mechanics of wood and wood composites. New York, Van Nostrand Reinhold Company, 1982, 712p.

BOLDIN, J. O.; FINGER, Z.; LOGSDON, N. B.. Angelim-Amargoso: Descrição Dendrológica e Caracterização Física. In: ENCONTRO BRASILEIRO EM MADEIRAS E EM ESTRUTURAS DE MADEIRA, 11., Londrina, PR, 2008. Anais. UEL, v, 1. 2008.

BURGER, L.M.; RICHTER, H. G.. Anatomia da madeira. São Paulo, Editora Nobel, 1991.

CALIL JR, C.; LAHR, F. A. R.; DIAS, A. A.. Dimensionamento de elementos estruturais de madeira. 1 ed. Barueri: Manole. Ltda, 2003.

CAMARGOS, J. A. A. STERNADT, G.H.. Novas perspectivas de utilização da cor da madeira Amazônica e seu aproveitamento comercial. LPF-SÉRIE TÉCNICA No7. Brasília, 1989.

CHRISTOFORO, A. L.; BLECHA, K. A.; CARVAlHO, A. L. C.; RESENDE, L. F. S.; ROCCO, F. A. L. Characterization of Tropical Wood Species for Use in Civil Constructions. Journal of Civil Engineering Research, v. 3, p. 98-103, 2013.

CISTERNAS, P. A.. Conversion de densidades de la madera. Ciencia e Inventigacón Forestal. V.8, n.2, Casila 9206 Santiago, Chile. P. 300-315.

CORADIN, V.T.R.; CAMARGOS, J. A. A.. A estrutura anatômica da madeira e princípios para a sua identificação. Brasília: Instituto Brasileiro do Meio Ambiente e dos Recursos Naturais Renováveis - IBAMA; Laboratório de Produtos Florestais LPF, 2002.

COUTO, L. C.; BARCELLOS, D. C.. As relações água-madeira e sua influência nas suas propriedades físicas. Renabio: Biomassa \& Energia, Bom-despacho, v. 4, n. 2, p.173-190, dez. 2011. 
82

CHRISTOFORO, A. L.; PANZERA, T. H.; MOLINA, J. C.; ALMEIDA, D. H.; ROCCO, F. A. L.. Determinação do módulo de elasticidade na compressão paralela às fibras da madeira: proposta de metodologia alternativa. Construindo, v. 6, p. 20-25, 2014.

DIAS, F. M. A densidade aparente como estimador de propriedades de resistência e rigidez da madeira. 2000. 145f. Dissertação (Mestrado em Ciência e Engenharia de Materiais) - Universidade de São Paulo, São Carlos, 2000.

DURLO, M. A.; MARCHIORI, J. N. C.. Tecnologia da madeira: Retratibilidade. Santa Maria. CEPEF/FATEC, 1992. 33p. (Série Técnica, 10).

GALVÃO, A. P. M.; JANKOWSKY, I. P.. Secagem racional da madeira. São Paulo, Nobel, 1985, 112p.

GREEN, D. W.. Moisture content and the shrinkage of lumber. Res. Pap. FPL-RP-489. Madison, WI: U.S. Department of Agriculture, Forest Service, Forest Products Laboratory. 11 p.1989.

HELLMEISTER, J. C.. Sobre a determinação de características físicas da madeira. São Carlos, 1973, 161p. Tese (Doutorado) - Escola de Engenharia de São Carlos, Universidade de São Paulo, 1973.

IMAFLORA - Instituto de Manejo e Certificação Florestal e Agrícola. Acertando o alvo 3: Desvendando o mercado brasileiro de madeira amazônica certificada FSC. 2013.

INSTITUTO DE PESQUISAS TECNOLÓGICAS. (1989). Fichas de características das madeiras brasileiras. São Paulo. 420p.

JANKOWSKY, I. P.. Madeiras brasileiras. Caxias do Sul, Spectrum comunicação, v.1. 1990.

KOLLMANN, F.; CÔTÉ, W. A.. Principles of wood science and technology. Germany, Springer Verlag, 1968, 592p.

LOGSDON, N. B.. Sobre os ensaios de retração e inchamento. Madeira:Arquitetura e Engenharia, São Carlos, v. 1, n. 2, p.19-24, maio 1999. Quadrimestral.

LOGSDON, N. B.; CALIL JR, C.. Influência da umidade nas propriedades de resistência e rigidez da madeira. Cadernos de Engenharia de Estruturas, n.18, p.77-107, 2002.

LOGSDON, N. B.. Adaptação do diagrama de kollmann às folhosas brasileiras. Ensaios e Ciência: Ciências Biológicas, Agrárias e da Saúde, Campo Grande, v. 9, n. 2, p.269-280, ago. 2005.

LORENZI, H.. Árvores brasileiras: manual de identificação e cultivo de plantas arbóreas nativas do Brasil. São Paulo, Plantarum, v.2. 1998.

LOUREIRO, A. A.; FREITAS, J. A.; FREITAS, C. A. A.. Essências Madeireiras da Amazônia. vol.3. MCT/INPA-CPPF, Manaus. 103p. 1997. 
LOUREIRO, A. A. \& SILVA, M. F.. Catálogo das madeiras da Amazônia, Belém, INPA, v.1, p.297-300, 1968.

LUBAS, L. M. S.; FINGER, Z. LOGSDON, N. B.. Itaúba: Descrição Dendrológica e Caracterização Física. In: ENCONTRO BRASILEIRO EM MADEIRAS E EM ESTRUTURAS DE MADEIRA, 11., Londrina, PR, 2008. Anais. UEL, v, 1. 2008.

MAINIERI C.. Manual de identificação das principais madeiras comerciais brasileiras. São Paulo: IPT; 1983.

MAINIERI, C.; CHIMELO, J. P.. Fichas características de madeiras brasileiras. São Paulo: IPT, 49p. 1989.

MELO, J. E.; SIQUEIRA, M. J.. Correlação entre propriedades físicas e mecânicas de madeiras da amazônia. In: ENCONTRO BRASILEIRO EM MADEIRAS E EM ESTRUTURAS DE MADEIRA, 4., São Carlos, SP, 1992. Anais. São Carlos, USP, EESC, SET, LaMEM, v, 1, p.67-76. 1992.

MONTGOMERY, D. C. Design and analysis of experiments. John Wiley \& Sons Inc., 6th edition, Arizona, 2005.

MOREY, P. R.. O crescimento das árvores. v. 19. Trad. por Maria de Fátima Domingos Aleixo Pereira. São Paulo. E. P. U. - EDUSP, p. 13-40.

PRATT, G. H.. Timber drying manual. London: Department of Environment, 1974.152p.

PINTO, M. L.. Propriedades e características da madeira de Teca (Tectonagrands) em Função da Idade. 2007. 131 f. Tese (Doutorado) - Curso de Engenharia Civil, Departamento de Construção Civil, Universidade Federal de Santa Catarina, Florianópolis, 2007.

PLIURA, A; YU, Q.; ZHANG, S.Y.; MACKAY, J.; PERINET, P E BOUSQUET, J.. Variation in wood density and shrinkage and their relationship to growth of selected young poplar hybrid crosses. Forest Science, vol.51, Ed. 5, 2005.

REZENDE, M. A.; ESCOBEDO, J. F.; FERRAZ, E. S. B.. Retratibilidade volumétrica e densidade aparente da madeira em função da umidade. Ipef - Instituto de Pesquisas e Estudos Florestais, Piracicaba, n. 39, p.33-40, ago. 1988.

REZENDE, R. N.. Secagem de toras de clones de Eucalyptus empregados na produção de carvão. 178f. Dissertação (Mestrado em Ciência e Tecnologia da Madeira) - Universidade Federal de Lavras, Lavras, MG, 2009.

RIZZINI, C. T. (1971). Árvores e arbustos do cerrado. Rodriguésia 38: 63-77. 1971.

SEVERIANO, L. C.. Estudo do efeito da radiação gama sobre algumas propriedades físico-mecânicas de madeiras usadas em patrimônios artísticos e culturais brasileiros. 2010. 86 f. Dissertação (Mestrado) - Curso de Mestrado em Ciências da área de Tecnologia Nuclear, Universidade de São Paulo, São Paulo, 2010. 
SHAKELFORD, J. F.. Introduction to materials science for engineers. 14.ed. New Jersey, Upper Saddle River, Prentice-Hall, 1996. p.399.

SUDAM.. Pesquisas e informações sobre espécies florestais da Amazônia. Belém, 1979. 111p.

TAYLOR, G.. La madera. Barcelona. Editora Blume, 1978, 274p.

WALKER, J.C.F., BUTTERFIELD, B.G., LANGRISH, T.A.G., HARRIS, J.M. UPRICHARD, J.M.. Primary Wood Processing. Chapman and Hall, London. 1993. 595p. 
APÊNDICE - DEDUÇÃO DA RELAÇÃO ENTRE DENSIDADE BÁSICA E DENSIDADE APARENTE VIA INCHAMENTO E RETRATIBILIDADE

Equação para a determinação Densidade Aparente:

$$
\rho_{T U}=\frac{m_{T U}}{V_{T U}}(\boldsymbol{I})
$$

Equação para determinação do Teor de Umidade:

$$
T U=\frac{m_{T U}-m_{s}}{m_{s}} * 100 \rightarrow m_{T U}=m_{s} *\left(1+\frac{T U}{100}\right)
$$

Pelo Inchamento: A figura 28 representa um gráfico do inchamento em função do teor de umidade da madeira.

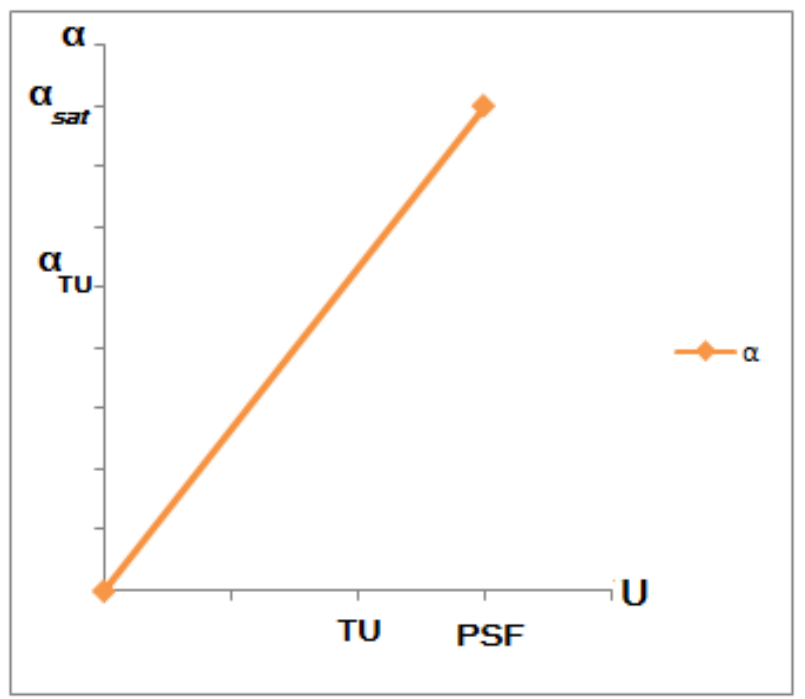

Figura 28: Gráfico genérico do Inchamento em função do Teor de Umidade.

$$
\begin{gathered}
\frac{\alpha_{s a t}}{P S F}=\frac{\alpha_{T U}}{T U} \\
\text { Como: } \alpha_{s a t}=\frac{V_{s a t}-V_{S}}{V_{S}} \text { e } \alpha_{T U}=\frac{V_{T U}-V_{S}}{V_{S}} \\
V_{T U}=\left(V_{s a t}-V_{S}\right) * \frac{T U}{P S F}+V_{S} \quad(\text { III })
\end{gathered}
$$

Substituindo as equações $\boldsymbol{I I}$ e $\boldsymbol{I I I}$ na equação $\boldsymbol{I}$, temos: 
86

$$
\begin{aligned}
& \rho_{u}=\frac{m_{s} *\left(1+\frac{T U}{100}\right)}{\left(V_{s a t}-V_{s}\right) * \frac{T U}{P S F}+V_{s}} \\
& \frac{1}{\rho_{u}}=\frac{V_{s a t} * \frac{T U}{100}-V_{s} * \frac{T U}{100}}{m_{s} *\left(1+\frac{T U}{100}\right) * P S F}+\frac{V_{S} * P S F}{m_{S} *\left(1+\frac{T U}{100}\right) * P S F} \\
& \frac{\left(1+\frac{T U}{100}\right) * P S F}{\rho_{u}}=\frac{V_{s a t} * \frac{T U}{100}}{m_{s}}-\frac{V_{s} * \frac{T U}{100}}{m_{s}}+\frac{V_{s} * P S F}{m_{s}} \\
& \text { Como: } \rho_{\text {bas }}=\frac{m_{s}}{V_{s a t}} \text { e } \rho_{s}=\frac{m_{s}}{V_{s}} \\
& \frac{T U}{\rho_{\text {bas }}}=\frac{\left(1+\frac{T U}{100}\right) * P S F}{\rho_{u}}-\frac{(P S F-T U)}{\rho_{s}}(V)
\end{aligned}
$$

Pela Retratibilidade: A figura 29 representa um gráfico da retração em função do teor de umidade da madeira.

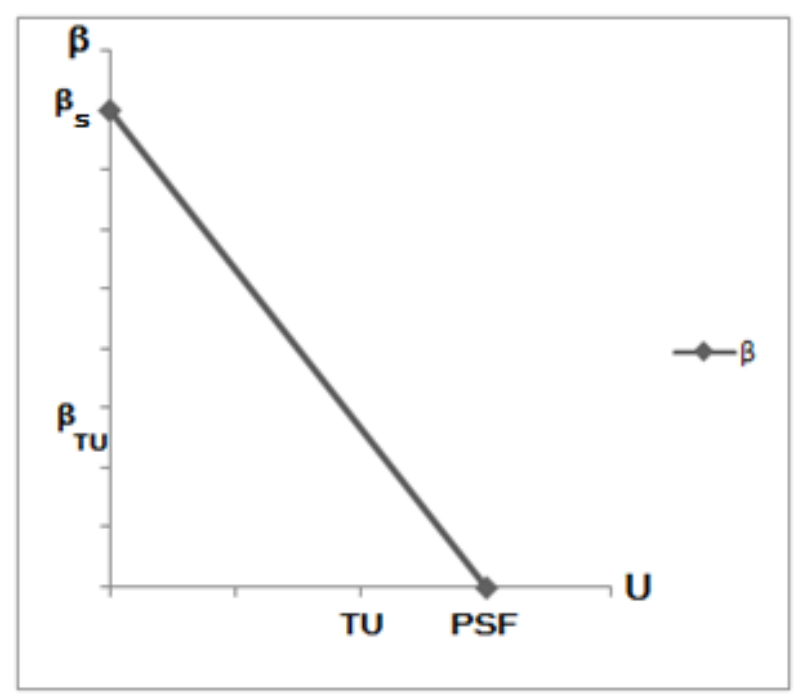

Figura 29: Gráfico genérico da retração em função do Teor de Umidade.

$$
\frac{\beta_{S}}{P S F}=\frac{\beta_{T U}}{(P S F-T U)}
$$




$$
\begin{gathered}
\text { Como: } \beta_{s}=\frac{V_{\text {sat }}-V_{s}}{V_{\text {sat }}} \text { e } \beta_{T U}=\frac{V_{\text {sat }}-V_{T U}}{V_{\text {sat }}} \\
V_{T U}=V_{\text {sat }}-\left(V_{\text {sat }}-V_{S}\right) * \frac{(P S F-T U)}{P S F}
\end{gathered}
$$

Substituindo as equações $\boldsymbol{I I}$ e $\boldsymbol{I V}$ na equação $\boldsymbol{I}$, temos:

$$
\begin{gathered}
\rho_{u}=\frac{m_{s} *\left(1+\frac{T U}{100}\right)}{V_{\text {sat }}-\left(V_{\text {sat }}-V_{s}\right) * \frac{(P S F-T U)}{P S F}} \\
\frac{1}{\rho_{u}}=\frac{V_{\text {sat }} * P S F}{m_{s} *\left(1+\frac{T U}{100}\right) * P S F}-\frac{\left(V_{s a t}-V_{s}\right) *(P S F-T U)}{m_{s} *\left(1+\frac{T U}{100}\right) * P S F} \\
\frac{\left(1+\frac{T U}{100}\right) * P S F}{\rho_{u}}=\frac{V_{\text {sat }} * P S F}{m_{s}}-\frac{V_{s a t} *(P S F-T U)}{m_{s}}+\frac{V_{s} *(P S F-T U)}{m_{s}} \\
\frac{\operatorname{Como:} \rho_{\text {bas }}=\frac{m_{s}}{V_{\text {sat }}} e \rho_{s}=\frac{m_{s}}{V_{s}}}{\boldsymbol{\rho}_{\text {bas }}}=\frac{\left(\mathbf{1}+\frac{\boldsymbol{T U}}{\mathbf{1 0 0}}\right) * \boldsymbol{P S F}}{\boldsymbol{\rho}_{\boldsymbol{u}}}-\frac{(\boldsymbol{P S F}-\boldsymbol{T U})}{\boldsymbol{\rho}_{\boldsymbol{s}}}(\boldsymbol{V})
\end{gathered}
$$

A equação $\boldsymbol{V}$, aqui deduzida estabelece a relação entre densidade básica $\left(\rho_{\text {bas }}\right)$ e densidade aparente $\left(\rho_{u}\right)$ via retratibilidade/inchamento. 
ANEXO - BREVE DESCRIÇÃO DAS ESPÉCIES UTILIZADAS

\section{CEDRO-DOCE}

NOME CIENTÍFICO: Pachira quinata

ZONA DE COLETA: Roraima

ZONAS DE MAIOR OCORRÊNCIA: Floresta Amazônica, estendendo-se até o Norte do estado do ES e de MG até o RS.

CARACTERÍSTICAS GERAIS: Árvore pode atingir até em torno de $10 \mathrm{~m}$ de altura com tronco entre 40 e $50 \mathrm{~cm}$ de diâmetro.

DADOS SEGUNDO AUTOR: RIZZINI (1971)

CORTE LONGITUDINAL:

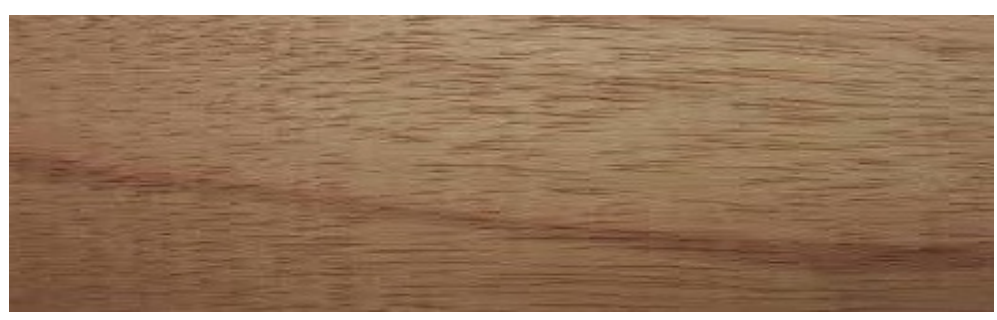

Figura 30: Grã da madeira de Cedro-doce. 


\section{CEDRO-AMARGO}

NOME CIENTÍFICO: Cedrela sp.

ZONA DE COLETA: Roraima

ZONAS DE MAIOR OCORRÊNCIA: O gênero Cedrela, no Brasil é representado por variadas espécies, mas apenas três se destacam como principais: - C. odorata 1., comum na floresta Amazônica, estendendo até o norte do Estado do ES; - C. angustifolia S. \& Moc. na região costeira, desde o Estado do ES até a região sul do País; - C. fissilis Vell., em matas do interior, desde o Estado de MG até o Estado do RS.

CARACTERÍSTICAS GERAIS: É comum em terra firme e várzeas altas, em florestas úmidas da região costeira. A madeira apresenta cerne variando do bege-rosado-escuro a castanho-claro-rosado, indo até o castanho-avermelhado; textura grossa; grã direita ou ligeiramente ondulada; superfície lustrosa e com reflexos dourados; cheiro característico, agradável, gosto ligeiramente amargo.

DADOS SEGUNDO AUTOR: CHIMELO \& MAINIERI (1989).

\section{CORTE LONGITUDINAL:}

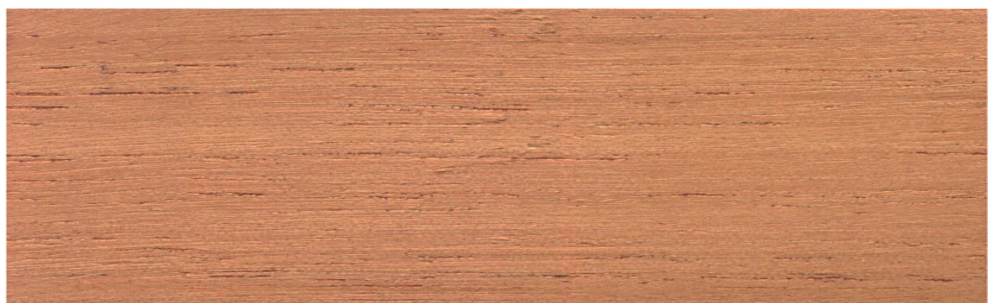

Figura 31: Grã da madeira de Cedro-amargo. 


\section{CAMBARÁ}

NOME CIENTÍFICO: Erisma sp.

ZONA DE COLETA: Roraima

ZONAS DE MAIOR OCORRÊNCIA: É de ocorrência na região Amazônica nos estados de AM, MT e Guianas.

CARACTERÍSTICAS GERAIS: Atinge entre 7 e $18 \mathrm{~m}$ de altura, com tronco ereto e ramificado desde a base medindo entre 40 e $70 \mathrm{~cm}$ de diâmetro.

DADOS SEGUNDO AUTOR: LORENZI (1998).

CORTE LONGITUDINAL:

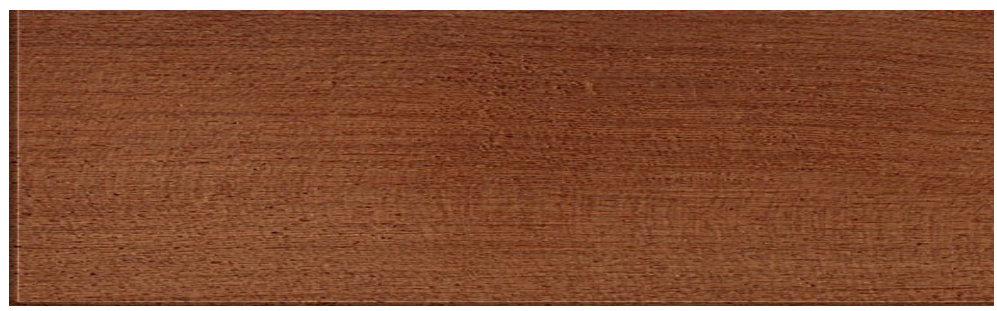

Figura 32: Grã da madeira de Cambará. 


\section{CANAFÍSTULA}

NOME CIENTÍFICO: Cassia ferruginea

ZONA DE COLETA: Mato Grosso

ZONAS DE MAIOR OCORRÊNCIA: Estados do CE até o PA; Estado do MT e no interior dos Estados de MG, SP e PA.

CARACTERÍSTICAS GERAIS: As árvores atingem 10-20 m e fornece toras de $\quad 8-10 \mathrm{~m} \times$ 50-70 cm. Cerne variável do bege-rosado-claro ao escuro, e do castanho-claro ao avermelhado; alburno diferenciado, branco, levemente rosado; grã irregular; textura média; superfície lustrosa medianamente lisa; cheiro e gosto imperceptíveis.

DADOS SEGUNDO AUTOR: CHIMELO \& MAINIERI (1989); RIZZINI (1971). CORTE LONGITUDINAL:

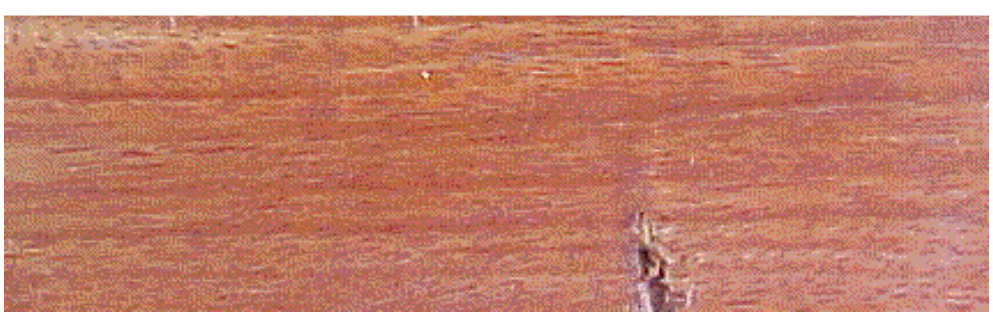

Figura 33: Grã da madeira de Canafístula. 


\section{CATANUDO}

NOME CIENTÍFICO: Calophyllum sp.

ZONA DE COLETA: Mato Grosso

ZONAS DE MAIOR OCORRÊNCIA: Norte do Mato Grosso e sul do Pará.

CARACTERÍSTICAS GERAIS: Atinge entre 5 e $20 \mathrm{~m}$ de altura, e entre 30 e $50 \mathrm{~cm}$ de diâmetro. Suas propriedades mecânicas se classificam entre média e baixa.

DADOS SEGUNDO AUTOR: JANKOWSKY (1990) e IPT (1989).

CORTE LONGITUDINAL:

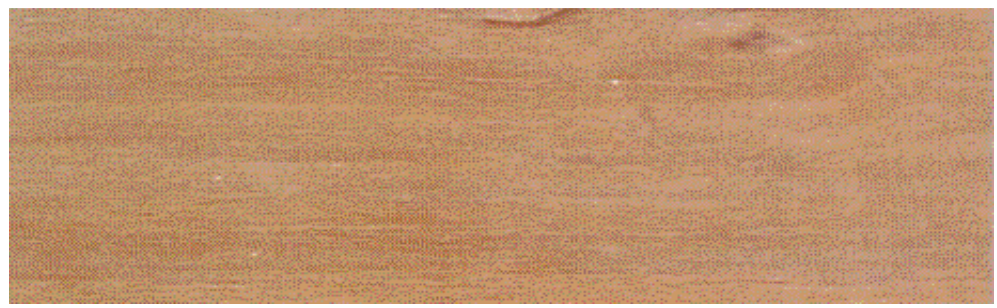

Figura 34: Grã da madeira de Catanudo. 
94

\section{CASCA GROSSA}

NOME CIENTÍFICO: Ocotea odorifera

ZONA DE COLETA: Mato Grosso

ZONAS DE MAIOR OCORRÊNCIA: Norte do AM, Roraima e Amapá.

CARACTERÍSTICAS GERAIS: Atinge altura entre 15 e 25m, com diâmetro entre 50 e $70 \mathrm{~cm}$. Madeira moderadamente pesada.

DADOS SEGUNDO AUTOR: RIZZINI (1971).

CORTE LONGITUDINAL:

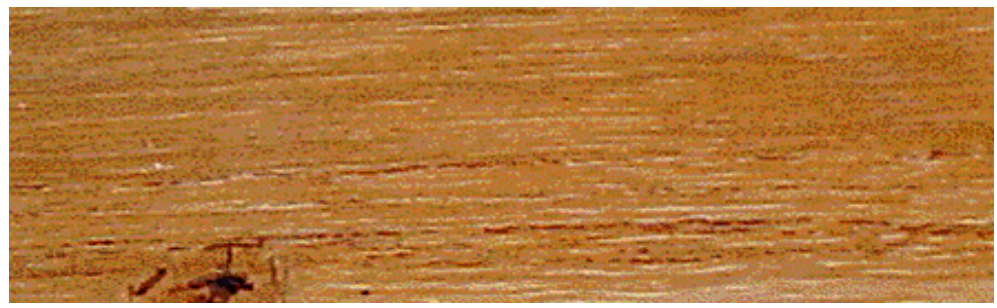

Figura 35: Grã da madeira de Casca Grossa. 


\section{ANGELIM ARAROBA}

NOME CIENTÍFICO: Vataireopsis araroba

ZONA DE COLETA: Roraima

ZONAS DE MAIOR OCORRÊNCIA: Estado de RR, sul do Estado da BA, norte do Estado do ES, vale do Rio Doce, Estado de MG, norte do Estado do RJ.

CARACTERÍSTICAS GERAIS: As árvores atingem $30 \mathrm{~m} \times 120 \mathrm{~cm}$, comumente com fustes de $12-20 \mathrm{~m} \times 40-70 \mathrm{~cm}$. Cerne apresenta cor uniforme, amarelo a amarelo-queimado, quando recém-cortado, passando para castanho-amarelado após exposição ao ar; camadas de crescimento pouco distintas; raios notados a olho nu no topo e na face tangencial só sob lente; grã direita; textura grossa; superfície de pouco brilho, áspera ao tato, de aspecto fibroso destacado; cheiro acentuadamente amargo.

DADOS SEGUNDO AUTOR: CHIMELO \& MAINIERI (1989); RIZZINI (1971)

CORTE LONGITUDINAL:

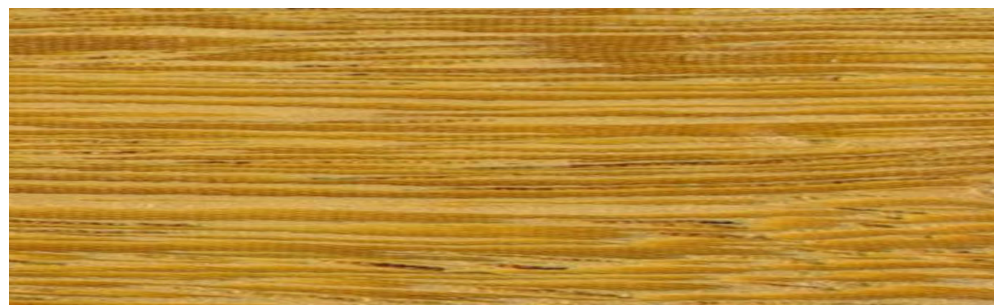

Figura 36: Grã da madeira de Angelim Araroba. 
96

\section{CUPIÚBA}

NOME CIENTÍFICO: Goupia glabra

ZONA DE COLETA: Roraima

ZONAS DE MAIOR OCORRÊNCIA: É presente nos Estados do AM, PA, MT e RO.

CARACTERÍSTICAS GERAIS: A madeira apresenta cerne e alburno pouco distintos, marrom-avermelhado-claro a castanho-rosado; anéis de crescimento pouco distintos; grã revessa; textura média; brilho ausente e cheiro desagradável, quando úmida.

DADOS SEGUNDO AUTOR: CAMARGOS et al. (1989).

CORTE LONGITUDINAL:

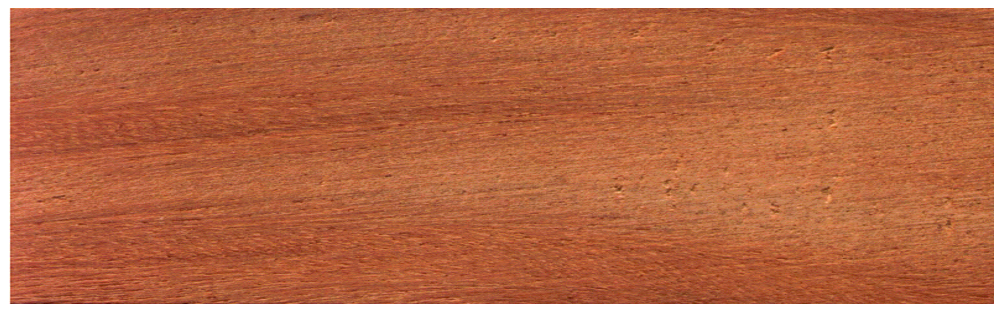

Figura 37: Grã da madeira de Cupiúba. 


\section{ANGELIM AMARGOSO}

NOME CIENTÍFICO: Vatairea fusca

ZONA DE COLETA: Roraima

ZONAS DE MAIOR OCORRÊNCIA: Estados do AM, PA, AC, RO.

CARACTERÍSTICAS GERAIS: A madeira apresenta cerne marrom-oliva, quando recémcortada, tornando-se marrom-avermelhado com listas amarelo-amarronzadas, distinto do alburno marrom muito pálido ou cinza rosado; anéis de crescimento indistintos; grã revessa; textura grossa; cheiro imperceptível.

DADOS SEGUNDO AUTOR: CAMARGOS et al. (1989). CORTE LONGITUDINAL:

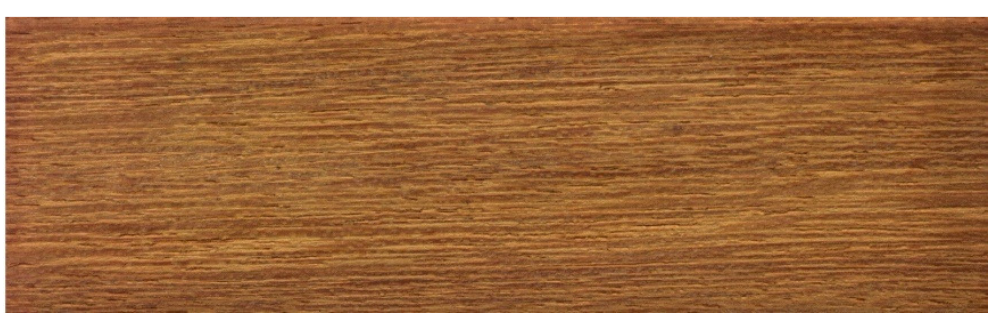

Figura 38: Grã da madeira de Angelim Amargoso. 


\section{MANDIOQUEIRA}

NOME CIENTÍFICO: Qualea albiflora

ZONA DE COLETA: Roraima

ZONAS DE MAIOR OCORRÊNCIA: Estados do AM, PA, AC. Guiana, Colômbia e Peru.

CARACTERÍSTICAS GERAIS: Árvore de $30 \mathrm{~m} \times 45 \mathrm{~cm}$, tronco reto e cilíndrico. Cerne bege-claro levemente rosado a bege-amarelado; grã irregular; textura grossa; camadas de crescimento indistintas, eventualmente demarcadas por zonas fibrosas, mais escuras; raios visíveis, somente com lente, no topo e na face tangencial; cheiro e gosto imperceptíveis.

DADOS SEGUNDO AUTOR: CAMARGOS et al.(1997); LOUREIRO et al. (1997).

\section{CORTE LONGITUDINAL:}

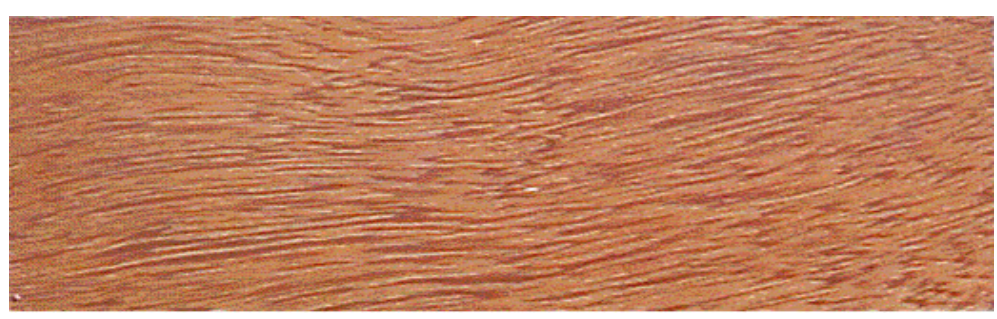

Figura 39: Grã da madeira de Mandioqueira. 


\section{CASTELO}

NOME CIENTÍFICO: Gossypiospermun praecox

ZONA DE COLETA: Mato Grosso

ZONAS DE MAIOR OCORRÊNCIA: Desde o norte do MT até MS.

CARACTERÍSTICAS GERAIS: Cerne amarelo-claro a pardo-claro levemente amarelado; em algumas espécies podem ocorrer manchas irregulares, de cor pardo-escura; camadas de crescimento indistintas, demarcadas por zonas fibrosas.

DADOS SEGUNDO AUTOR: MAINIERI (1983).

CORTE LONGITUDINAL:

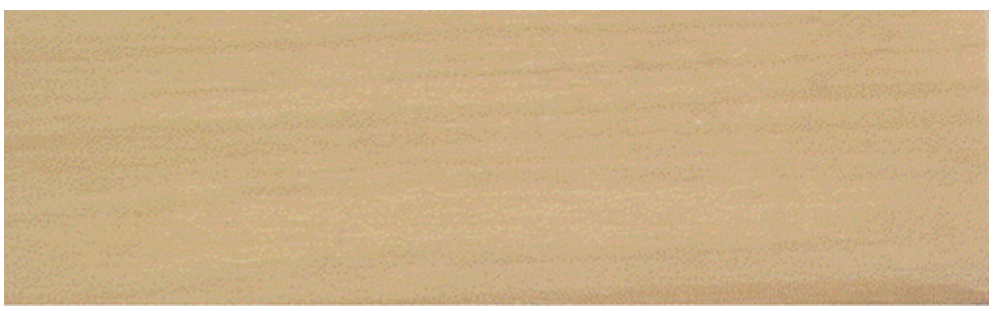

Figura 40: Grã da madeira de Castelo. 
100

\section{TATAJUBA}

NOME CIENTÍFICO: Bagassa guianensis

ZONA DE COLETA: Roraima

ZONAS DE MAIOR OCORRÊNCIA: Estados do AM, AC, RO, PA, e MA. Encontra-se também na Guiana Francesa e no Suriname.

CARACTERÍSTICAS GERAIS: Ocorre nas matas em terra firme e em solo argiloso. As árvores são de grande porte, $25 \mathrm{~m}$. Fuste reto e cilíndrico, casca com superfície escamosa espessa que produz látex branco adocicado que logo se coagula. $\mathrm{O}$ cerne apresenta-se na cor amarelo-dourado quando recém-cortado, escurecendo para amarelo-queimado ou castanhoamarelado; alburno amarelo-pálido, quase branco; textura grossa; grã direita a irregular; superfície lustrosa; cheiro e sabor imperceptíveis.

DADOS SEGUNDO AUTOR: SUDAM (1979); CHIMELO \& MAINIERI (1989). CORTE LONGITUDINAL:

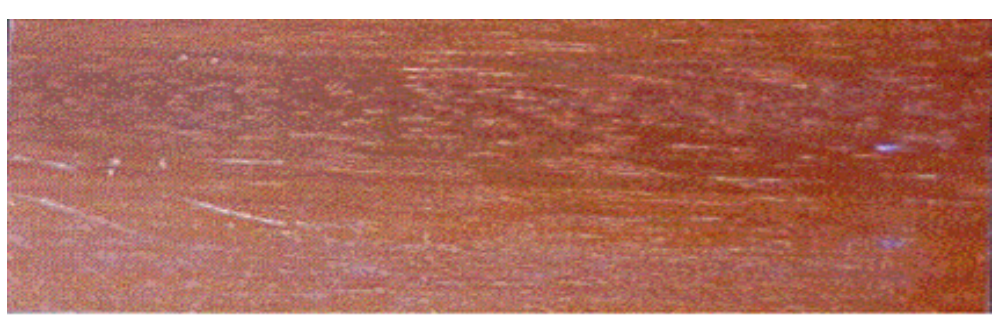

Figura 41: Grã da madeira de Tatajuba. 


\section{AMGELIM VERMELHO}

NOME CIENTÍFICO: Dinizia excelsa

ZONA DE COLETA: Roraima

ZONAS DE MAIOR OCORRÊNCIA: Região Amazônica, principalmente nos Estados de AC, RO, AM, PA e RR; Guiana Francesa.

CARACTERÍSTICAS GERAIS: As árvores desta espécie são de porte gigante, $55-60 \mathrm{~m} \times$ $2 \mathrm{~m}$, ocorre em terrenos sílico-argilosos ou argilosos. O cerne e alburno são pouco diferenciados, cerne de cor castanho rosado, adquire coloração avermelhada quando em contato com a luz solar; grã direita a irregular; textura média a grossa; superfície lisa ao tato e sem brilho; cheiro característico de madeira verde e gosto quase imperceptível.

DADOS SEGUNDO AUTOR: LOUREIRO \& SILVA (1968); CHIMELO \& MAINIERI (1989).

CORTE LONGITUDINAL:

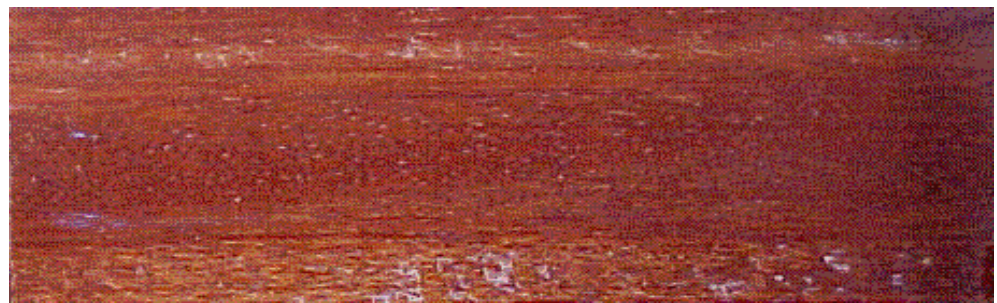

Figura 42: Grã da madeira de Angelim Vermelho. 


\section{CHAMPANHE}

NOME CIENTÍFICO: Dipteryx sp.

ZONA DE COLETA: Roraima

ZONAS DE MAIOR OCORRÊNCIA: É presente desde os Estados do AM, AC até o MA.

CARACTERÍSTICAS GERAIS: Árvore de $30 \mathrm{~m}$ de altura, na mata de várzea alta e terra firme. Cerne diferenciado do alburno, de cor mais clara, variando do bege-amarelado, eventualmente rosado a castanho-claro-amarelado; camadas de crescimento pouco distintas, demarcadas por zonas fibrosas; grã revessa; textura média a fina; superfície de pouco brilho e lisa ao tato; aspecto fibroso atenuado; cheiro e gosto imperceptíveis.

DADOS SEGUNDO AUTOR: MAINIERI, C. (1983); CHIMELO \& MAINIERI (1989); CAMARGOS et al. (1989).

CORTE LONGITUDINAL:

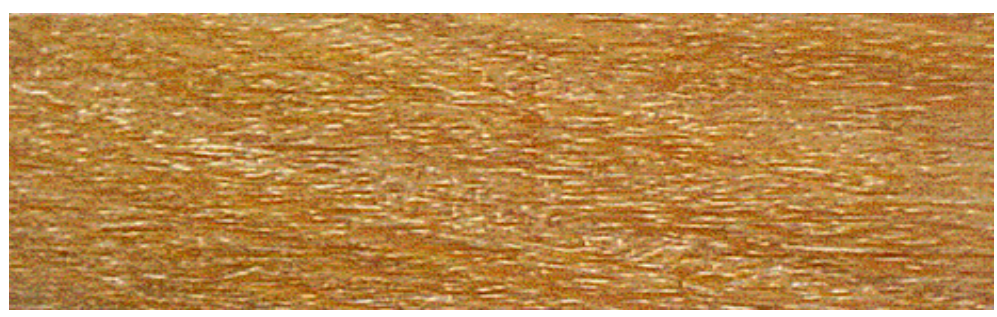

Figura 43: Grã da madeira de Champanhe. 


\section{ITAÚBA}

NOME CIENTÍFICO: Mezilaurus itauba

ZONA DE COLETA: Mato Grosso

ZONAS DE MAIOR OCORRÊNCIA: As espécies do gênero Mezilauros itauba ocorre no Estado do AM, região do Rio Negro. Estado do PA, região do Tocantins, estendendo ao norte até o território do AP e Guianas e ao sul, a região norte do Estado do MT e RO.

CARACTERÍSTICAS GERAIS: As árvores chegam a atingir $40 \mathrm{~m} \times 80 \mathrm{~cm}$, quando em floresta. Ocorre na terra firme, em solos silicosos e argilo-silicosos não inundáveis. Em locais arenosos ou pedregosos, não passa de uma árvore pequena. A madeira apresenta cerne amarelo-oliváceo quando recém-polido, tornando-se pardo-havana-claro, escurecendo para pardo-havana-escuro, uniforme; alburno pardo-amarelado; grã ondulada ou revessa; superfície irregularmente lustrosa e lisa ao tato; cheiro ligeiramente adocicado; gosto imperceptível.

DADOS SEGUNDO AUTOR: RIZZINI (1971); SUDAM (1979); CHIMELO \& MAINIERI (1989).

CORTE LONGITUDINAL:

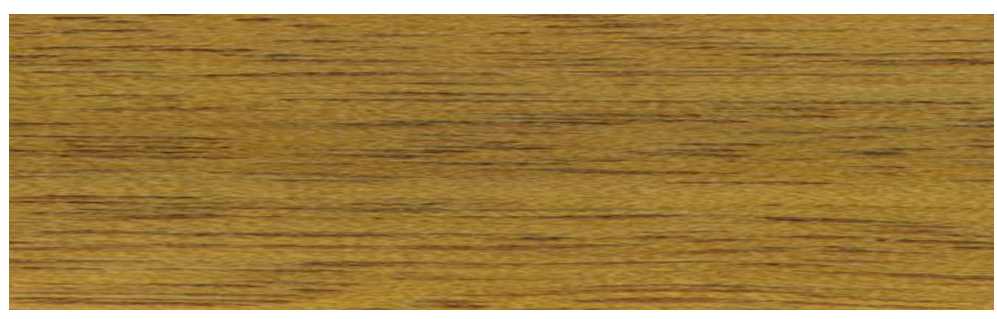

Figura 44: Grã da madeira de Itaúba. 